\title{
5 Historische Entwicklung der A+N-Verbindungen seit 1700
}

In diesem Kapitel wird die historische Entwicklung der A+N-Verbindungen im Deutschen und Niederländischen seit 1700 behandelt. In Kapitel 4 wurde bereits gezeigt, dass im Bereich klassifikatorischer $\mathrm{A}+\mathrm{N}$-Verbindungen eine interessante Variationskonstellation vorliegt, die sich nur zum Teil durch sprachstrukturelle Bildungsbeschränkungen erklären lässt. Im Folgenden soll daher detailliert untersucht werden, wie sich die $\mathrm{A}+\mathrm{N}-$ Verbindungen in den letzten drei Jahrhunderten entwickelt haben und ob die inner- und zwischensprachliche Variation auf einen grundlegenden Wandelprozess bezüglich des Gebrauchs morphologischer und syntaktischer A+N-Benennungseinheiten im Deutschen und Niederländischen hinweist. Zunächst werden Materialgrundlage und Analyseprinzipien vorgestellt (vgl. Kap. 5.1), danach werden die Ergebnisse der Untersuchung präsentiert (vgl. Kap. 5.2-5.7).

\subsection{Materialgrundlage und methodisches Vorgehen}

Die empirische Untersuchung basiert auf Fallstudien zu einzelnen Adjektiven und ihrer Verwendung in morphologischen und syntaktischen Benennungseinheiten. Hierfür wurden historisches Wörterbuchmaterial sowie diachrone Korpora und Textsammlungen analysiert. Es folgen einige grundsätzliche Bemerkungen zur Auswahl der Adjektive und zu Problemen bei der Unterscheidung von Phrasen und Komposita, danach steht das verwendete historische Material im Mittelpunkt.

\subsubsection{Adjektive als Ausgangspunkt}

Adjektive sind der Ausgangspunkt der Untersuchung, weil ihr formaler Aufbau gegenwärtig die wichtigste strukturelle Voraussetzung für die Konkurrenz von Phrase und Kompositum darstellt. Während Phrasen prinzipiell mit Adjektiven jeglicher morphologischer Struktur gebildet werden können, muss das Adjektiv als Erstglied eines Kompositums in der Regel monomorphemisch sein, wobei eine deutliche Präferenz bei einsilbigen Adjektiven wie DE neu, alt bzw. NL klein, zoet liegt. Ferner sind im Deutschen auch zweisilbige Adjektive auf -er, -el, -en (wie in Sauerkirsche, Edelmann, Eigenname) und endbetonte mehrsilbige Adjek- 
tive (wie in Direktbank, Mobiltelefon) zulässig. Eine endbetonte Silbe tritt in der Regel bei Adjektiven auf, die entweder vollständig entlehnt wurden, oder bei adjektivischen Bildungen mit Lehnsuffixen wie -(i)al, -iv, -il, z.T. auch bei Bildungen mit nativen Adjektiven wie (all)gemein, geheim (wie in Allgemeinwissen, Geheimagent etc.). Außerdem gibt es auch A+N-Komposita mit formal komplexen Adjektiven ohne Endbetonung (z.B. Mehrfachbelastung, Endlosdebatte). Im Niederländischen gelten im Wesentlichen die gleichen Beschränkungen: $\mathrm{A}+\mathrm{N}$ Komposita werden fast ausschließlich mit monomorphemischen, ein- oder zweisilbigen Adjektiven germanischen Ursprungs gebildet. Entlehnte, mehrsilbige Adjektive als Erstglied bilden die Ausnahme (vgl. speciaalzaak, ideaalbeeld), lediglich Bildungen mit totaal (wie totaalbedrag, totaalbeeld, totaalindruk) gelten als produktiv (vgl. van der Sijs 2005: 266). In den Fallstudien werden Adjektive unterschiedlicher Form (d.h. mit unterschiedlicher Silbenstruktur und mit bzw. ohne Endbetonung) berücksichtigt.

Relationsadjektive stellen eine besondere Adjektivklasse dar. Im Gegensatz $\mathrm{zu}$ qualitativen Adjektiven wie neu, alt, bitter spezifizieren sie keine Eigenschaft ihres Bezugsnomens. Sie sind von einem Substantiv abgeleitet, d.h. morphologisch komplex, und stellen einen Bezug zwischen dem Nomen, das diesen Adjektiven zugrunde liegt, und dem Bezugsnomen in einer A+N-Verbindung her (vgl. Bally 1965: 97; Frevel/Knobloch 2005). Denominale Relationsadjektive mit nativem Suffix wie -lich in häuslich treten im Deutschen normalerweise nicht in Komposita auf, vgl. *Häuslich-gewalt, (entlehnte) Relationsadjektive mit endbetonten, gräko-lateinischen Lehnsuffixen wie -al in national hingegen schon (vgl. Fleischer/Barz 1995; Zifonun 2011). Bei der Verwendung solcher Relationsadjektive als Erstglied in Komposita unterscheiden sich das Deutsche und das Niederländische deutlich. Während das Deutsche Bildungen wie Sozialstruktur, Nationalflagge erlaubt, gelten diese im gegenwartssprachlichen Niederländisch als unzulässig ( ${ }^{\star}$ sociaalstructuur, ${ }^{\star}$ nationaalvlag). Um das Bindungsverhalten solcher Adjektive historisch-vergleichend zu überprüfen, wurden zwei Relationsadjektive ebenfalls in der Analyse berücksichtigt.

Aus diesen Vorüberlegungen heraus wurde mit Hilfe von CELEx (Baayen/Piepenbrock/Gulikers 1995) eine Liste mit Adjektiven für das Deutsche und Niederländische erstellt und aus ihnen zehn qualitative und zwei Relationsadjektive ausgewählt. Bei CELEX handelt es sich um eine lexikalische Datenbank, die Informationen zu Wortfrequenz, Wortform und morphologischer Struktur des Wortschatzes im Deutschen, Niederländischen und Englischen enthält. Alle ausgewählten Adjektive haben in der jeweils anderen Sprache ein stammverwandtes Kognat mit den gleichen morphologischen Eigenschaften und ein über weite Strecken ähnliches Bedeutungsspektrum. Voneinander unterscheiden sich die 
Adjektive zum Teil in ihrem phonologischen Aufbau (Silbenstruktur, Endbetonung), während ihre Vorkommenshäufigkeit relativ konstant ist. Dadurch soll vermieden werden, dass Unterschiede bei der Produktivität einzelner Adjektive - einzelsprachlich und sprachvergleichend - auf stark unterschiedliche Frequenzen zurückgeführt werden können. Die in Tabelle 5.1 aufgeführten Adjektive werden im Rahmen der Arbeit für das Deutsche und das Niederländische untersucht.

Tab. 5.1: Adjektivauswahl für Fallstudien

\begin{tabular}{lll}
\hline Einsilbig & Zweisilbig & Mehrsilbig \\
\hline $\begin{array}{l}\text { fremd - vreemd } \\
\text { gelb - geel }\end{array}$ & $\begin{array}{l}\text { Ohne Endbetonung: } \\
\text { bitter - bitter }\end{array}$ & negativ - negatief \\
kalt - koud & Mit Endbetonung: & \\
rot - rood & geheim - geheim & \\
schwarz - zwart & sozial - sociaal & \\
still - stil & zivil - civiel & \\
tief - diep &
\end{tabular}

\subsubsection{Zur Unterscheidung von Komposita und Phrasen}

$\mathrm{A}+\mathrm{N}-\mathrm{Phrasen}$ und $\mathrm{A}+\mathrm{N}-\mathrm{Komposita}$ können im Niederländischen und Deutschen in der Regel deutlich voneinander differenziert werden. A+N-Komposita werden in der Regel auf dem Erstglied betont, das Adjektiv wird nicht flektiert. Bei Phrasen liegt die Hauptbetonung auf dem Nomen, das Adjektiv wird flektiert.

Diese allgemeine Regel wird zum einen durch die Existenz von Phrasen mit Schwa-Apokope im Niederländischen wie het centraal-Ø station 'Hauptbahnhof' oder de geheim- $\emptyset$ agent 'Geheimagent' verkompliziert (vgl. Kap. 4.4.2). Hier entfällt mit der Flexion des Adjektivs ein typisches phrasales Merkmal und es kann nur aufgrund der Betonung davon ausgegangen werden, dass es sich um Phrasen handelt. Da in schriftlichen Quellen allerdings selten Angaben zur Betonung zu finden sind (eine Ausnahme bilden neuere Wörterbücher, die das Betonungsmuster im Lemmaeintrag angeben), wird als Hilfskriterium für die Klassifizierung einer Bildung als Phrase oder Kompositum die Zusammen- oder Getrenntschreibung einer Verbindung herangezogen. Die Zusammenschreibung gilt demnach als Indiz für den morphologischen Charakter einer Verbindung, wenn das Adjektiv nicht flektiert wird. 
Hilfreich ist dieses Kriterium beispielsweise im Deutschen, wo sich die obligatorische Flexion attributiver, pränominaler Adjektive erst im 19. Jahrhundert auch im Schriftlichen endgültig durchgesetzt hat (vgl. Kap. 6.3). Bis dahin war die Verwendung flexionsloser Formen zeitweise auch im Deutschen zulässig (vgl. Pounder 2001: 312f.): Stark flektierende, attributiv verwendete Adjektive im Nominativ (und ggf. auch im Akkusativ bei nicht-maskulinen Bezugsnomen) konnten seit dem Althochdeutschen optional auch ohne Flexionsendung auftreten (vgl. Beispiele wie „ein sandig und salpetrig Erdreich“ (Amaranthes 1715, zitiert nach Pounder 2001: 313; Hervorhebung im Original)). Auch bei den $\mathrm{A}+\mathrm{N}$ Verbindungen sind in Wörterbüchern des 18. Jahrhunderts noch Beispiele mit einem Nomen im Neutrum und unflektiertem Adjektiv zu finden (z.B. schwartz brod anstelle von schwarzes Brot, schwartz meel anstelle von schwarzes Mehl). Diese werden getrennt geschrieben, während andere Verbindungen mit nichtflektiertem Adjektiv zusammen geschrieben werden, z.B. Schwartz-beer, Schwartzkunst, Schwartz-mantel. Da die Flexion als Unterscheidungskriterium ausfällt und Angaben zur Betonung fehlen, ist hier das orthografische Kriterium ausschlaggebend. Sobald eine Verbindung getrennt geschrieben wird, gilt sie als Phrase, in der die gegenwartssprachlich obligatorische Flexion noch fehlt. Die Zusammenschreibung kann allerdings täuschen: So würde NL roodkoper 'Rotkupfer', das seit 1870 in allen untersuchten niederländischen Wörterbüchern verzeichnet ist, als Kompositum gewertet. Betonungsangaben in neueren Wörterbüchern (z.B. in Van Dale 2005: ROODKOPER) weisen die Verbindung jedoch als zusammen geschriebene Phrase aus: roodkóper. Daraus ergibt sich die folgende Bewertungsskala für die Kategorisierung von Komposita und Phrasen:

i. Flexion des Adjektivs; wenn keine Flexion vorhanden;

ii. Betonungsstruktur der Verbindung; wenn keine Angaben zur Betonung vorhanden;

iii. Zusammen-/Getrenntschreibung der Verbindung.

Auf diese Weise wurden alle relevanten $\mathrm{A}+\mathrm{N}-$ Verbindungen im Material entweder als morphologische oder syntaktische Bildung klassifiziert.

Die Verwendung des Kriteriums Zusammen-/Getrenntschreibung setzt voraus, dass die Zusammenschreibung von Komposita zu Beginn des Untersuchungszeitraums bereits allgemein verbreitet ist. Für die verwendeten Wörterbücher ist dies von 1700 an sicher der Fall. Eindeutige Phrasen werden in der Regel getrennt, Komposita zusammen geschrieben (wobei Adjektiv und Nomen z.T. auch durch Bindestrich oder Gleichheitszeichen verbunden sind). Ausnahmen sind einige lexikalisierte Phrasen. Hier tendieren Wörterbücher oftmals zur Zusammenschreibung, vgl. DE Langeweile, Hohepriester, NL rodekool, zwartehandelaar, hogeschool, wittebrood (wobei diese aber zum Teil bereits worttypi- 
sche Eigenschaften aufweisen, vgl. Kap. 4.4.1). ${ }^{36}$ Dass auch in der Gegenwartssprache Sprecher zur Zusammenschreibung tendieren können, illustriert das Beispiel der stillen SMS (geschrieben als „Stille-SMS“, vgl. Kap. 4.2).

\subsubsection{Materialgrundlage}

Das Material für die historische Analyse stammt aus zwei Quellen. Als Grundlage für die Identifizierung relevanter Benennungseinheiten dienen Einträge in historischen Wörterbüchern ab 1700. Die Wörterbücher bilden die Basis für eine qualitative Analyse deutscher und niederländischer A+N-Verbindungen. Kleinere Korpusstudien sollen vermutete Trends bestätigen oder widerlegen und die Entwicklung einzelner Konkurrenzen zwischen Phrase und Kompositum nachzeichnen.

\subsubsection{Wörterbücher}

Der zeitliche Beginn der Untersuchung ergibt sich aus der Annahme, dass erst mit dem Ausgang des 17. Jahrhunderts von einer richtigen Lexikografie des Deutschen gesprochen werden kann (vgl. Kühn/Püschel 1990: 2051). Es sind allerdings auch praktische Erwägungen, die hier eine Rolle spielen. Für beide Sprachen ist erst nach 1700 ausreichendes lexikografisches, z.T. auch digital verfügbares Material vorhanden. Mit dieser Eingrenzung des Untersuchungsbeginns auf den Beginn des 18. Jahrhunderts ist es zwar nicht möglich, die Verwendung beider Konstruktionsmuster seit dem Althochdeutschen (ab 800) bzw. Altniederländischen (ab 850) nachzuzeichnen. Ältere lexikografische Quellen verzeichnen allerdings oft nur wenige Phrasen und die Identifikation von Benennungseinheiten in Textkorpora geht über das im Rahmen dieser Arbeit Leistbare hinaus (vgl. aber Friedrich 2006 und weiter unten). Für beide Sprachen existieren zwar zwei detaillierte historische Wörterbücher, deren Materialsammlung weit vor 1700 zurückreicht (das „Deutsche Wörterbuch“ der Gebrüder Grimm bzw. das Woordenboek der „Nederlandsche Taal“, kurz WNT), allerdings sind beide nicht als synchrone Sammlungen der jeweiligen Epoche gedacht und sie verzeichnen auch auffällige, jedoch jeweils nur einmalig belegte Bildungen, denen nicht zwingend ein etablierter Benennungscharakter zukommt.

36 Die Zeitschrift „Onze Taal“ verzeichnet eine ganze Reihe solcher Schreibungen im Niederländischen. Diese sind zu finden unter: www.onzetaal.nl/taaladvies/advies/groenekool-groenekool-rodekool-rode-kool-wittekool-witte-kool (Stand: 28.2.2013). 
Aufgrund dieser Überlegungen stellt daher Kramers „Teutsch-Italiänisches Dictionarium“ (1700-1702) den Ausgangspunkt für das Deutsche dar. Die lexikografisch basierte Beschreibung des Niederländischen beginnt mit Hoogstratens „Nieuw Woordenboek der Nederlantsche en Latynsche Tale“ (1704). Der Anfang des Untersuchungszeitraums fällt für das Deutsche in die letzte Phase eines vom 16. bis zum 18. Jahrhundert dauernden Prozesses, in dem regionale Sprachunterschiede zunehmend zugunsten überregionaler Normen verschwinden (von Polenz 2000: 16). Der Standardisierungsprozess im Niederländischen ist ebenfalls seit dem späten 16. Jahrhundert im Gange und verlagert sich in Folge politisch-kultureller Umwalzungen schnell vom südlichen Brabant ins nördliche Holland (Willemyns 2003). Es kommt allerdings erst im 19. Jahrhundert zur Entwicklung einer gemeinsamen (Schrift-)Standardsprache für die Niederlande und Flandern.

Wörterbücher dienen als Ausgangspunkt, weil in der Arbeit lexikalische Einheiten im Mittelpunkt stehen und nur historische Dokumente einen Zugriff auf die muttersprachliche Kompetenz der jeweiligen Epoche ermöglichen, d.h. nur so die Frage, welche Bildungen zum jeweiligen Zeitpunkt als Benennungen etabliert sind, annähernd beantwortet werden kann. Wie in Kapitel 2 diskutiert sind die Begriffe lexikalische Einheit und Benennung nicht deckungsgleich. Um aber die spezifischen Probleme historischer Phraseologieforschung zu lösen - wie sich nämlich Wortverbindungen als Phraseologismen identifizieren lassen, wenn keine Muttersprachler mehr über die Natur einer Verbindung entscheiden können und die Quellenauswahl beschränkt ist (vgl. Burger/Linke 1998) - bieten historische Wörterbücher und die in ihnen enthaltenen Beschreibungen des zeitgenössischen Wortschatzes die beste Annäherung.

Das lexikografische Material dieser Arbeit wurde wie folgt ermittelt: Für jedes Adjektiv wurde der jeweilige Lemmaeintrag auf $\mathrm{A}+\mathrm{N}-$ Verbindungen überprüft und alle mit dem Adjektiv als Erstglied gebildeten und als Lemma verzeichneten Komposita als Beleg aufgenommen. Nachdem so alle für die jeweilige Sprache ausgewählten Wörterbücher ausgewertet waren, wurden noch einmal in jedem Wörterbuch die Lemmaeinträge aller ermittelten nominalen Konstituenten daraufhin kontrolliert, ob dort eventuell eine entsprechende (in der Regel phrasale) Verbindung notiert war, die noch nicht im Lemmaeintrag des Adjektivs vermerkt war. Verbindungen, bei denen das Nomen kein freies Lexem darstellt (z.B. Rotflosser 'Fischart') oder eine Derivation der wahrscheinlichere Wortbildungsprozess ist (z.B. Schwarzmalerei), wurden nicht berücksichtigt.

Die so gewonnene Datenmenge für den Zeitraum seit 1700 stellt das Ausgangsmaterial für die folgenden Fragen dar: 1. Gibt es im 18., 19. bzw. 20. Jahrhundert sowohl Phrasen als auch Komposita, die als Benennungen gebraucht werden, oder wird ein Verfahren erst später produktiv? 2. Gleichen sich Adjektive 
ähnlicher Struktur (z.B. einsilbig oder mit Endbetonung) in ihrem Bindungsverhalten? 3. Gibt es spezifische Form-Bedeutungskorrelationen (z.B. die Korrelation von Metapher - Phrase oder bei einzelnen Adjektivbedeutungen)? 4. Kommt es zur Dublettenbildung, d.h. zur Koexistenz funktional äquivalenter bzw. bedeutungsidentischer Phrasen und Komposita? Wenn dies der Fall ist: Welche Bildung wurde zunächst verwendet? Verschwindet eine Variante langfristig? Anhand der Antworten auf diese Fragen soll die Entwicklung der A+N-Verbindungen in beiden Sprachen beschrieben werden.

Die Arbeit mit Wörterbüchern birgt bekanntermaßen einige Probleme. Wörterbücher sind nicht immer deskriptiv, d.h., sie stellen nicht zwangsläufig eine Beschreibung des realen Sprachgebrauchs dar, sondern enthalten auch normative Vorstellungen des Verfassers. Der aufgenommene Wortschatz ist bisweilen sehr heterogen, ohne dass dies explizit markiert wird. Zum Teil handelt es sich um regionale Ausdrücke, die zusätzliche dialektale Variation ins Spiel bringen. Zum Teil handelt es sich um fachsprachliche Termini, wobei eine eindeutige Trennung von Fachterminologie und Allgemeinsprache sehr schwierig ist, da „sich heute weniger denn je auch nur einigermaßen sicher sagen [lässt], wo die Gemeinsprache aufhört und die Fachsprache beginnt“ (Wilss 1998: 144 f.; vgl. auch Kap. 2.1). Viele Wörterbücher enthalten veraltete Wörter und Wendungen, die nicht mehr gebraucht werden. Wörterbücher können grundsätzlich nie vollständig sein und insbesondere im Zusammenhang mit der Problematik dieser Arbeit kann davon ausgegangen werden, dass in den meisten Werken tendenziell eher Komposita als phrasale Benennungseinheiten verzeichnet sind, weil letztere nun einmal keine Wortbildungen darstellen oder es zum Teil um nur gering idiomatische phraseologische Einheiten geht.

Die Abgrenzung zwischen Kollokation und tatsächlicher Benennungseinheit ist oftmals problematisch und die Entscheidung, ob es sich nur um eine reguläre, häufig vorkommende Verbindung wie blondes Haar oder eine feste Benennungseinheit handelt, ist oft schwer zu treffen. Eine Arbeit, in der phraseologische Einheiten des Mittelhochdeutschen allein auf Basis von Texten entschlüsselt werden, stellt die Studie von Friedrich (2006: 16-20) dar, der seine Kriterien ausführlich erläutert. Phraseologische Einheiten sind zwar nicht immer deckungsgleich mit den hier zentralen Benennungseinheiten, aber einige der von Friedrich verwendeten Kriterien scheinen auch in dieser Arbeit nützlich, um relevante Einheiten im Wörterbuch zu identifizieren. Vgl. die folgende Übersicht angewendeter Kriterien zur Identifizierung von Benennungseinheiten:

a) Relevante Phrasen bzw. Komposita werden als autonome Einträge präsentiert, d.h., sie sind nicht ausschließlich Teil eines Phraseologismus wie z.B. schwarze Zahlen in schwarze Zahlen schreiben. 
b) Im Wörterbuch wird eine Verbindung als Name, Begriff etc. bezeichnet. In der Regel kann dies als ein verlässlicher Hinweis auf den Benennungscharakter einer Verbindung gelten.

c) Es gibt neuhochdeutsche Entsprechungen, die durch Muttersprachler intuitiv als Benennung eingestuft werden. Wenn dies zutrifft, wird die Verbindung als Benennungseinheit aufgenommen.

d) Die Bedeutung der Verbindung wird im Wörterbuch erklärt, es wird also angezeigt, dass die Konzeptbedeutung nicht kompositional ist.

e) Bei zweisprachigen Wörterbüchern: Die Verbindungen werden nicht eins zu eins übersetzt (wie z.B. schwarzes Haar - capegli (= 'Haar') neri (= 'schwarz'), Kramer 1700-1702), sondern offenbaren Bedeutungsspezialisierungen (z.B. wird bei Frisch 1741 schwartz Geblüt mit melancholia übersetzt).

Traf im Material zumindest a) sowie ein weiteres Kriterium auf die jeweilige $\mathrm{A}+\mathrm{N}$ Verbindung zu, wurde die Verbindung in der Regel als (mögliche) Benennungseinheit kategorisiert und in der Analyse berücksichtigt. Wie in Kapitel 2 bereits besprochen, ist es möglich, dass die Menge der Benennungen einer Sprache von Sprecher zu Sprecher variiert. Die Kategorisierung der Verbindungen kann in einzelnen Fällen also durchaus diskutiert werden, insbesondere wenn Kriterium c), d.h. die eigene Einschätzung, relevant wird.

Weitere methodische Probleme sind die Vergleichbarkeit zwischen einzelnen Wörterbüchern, weil Umfang und Qualität der Einträge von Wörterbuch zu Wörterbuch stark schwanken können. Auch müssen in einem Wörterbuch erstmals verzeichnete Verbindungen nicht automatisch auf neue bzw. neu benannte Konzepte zurückgeführt werden. Zum Beispiel werden stille vrijdag 'Karfreitag' bzw. stille week 'Karwoche' in den hier zentralen Wörterbüchern (das sogenannte „Primärmaterial“, vgl. unten) erstmalig im 19. Jahrhundert genannt, obwohl die Verbindungen bereits für das 16. Jahrhundert belegt sind (z.B. in Kiliaans Etymologicum Teutonicae Linguae von 1599). Auch der Umfang älterer Wörterbücher ist im Vergleich zu moderneren Werken oft geringer und für das Deutsche werden mehr Verbindungen als für das Niederländische verzeichnet. Dies kann ebenso gut lexikografischen Gründen wie dem realen Sprachgebrauch geschuldet sein, zeigt aber vor allem, dass eine quantitative Analyse von Wörterbüchern problematisch ist und nur eine qualitative Annäherung an tatsächliche Verhältnisse erlaubt.

Schließlich stellt sich die Frage, wie Produktivität und Produktivitätsveränderungen aufgrund von Wörterbuchdaten gemessen werden können, d.h., wie festgestellt werden kann, ob die syntaktische oder morphologische Benennungsbildung an Produktivität zu- bzw. abnimmt. Allgemeiner Forschungskonsens ist, dass dies mit Wörterbuchdaten unmöglich sei (vgl. Baayen/Renouf 1996; Bauer 
2003: 76f.). Tatsächlich ist dies methodisch höchst problematisch. Denn abgesehen von der Heterogenität der Daten und der schwierigen Vergleichbarkeit von Wörterbüchern untereinander bleiben Wörterbuchdaten prinzipiell unvollständig. Die Angaben zur Entwicklung der Nutzungsfrequenz beider A+N-Verfahren sind deshalb bewusst vorsichtig formuliert und meist nur als Tendenzen zu verstehen. Qualitative Aussagen zur Produktivität eines Verfahrens sind demgegenüber einfacher. Die Wörterbuchdaten belegen zumindest für die beschriebenen Sprachvarietäten, ob für das jeweilige Adjektiv sowohl Phrasenbildung als auch Komposition zu einem gegebenen Zeitpunkt durch entsprechende Bildungen vertreten sind, und sie ermöglichen einen Rückschluss auf bestehende Input- und Outputbeschränkungen beider Verfahren (auftretende Bedeutungen des Adjektivs, Korrelation von Phrase und Kompositum mit metaphorischer und metonymischer/possessiver Interpretation etc.). Auf diese Weise können erste Eindrücke bezüglich der Dominanz eines Musters in der Benennungsbildung gewonnen werden, die durch Korpusuntersuchungen bestätigt werden müssen (vgl. unten). In Tabelle 5.2 und 5.3 sind die für beide Sprachen verwendeten Wörterbücher aufgelistet, sie stellen das Primärmaterial dar. Zu Ergänzungszwecken wurden das „Deutsche Wörterbuch“ (DWB, 1854-1971) und das „Woordenboek der Nederlandsche Taal“ (WNT, 1851-1998) verwendet. Beide gehören allerdings nicht zu den Primärquellen, da sie in erster Linie - wie bereits erwähnt - den gesamten historischen Wortschatz wiedergeben und nicht als synchrone Sammlung der jeweiligen Epoche gedacht sind. Zusätzlich sind in beiden Wörterbüchern auch seltene, aber auffällige Bildungen aufgenommen, die nicht zwingend etablierte Benennungen darstellen müssen.

Tab. 5.2: Verwendete Wörterbücher des Deutschen (Primärmaterial)

\begin{tabular}{ll}
\hline Jahr & Titel \\
\hline $1700-1702$ & Kramer: „Das herrlich-Grosse Teutsch-Italiänische Dictionarium“ \\
1741 & Frisch: „Teutsch-Lateinisches Wörter-Buch“ \\
1787 & Kramer/Moerbeek: „Neues Deutsch-Holländisches Wörterbuch“ \\
$1793-1801$ & Adelung: „Grammatisch-kritisches Wörterbuch der hochdeutschen Mundart“ \\
$1807-1811$ & Campe: „Wörterbuch der Deutschen Sprache“ \\
$1890-1895$ & Heyne: „Deutsches Wörterbuch“ \\
$1967-1982$ & „Wörterbuch der deutschen Gegenwartssprache“ \\
& (Teilbände mit verschiedenen Aufl.) \\
$1980-1984$ & Brockhaus Wahrig: „Deutsches Wörterbuch“ \\
1999 & Duden: „Das große Wörterbuch der deutschen Sprache“ \\
2012 & Duden Online: „Online-Duden auf Basis des Dudenkorpus“ \\
\hline
\end{tabular}


Für die synchrone Analyse wurden in Einzelfällen das online verfügbare „Van Dale Woordenboek Duits - Nederlands“ (Version von 2012) und die deutsche und niederländische Version der Wikipedia herangezogen.

Tab. 5.3: Verwendete Wörterbücher des Niederländischen (Primärmaterial)

\begin{tabular}{ll}
\hline Jahr & Titel \\
\hline 1704 & Hoogstraten: „Nieuw Woordenboek der Nederlantsche en Latynsche Tale“ \\
1771 & Verheyk: „Nederduitsch en Latynsch Woordenboek“ \\
1786 & Des Roches: „Nieuw Nederduytsch en Fransch Woorden-Boek“ \\
$1799-1811$ & Weiland: „Nederduitsch taalkundig woordenboek“ \\
1870 & Sicherer/Akveld: „Nederlandsch-Hoogduitsch en Hoogduitsch-Nederlandsch \\
& Woordenboek“ \\
1909 & Koenen: „Verklarend Handwoordenboek“ \\
1924 & Van Dale: „Groot woordenboek der Nederlandsche taal“ \\
1937 & Koenen: „Verklarend Handwoordenboek“ \\
1961 & Van Dale: „Groot woordenboek der Nederlandse taal“ \\
1966 & Koenen: „Verklarend Handwoordenboek“ \\
1984 & Van Dale: „Groot woordenboek der Nederlandse taal“ \\
1986 & „Wolter’s woordenboek eigentijds Nederlands: Grote Koenen“ \\
2005 & Van Dale: „Groot woordenboek der Nederlandse taal“ \\
\hline
\end{tabular}

\subsubsection{Korpora und andere Textsammlungen}

Der zweite Teil der Analyse basiert auf diachronen Korpora und Textsammlungen. Hier werden im Wörterbuch angedeutete Trends und Entwicklungsprozesse für einzelne Lexeme im günstigsten Falle nachgezeichnet und es kann gezeigt werden, ob konkurrierende Bildungen einander verdrängen oder stabil nebeneinander bestehen bleiben.

Die meisten historischen Korpora im Deutschen und Niederländischen sind zu klein für eine Untersuchung lexikalischer Einheiten. Korpora der Gegenwartssprache umfassen inzwischen mindestens 100 Mio. Tokens (z.B. das „DWDS-Kernkorpus" für das Deutsche des 20. Jahrhunderts), viele historische Korpora jedoch weniger als 1 Mio. (z.B. „GerManC-Korpus“ $1650-1800,{ }^{37}$ „Compilatiecorpus Historisch Nederlands“ $1285-2000^{38}$ ). Für das Deutsche hat das Institut für Deutsche

37 www.llc.manchester.ac.uk/research/projects/germanc/.

38 www.diachronie.nl/corpora/. 
Sprache u.a. das „Historische Korpus“39 erstellt, das Texte des Zeitraums 17001918 umfasst und immerhin einen Umfang von etwa 45 Millionen laufenden Wörtern hat (Stand: November 2012), öffentlich aber nur beschränkt zugänglich ist. Daher wird in erster Linie mit dem ZEIT-Korpus gearbeitet, das alle Ausgaben der Wochenzeitung „Die ZEIT“ seit 1946 enthält und etwa 460 Millionen Tokens zählt. Das ZEIT-Korpus scheint für eine historische Untersuchung eigentlich zu aktuell zu sein, allerdings bietet es für einige der gewählten Adjektive sehr viele Treffer und ermöglicht aufgrund der Größe die Beobachtung der Entwicklung von Benennungsdubletten innerhalb einer Textsorte über immerhin mehr als sechs Jahrzehnte hinweg. Als ergänzende historische Textsammlungen für das 18. und 19. Jahrhundert sowie für den Beginn des 20. Jahrhunderts wurde die Datenbank „Deutsche Literatur von Lessing bis Kafka“ ausgewählt. Sie enthält Auszüge und Volltexte von mehr als 100 Autoren zwischen dem 18. und dem Beginn des 20. Jahrhunderts. Außerdem steht eine kleine Auswahl historischer Lexika zur Verfügung (vgl. Tab. 5.4). (Digitalisierte) Lexika bieten einen idealen Rahmen für die Untersuchung von Benennungseinheiten, da sie auf die Definition und Beschreibung relevanter Konzepte (die benannt werden müssen!) ausgerichtet und durch längere Textpassagen auch für Volltextsuchen geeignet sind. Teilweise ermöglichen sie auch einen Blick auf fachsprachliche Besonderheiten.

Tab. 5.4: Verwendete Enzyklopädien des Deutschen (DELEX; 1809-1906)

\begin{tabular}{ll}
\hline Jahr & Titel \\
\hline $1809-1811$ & „Conversations-Lexikon oder kurzgefaßtes Handwörterbuch“ (1. Aufl.) \\
$1834-1838$ & „Damen-Conversations-Lexikon“ \\
$1837-1841$ & „Bilder-Conversations-Lexikon“(1. Aufl.) \\
$1854-1857$ & „Herders Conversations-Lexikon“(1. Aufl.) \\
$1857-1865$ & „Pierer’s Universal-Lexikon“(4. Aufl.) \\
$1905-1909$ & „Meyers Großes Konversationslexikon“ (6. Aufl.) \\
1906 & „Brockhaus Kleines Konversations-Lexikon“ (5. Aufl.) \\
\hline
\end{tabular}

Das niederländische Pendant zum ZEIT-Korpus ist das LCA, das Zeitungsarchiv des „Leeuwarder Courant“, einer im Norden der Niederlande erscheinenden Zeitung. Alle Jahrgänge sind ab 1752 elektronisch verfügbar und durchsuchbar. Innerhalb einer Textsorte können also für fast zweieinhalb Jahrhunderte durchgängig

39 www1.ids-mannheim.de/lexik/HistorischesKorpus/. 
Texte durchsucht werden. Eine Herausforderung war, dass das Archiv nicht für linguistische Untersuchungen ausgelegt und die Funktionalitäten dementsprechend eingeschränkt sind. So kann zwar auch nach Wortgruppen gesucht werden, allerdings erhält man keine zusammenfassenden Statistiken, sondern nur eine Übersicht mit Links zu allen Artikeln, in denen die gesuchte Verbindung vorkommen kann. Diese Einzeltreffer müssen manuell überprüft und gezählt werden. Ähnlich wie das ZEIT-Korpus enthält es viele Wiederholungen, die manuell entfernt werden müssen. Als ergänzende Quellen stehen die Zitatsammlung des „Woordenboek der Nederlandsche Taal“, die für den Zeitraum 1500-1976 etwa 1,7 Mio. Tokens umfasst und für die Datierung von Erstbelegen verwendet werden kann, zur Verfügung sowie die niederländische „Digitale Bibliotheek voor de Nederlandse letteren“, eine Online-Bibliothek der niederländischen Belletristik und Sachliteratur seit ca. 1200, in der alle aufgenommenen Texte durchsucht werden können. Auch hier sind die Suchoptionen nicht für linguistische Analysen ausgelegt und ist eine Recherche dementsprechend beschwerlich. Zudem unterscheidet die DBNL nicht zwischen Originalausgaben und in späteren Editionen hinzugefügtem Kommentartext. Auch tragen neu aufgelegte Werke oftmals die Datierung ihrer Neuausgabe, nicht der Erstauflage. Die DBNL enthält auch einige historische Enzyklopädien und Lexika, die als Äquivalent zu den gewählten Enzyklopädien im Deutschen verwendet werden können. Die digital verfügbare Auswahl ist allerdings deutlich kleiner als im Deutschen und auf den Zeitraum 1894-1918 beschränkt, vgl. Tabelle 5.5 .

Tab. 5.5: Verwendete Enzyklopädien des Niederländischen (NLLEX; 1894-1918)

\begin{tabular}{ll}
\hline Jahr & Titel \\
\hline 1894 & Brouwer: „Geïllustreerde Encyclopaedie“(2. Aufl.) \\
$1899-1908$ & Kramer: „Vivat’s geïllustreerde encyclopedie“ \\
$1912-1918$ & Kuiper: „Encyclopaedisch woordenboek“ \\
\hline
\end{tabular}

Für die deutsche Gegenwartssprache wird das ZEIT-Korpus (1989-2009) und für das Niederländische das selbst zusammengestellte LEXNEX-Korpus verwendet. Letzteres umfasst alle Ausgaben der drei niederländischen Tageszeitungen „Leeuwarder Courant“, „NRC“, „Volkskrant“ und der Wochenzeitschrift „De Groene Amsterdammer“ (Zeitraum 1997-2011; ein mit dem ZEIT-Korpus identischer Zeitraum ist leider nicht verfügbar). Diese Sammlung basiert auf „Lexis Nexis“, einer Volltextdatenbank, die u.a. Zeitungsmaterial aus zahlreichen Ländern archiviert und für Suchanfragen bereitstellt. Beide Sammlungen erlauben u.a. eine An- 
näherung an die quantitative Produktivität der A+N-Komposition mit verschiedenen Adjektiven und damit eine weitere Perspektive auf die morphologische und syntaktische Benennungsbildung im Deutschen und Niederländischen. Tabelle 5.6 fasst die verwendeten Korpora und Textsammlungen zusammen.

Tab. 5.6: Korpora und Textsammlungen

\begin{tabular}{|c|c|}
\hline \multicolumn{2}{|l|}{ Deutsch } \\
\hline ZEIT-Korpus & $\begin{array}{l}\text { Text-Korpus, das alle Ausgaben der Wochenzeitung „Die ZEIT“ seit } 1946 \\
\text { umfasst ( } 460 \text { Mio. Tokens) }\end{array}$ \\
\hline DBLK & $\begin{array}{l}\text { Datenbank „Deutsche Literatur von Lessing bis Kafka“ umfasst Volltexte, } \\
\text { Auszüge, Zitate der deutschsprachigen Literatur von der Mitte des 18. Jahr- } \\
\text { hunderts bis in die 1920er Jahre }\end{array}$ \\
\hline DELEX & verschiedene Enzyklopädien des Deutschen, vgl. Tab. 5.4 \\
\hline \multicolumn{2}{|l|}{ Niederländisch } \\
\hline LEXNEX-Korpus & $\begin{array}{l}\text { Korpus mit Volltexten der Tageszeitungen „Volkskrant“, „NRC“, „Leeuwarder } \\
\text { Courant“ und der Wochenzeitschrift „De Groene Amsterdammer“ (1997-2011) }\end{array}$ \\
\hline LCA & $\begin{array}{l}\text { „Leeuwarder Courant Archief“, Archiv des „Leeuwarder Courant“, Tageszei- } \\
\text { tung im Norden der Niederlande (alle Ausgaben ab 1752) }\end{array}$ \\
\hline DBNL & $\begin{array}{l}\text { „Digitale bibliotheek voor de Nederlandse letteren“, Volltextdatenbank } \\
\text { niederländischer Literatur seit } 1200\end{array}$ \\
\hline NLLEX & verschiedene Enzyklopädien des Niederländischen; vgl. Tab. 5.5 \\
\hline WNT-Zitate & $\begin{array}{l}\text { „Woordenboek der Nederlandsche Taal“, Zitatsammlung mit ca. } 1.7 \text { Mio. } \\
\text { Tokens (Zeitraum 1500-1976) }\end{array}$ \\
\hline
\end{tabular}

\subsection{Benennungsbildung bei qualitativen Adjektiven seit 1700}

Im Folgenden wird für die ausgewählten qualitativen Adjektive die Entwicklung der Konkurrenz zwischen Phrasen und Komposita seit 1700 im Sprachvergleich nachgezeichnet.

Aufgrund des Wörterbuchmaterials des 20. Jahrhunderts lassen sich erste Präferenzen in der Gegenwartssprache erkennen (vgl. Abb. 5.1 und 5.2). Diese Einteilung beruht auf einer Einschätzung der Realisierungspräferenzen aufgrund der Anzahl verzeichneter A+N-Benennungseinheiten. In beiden Sprachen gibt es Adjektive, die gleichermaßen in syntaktischen und morphologischen Benennungseinheiten auftreten, dazu gehören u.a. die drei untersuchten Farbadjektive schwarz - zwart, rot - rood und gelb - geel. Andere Adjektive zeigen in ihrem 
Bindungsverhalten eine deutliche Formpräferenz. Vier Adjektive im Deutschen haben eine deutliche Präferenz zur Komposition, jedoch nur eines einen ausgeprägten Bias zur Phrasenbildung (nämlich still). Im Niederländischen verhält es sich umgekehrt, hier tendieren nur diep und - mit Abstrichen - bitter eindeutig zur Komposition, während stil, vreemd und negatief i.d.R. nur in phrasalen Benennungseinheiten auftreten.

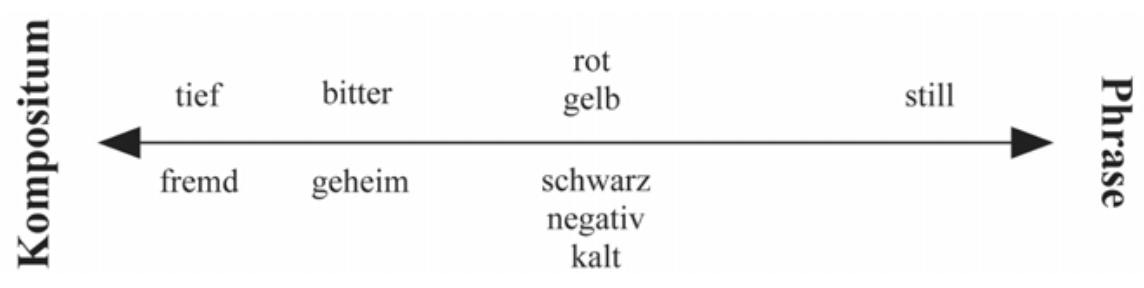

Abb. 5.1: Bias einzelner Adjektive im Deutschen

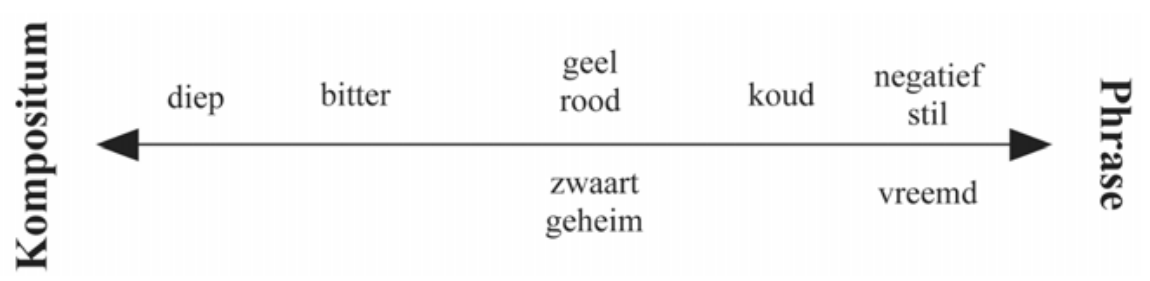

Abb. 5.2: Bias einzelner Adjektive im Niederländischen

Diese Einschätzung wird bei der A+N-Komposition indirekt durch die unterschiedliche Anzahl an Hapaxen, die ein wichtiger Indikator für die Produktivität eines Verfahrens sein können (als Teil der sogenannten 'expanding productivity' und 'potential productivity’, vgl. Baayen 2009), bestätigt. Hapaxe sind Worteinheiten, die in einem gegebenen Korpus nur ein einziges Mal vorkommen, und dienen als statistische Maßeinheit, um darzustellen, wie produktiv ein Verfahren, d.h., wie hoch der Anteil eines Verfahrens an der Expansion des Wortschatzes durch die Bildung von Neologismen ist. Grundlegend dafür ist die Annahme, dass Neologismen ,are found primarily among the hapax legomena, and to a lesser extent among the words occurring twice, three times“ (vgl. Baayen 2009: 905). ${ }^{40}$

40 Es ist zwar nicht ausgeschlossen, dass unter den Hapaxen auch lexikalisierte, seit Jahrhunderten etablierte Bildungen zu finden sind. Solange Hapaxe allerdings nur als Mittel zur statisti- 
Die Tabellen 5.7 und 5.8 verzeichnen die Anzahl gefundener Hapaxe für alle ausgewählten Adjektive im Deutschen und Niederländischen auf Basis des ZEIT-Korpus (eingeschränkt auf 1989-2009) bzw. des LEXNEX-Korpus (19972011). Eine weitergehende Berechnung der Produktivität, hier in erster Linie der 'expanding productivity' (EP), d.h. des Maßes, mit dem sich eine neue Kategorie ausbreitet und neue Einheiten im Wortschatz ausbildet, kann aus technischen Gründen nicht geleistet werden. Die EP ist der Quotient aus der Anzahl der Hapaxe einer morphologischen Kategorie (also z.B. Anzahl der Hapaxe mit still) geteilt durch die Anzahl aller Hapaxe im Korpus (unabhängig von ihrer Kategorie). Da die verwendeten Korpora aber keine Ermittlung aller Hapaxe zulassen, können die Hapaxzahlen in Tabelle 5.7 bzw. 5.8 nur als Produktivitätsindikator dienen. ${ }^{41}$

Tab. 5.7: Hapaxe im Deutschen (ZEIT-Korpus, 1989-2009)

\begin{tabular}{lcc}
\hline A+N-Komposita mit & Types & Hapaxe \\
\hline geheim & 279 & 141 \\
fremd & 225 & 135 \\
negativ & 144 & 77 \\
schwarz & 113 & 53 \\
rot & 76 & 36 \\
tief & 71 & 32 \\
bitter & 28 & 21 \\
kalt & 31 & 14 \\
gelb & 29 & 13 \\
still & 3 & 1 \\
\hline
\end{tabular}

schen Annäherung dienen und ihnen kein eigener Wert unterstellt wird, sind sie eine geeignete Einheit, um die Expansion einer morphologischen Kategorie zu messen (vgl. Baayen/Renouf 1996; Plag 2003; Baayen 2009).

41 Die Berechnung der 'potential productivity' (PP), d.h. das Wachstum einer bestimmten morphologischen Kategorie selbst (ohne Blick auf die Gesamtentwicklung des Wortschatzes), ließe sich sehr wohl berechnen. Die PP wird definiert als Quotient der Anzahl von Hapaxen einer Kategorie geteilt durch die Gesamtzahl aller Tokens dieser Kategorie im Korpus (vgl. Baayen 2009). Das Problem hierbei ist allerdings, dass nicht die Gesamtgröße des Korpus berücksichtigt wird. So würde sich mit diesem Maß die höchstmögliche Produktivität von 1 für Komposita mit vreemd ergeben, weil die Tokenanzahl der Hapaxanzahl entspricht. Allerdings kann die PP nicht abbilden, dass Neubildungen mit vreemd nur in sehr großen Korpora zu finden sind, während Hapaxe mit zwart oder bitter schon in viel kleineren Korpora wahrscheinlich sind (Baayen: pers. Komm.). 
Tab. 5.8: Hapaxe im Niederländischen (LEXNEX-Korpus, 1997-2011)

\begin{tabular}{lcc}
\hline A+N-Komposita mit & Types & Hapaxe \\
\hline rood & 55 & 25 \\
zwart & 51 & 22 \\
geel & 32 & 17 \\
diep & 21 & 11 \\
bitter & 20 & 8 \\
geheim & 16 & 6 \\
koud & 7 & 4 \\
vreemd & 3 & 3 \\
stil & 3 & 2 \\
negatief & 2 & 1 \\
\hline
\end{tabular}

Die deutschen und niederländischen Werte erlauben aufgrund der unterschiedlichen Korpusgröße keinen Vergleich. Die Maße sind zudem textsortenspezifisch (vgl. Plag/Dalton-Puffer/Baayen 1999), d.h., die Rangordnung kann nur bedingt auf andere Register übertragen werden.

Zum Teil werden die auf den Wörterbuchdaten basierenden Intuitionen bestätigt: Wortbildungen mit still im Deutschen und mit stil und negatief im Niederländischen sind sehr selten. Abweichungen ergeben sich z.B. mit Bezug auf die Position der Farbadjektive. So scheinen im Niederländischen laut Tabelle 5.8 die drei Farbadjektive bezüglich der $\mathrm{A}+\mathrm{N}-$ Komposition im Niederländischen am produktivsten zu sein, obwohl sie gleichermaßen phrasale und morphologische Benennungseinheiten ausbilden. Diese Abweichungen lassen sich allerdings erklären. Sie haben erstens methodische Ursachen. Die in Abbildung 5.1 und 5.2 verdeutlichten Präferenzen basieren auf anderem Quellenmaterial als die Angaben in Tabelle 5.7 und 5.8. Zweitens sagen absolute Präferenzen nichts darüber aus, wie häufig ein Verfahren gebraucht wird. So taucht diep zwar fast ausschließlich in morphologischen Benennungseinheiten auf, Neubildungen mit diep scheinen aufgrund unterschiedlicher Benennungsbedürfnisse aber eine viel geringere Rolle zu spielen als etwa Bildungen mit Farbadjektiven. Drittens ist die Bildung von Komposita nicht mit der Benennungsbildung gleichzusetzen. Im Wörterbuch werden ausschließlich etablierte Benennungseinheiten beschrieben. Unter die Hapaxe fallen aber nicht nur (neue) Benennungseinheiten, sondern auch Wortbildungen, die aus stilistischen oder syntaktischen Gründen entstanden sind (vgl. Schlücker/Hüning 2009). Eine hohe Anzahl von Hapaxen bei der Komposition muss also nicht zwangsläufig mit einer ausgeprägten morphologischen Benennungsbildung einhergehen. Zudem muss die phrasale Benennungsbildung auch nicht automatisch unmöglich sein. Bei fremd und geheim korreliert im Deutschen eine hohe Anzahl von Hapaxen 
zwar mit einer zu vernachlässigenden phrasalen Benennungsbildung, aber schon bei negativ, das ebenfalls viele Hapaxe ausbildet, aber auch in phrasalen Benennungseinheiten häufig vorkommt, ist dieser Zusammenhang nicht mehr gegeben (vgl. die entsprechenden Abschnitte in diesem Kapitel). Die Anzahl der Hapaxe eines Wortbildungsverfahrens ist also nur ein indirekter Indikator, zeigt aber an, ob ein Bildungsmuster für die Benennungsbildung überhaupt zur Verfügung steht und genutzt werden kann. So ist es sehr unwahrscheinlich, dass eine neue Benennungseinheit mit still/stil als Kompositum realisiert wird (wenn auch nicht unmöglich), die Bildung einer phrasalen Einheit wie DE stille SMS hingegen naheliegend. Zudem führt eine geringe Produktivität der Komposition nicht automatisch zu einer verstärkten phrasalen Benennungsbildung - das Adjektiv kann prinzipiell relativ wenig Anteil an der Benennungsbildung haben (wie z.B. NL vreemd).

In den folgenden Abschnitten wird die historische Entwicklung der Konkurrenz zwischen Komposition und Phrasenbildung anhand von Fallstudien für einzelne Adjektive dargestellt. Die Untersuchung konzentriert sich zunächst vornehmlich auf klassifikatorische Verbindungen, da diese den Hauptbereich der Konkurrenz zwischen beiden Verfahren darstellen. In Kapitel 5.2.1 werden alle Adjektive vorgestellt, die in beiden Sprachen eine ähnliche Entwicklung aufweisen. Danach geht es um jene Adjektive, bei denen sich das Deutsche und das Niederländische am deutlichsten auseinander entwickelt haben (vgl. 5.2.2). Als Ausgangspunkt jeder Beschreibung wird die Entwicklung im Deutschen geschildert und dann mit dem Niederländischen kontrastiert. Für einen schnellen Überblick über die wesentlichen Entwicklungstrends bei den qualitativen Adjektiven sei auf das Zwischenfazit in Kapitel 5.2.3 verwiesen. In Kapitel 5.3 werden dann die Relationsadjektive behandelt und in Kapitel 5.4 geht es um die Entwicklung von Phrasen mit Schwa-Apokope.

\subsubsection{Adjektive mit ähnlicher Entwicklung im Deutschen und Niederländischen}

Die Adjektive gelb/geel, rot/rood, schwarz/zwart, bitter/bitter, still/stil und tief/ diep haben in beiden Sprachen ähnliche Bildungspräferenzen entwickelt.

\subsubsection{1 gelb - geel, rot - rood, schwarz - zwart}

Für die Farbadjektive ist in beiden Sprachen charakteristisch, dass

a) Verbindungen mit diesen Adjektiven, insbesondere mit schwarz/zwart und rot/rood, in beiden Sprachen sehr häufig sind; 
b) über den gesamten Untersuchungszeitraum sowohl phrasale als auch morphologische Benennungseinheiten mit klassifikatorischer Bedeutung belegt sind (dies gilt nur in geringerem Umfang auch für andere Adjektive);

c) Possessivkomposita eine wichtige Rolle spielen.

$\mathrm{Zu}$ a): Verbindungen mit Farbadjektiven bieten die Möglichkeit, einen Referenten anhand einer visuell auffälligen Eigenschaft sprachlich genauer zu kategorisieren. Ein frequenter Gebrauch von Farbadjektiven in Benennungseinheiten verwundert daher nicht. Das Referenzkonzept selbst muss dabei nicht die durch das Adjektiv bezeichnete Eigenschaft tragen, vgl. Gelbfieber bzw. gele koorts.

Tab. 5.9: Verbindungen mit gelb/geel im Primärmaterial

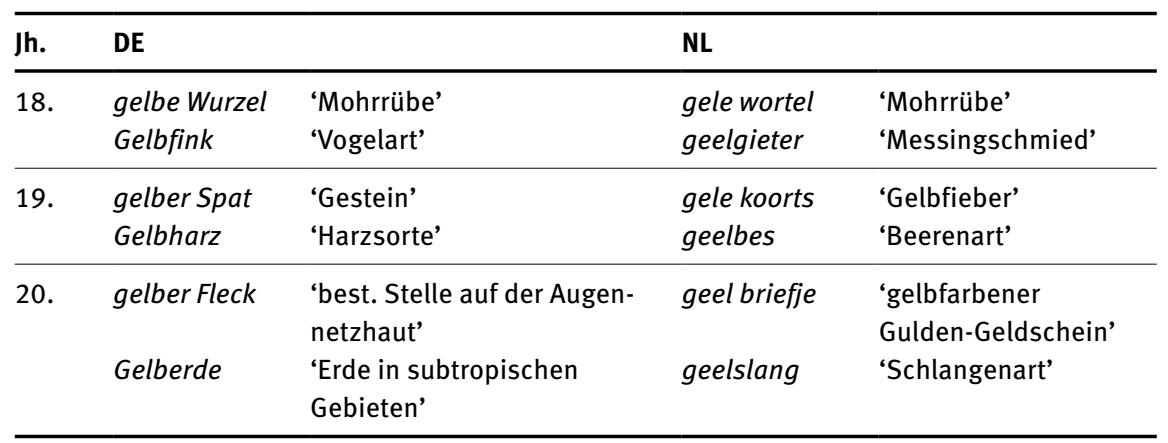

Tab. 5.10: Verbindungen mit rot/rood im Primärmaterial

\begin{tabular}{lllll}
\hline Jh. & DE & & NL & \\
\hline 18. & $\begin{array}{l}\text { rotes Wild } \\
\text { Rotweide }\end{array}$ & $\begin{array}{l}\text { 'Hirsche, Rehe' } \\
\text { 'Gewächs' }\end{array}$ & $\begin{array}{l}\text { rode kool } \\
\text { roodgloeihitte }\end{array}$ & $\begin{array}{l}\text { 'Rotkohl' } \\
\text { 'Wärmegrad eines } \\
\text { rotglühenden Metalls' }\end{array}$ \\
\hline 19. & $\begin{array}{l}\text { rote Rüster } \\
\text { Rotgold }\end{array}$ & $\begin{array}{l}\text { 'Gewächs' } \\
\text { 'mit Kupfer legiertes Gold' }\end{array}$ & $\begin{array}{l}\text { rode bessen } \\
\text { roodschimmel }\end{array}$ & $\begin{array}{l}\text { 'Johannisbeeren' } \\
\text { 'Rotschimmel' }\end{array}$ \\
\hline $\begin{array}{l}\text { rotes Blut- } \\
\text { körperchen } \\
\text { Rotalge }\end{array}$ & 'Blutbestandteil' & rode steen & 'Ziegelsteinsorte' \\
& & 'Pflanze' & roodwild & 'Rotwild' \\
\hline
\end{tabular}


Tab. 5.11: Verbindungen mit schwarz/zwart im Primärmaterial

\begin{tabular}{|c|c|c|c|c|}
\hline Jh. & DE & & NL & \\
\hline \multirow[t]{2}{*}{18.} & $\begin{array}{l}\text { schwarzer } \\
\text { Pfeffer }\end{array}$ & ‘Gewürz’ & zwarte gal & 'schwarze Galle' \\
\hline & Schwarzamsel & 'Vogel' & - & - \\
\hline 19. & $\begin{array}{l}\text { schwarzer Tee } \\
\text { Schwarzbrot }\end{array}$ & $\begin{array}{l}\text { 'Pflanze; Getränk' } \\
\text { 'Brotsorte' }\end{array}$ & $\begin{array}{l}\text { zwarte staar } \\
\text { zwartvos }\end{array}$ & $\begin{array}{l}\text { 'Augenkrankheit' } \\
\text { 'Pferdeart' }\end{array}$ \\
\hline \multirow[t]{2}{*}{20.} & $\begin{array}{l}\text { schwarzer } \\
\text { Markt }\end{array}$ & ‘illegaler Warenaustausch’ & zwarte lijst & $\begin{array}{l}\text { 'Liste unerwünschter } \\
\text { Personen o.Ä.' }\end{array}$ \\
\hline & Schwarzpulver & 'Schießpulver’ & zwartbaars & 'Fischart' \\
\hline
\end{tabular}

$\mathrm{Zu}$ b): Für alle Jahrhunderte lassen sich im Primärmaterial Beispiele für neue, klassifikatorische Benennungseinheiten finden (vgl. Tab. 5.9-5.11), die sowohl phrasal als auch morphologisch realisiert werden..$^{42}$ Bei $z$ wart ist im Primärmaterial für das 18. Jahrhundert kein klassifikatorisches Kompositum verzeichnet; allerdings lässt sich die Konstruktion in diesem Zeitraum im WNT belegen (z.B. zwarterts 'Gesteinsart'; vgl. WNT: zWARTERTS, 1997).

Die prinzipielle Ko-Existenz von Phrasenbildung und Komposition im Untersuchungszeitraum wird durch Daten in historischen Lexika und Enzyklopädien des Deutschen und Niederländischen (DELEX- bzw. NLLEX-Lexika) für das 19. Jahrhundert bestätigt, vgl. (97)-(99): ${ }^{43}$

a. DE

Phrasen: gelbe Bachstelze 'Vogel', gelbes Sandelholz 'Holzsorte'

Komposita: Gelbkraut 'Pflanze', Gelbsucht 'Krankheit'

b. NL

Phrase: gele koorts 'Gelbfieber'

Kompositum: geelzucht 'Gelbsucht'

42 Wie bereits erwähnt beruht die zeitliche Einteilung darauf, ob eine Verbindung im jeweiligen Zeitraum neu in einem Wörterbuch des Primärmaterials erscheint. Dies bedeutet aber nicht notwendigerweise immer, dass sie im jeweiligen Zeitraum auch neu entstanden ist.

43 Vor allem bei den deutschen Beispielen fällt auf, dass die phrasalen Benennungseinheiten oft ein formal komplexes Nomen haben. Es stellt sich die Frage, ob dies ein die phrasale Realisierung begünstigender Faktor ist (Schlücker, pers. Komm.). 
(98) a. DE

Phrasen: rote Republik 'notfalls durch Gewalt zu schaffende republikanische Staatsform mit absoluter Gleichstellung', roter Schnee 'rot gefärbter Schnee in bestimmten Gegenden' Komposita: Rotbeize 'Mineral', Rotware 'aus Ton und Lehm gebrannte Steine'

b. NL

Phrasen: rood bloedloogzout 'Kaliumferricyanid', rode veenwortel 'Pflanzenart'

Kompositum: roodwier 'Rotalge'

(99) a. DE

Phrasen: schwarze Glasur 'best. Mischung für das Glasieren von Töpferwaren', schwarze Harnwinde 'Krankheit' Komposita: Schwarzespe 'Baum', Schwarzkohle 'Mineral'

b. $\mathrm{NL}$

Phrasen: zwarte mees 'Vogelart', zwarte staar 'schwarzer Star' Komposita: zwartkoren 'Wachtelweizen', zwartspecht 'Schwarzspecht'

Im Übrigen treten neben Komposita und regulären Phrasen auch klassifikatorische Phrasen mit Schwa-Apokope auf: het geel- $\varnothing$ bloedloogzout 'Kaliumferrocyanid, gelbes Blutlaugensalz', het rood- $\emptyset$ weeskind 'Schmetterlingsart' (wörtl. 'rotes Waisenkind'), het zwart- $\emptyset$ krijt (im Wörterbuch als zwartkrijt aufgenommen) 'schwarze Zeichenkreide' (für Einzelheiten vgl. Kap. 5.4).

$\mathrm{Zu} \mathrm{c):} \mathrm{Morphologische} \mathrm{Verbindungen} \mathrm{mit} \mathrm{einer} \mathrm{possessiven} \mathrm{Interpretation,} \mathrm{die}$ sogenannten Possessiv- oder Bahuvrihi-Bildungen, spielen in beiden Sprachen bei Farbadjektiven eine große Rolle (vgl. Rotkehlchen - roodborstje, Schwarzrock - zwartrok, Gelbschnabel - geelbek). Es handelt sich dabei durchgehend um Personen-, Tier- und Pflanzen-, manchmal auch Krankheitsbezeichnungen, also um für Possessivbildungen typische Bezeichnungsbereiche (vgl. Brekle 1966; Simoska 1999). Auch diese lassen sich im Primärmaterial fast durchgängig belegen (die Schreibweise wurde ggf. modernisiert; die Bedeutung wird nur dann angegeben, wenn es sich nicht um eine Personen-, Tier-, Krankheitsbezeichnung etc. handelt):

(100) a. DE

18. Jh.: Gelbbein, Gelbfuß

19. Jh.: Gelbflügel, Gelbkehle

20. Jh.: Gelbstrieme, Gelbkreuz 'Senfgas’ 
b. NL
18. Jh.: -
19. Jh.: geelbek, geelborstje
20. Jh.: geelbuikje, geelgatje

(101) a. DE
18. Jh.: Rotauge, Rotfeder
19. Jh.: Rothaut, Rotlinie
20. Jh.: Rotarsch, Rotschopf

b. NL

18. Jh.: roodbol, roodsteertje

19. Jh.: roodhuid, roodkorst 'Edamer Käse'

20. Jh.: roodblaar, roodhemd

(102) a. DE
18. Jh.: Schwarzkamm, Schwarzmantel
19. Jh.: Schwarzflügel, Schwarzwolle
20. Jh.: Schwarzhemd, Schwarzkittel

b. NL
18. Jh.: zwartkopje
19. Jh.: zwarthoofd, zwartkeeltje
20. Jh.: zwartblaar, zwartstip

Die Bildung von Komposita mit einer possessiven Interpretation ist bis heute produktiv, wobei die Unterschiede zwischen dem Deutschen und dem Niederländischen jedoch vernachlässigt werden können. In der Gegenwartssprache scheinen im Sprachvergleich ausschließlich klassifikatorische A+N-Verbindungen unterschiedliche Realisierungspräferenzen aufzuweisen. So zeigt eine Gegenüberstellung von A+N-Bildungen mit schwarz - zwart in Van Dale (2005) und Duden (1999), dass es ausschließlich klassifikatorische Verbindungen sind, die in beiden Sprachen unterschiedlich realisiert werden (vgl. Tab. 5.12). Es gibt allerdings auch Gemeinsamkeiten in der Realisierung, entweder als Phrase (z.B. schwarze Kunst - zwarte kunst 'Zauberei') oder als Kompositum (z.B. Schwarzbuch - zwartboek). Ähnliches gilt im Übrigen auch für gelb/geel und rot/rood. 
Tab. 5.12: Äquivalente mit schwarz/zwart (Duden 1999; Van Dale 2005)

\begin{tabular}{ll}
\hline Kompositum & Phrase \\
\hline Schwarzdrossel & zwarte lijster \\
Schwarzerde & zwarte aarde \\
Schwarzgeld & zwart geld \\
Schwarzhandel & zwarte handel \\
Schwarzkiefer & zwarte den \\
Schwarzkunst & zwarte kunst ('Schabkunst') \\
Schwarzpappel & zwarte populier \\
Schwarzspecht & zwarte specht \\
Schwarzstorch & zwarte ooievaar \\
\hline Phrase & Phrase \\
\hline schwarze Johannisbeere & zwarte bes \\
schwarzes Loch & zwart gat \\
schwarzer Humor & zwarte humor \\
schwarze Kunst & zwarte kunst ('Zauberei') \\
schwarze Liste & zwarte lijst \\
schwarze Schwertlilie & zwarte lis \\
schwarze Messe & zwarte mis \\
schwarzer Pfeffer & zwarte peper \\
schwarzer Freitag & zwarte vrijdag \\
\hline Kompositum & Kompositum \\
\hline Schwarzbuch & zwartboek \\
Schwarzschimmel & zwartschimmel \\
Schwarztorf & zwartveen \\
Schwarzwild & zwartwild \\
\hline & \\
\hline
\end{tabular}

Ein Blick auf die übrigen Komposita in beiden Wörterbüchern, d.h. auf jene Bildungen, die kein passendes Äquivalent in der jeweils anderen Sprache haben und deshalb nicht verglichen werden können, zeigt zudem Folgendes: Für das Deutsche werden 18 Komposita (z.B. Schwarzfilter, Schwarzpulver) verzeichnet, davon sind nur zwei Possessivbildungen (Schwarzdorn, Schwarzplättchen). Die klassifikatorische Komposition ist also sehr stark vertreten. Im Niederländischen sind von 23 Komposita nur 13 klassifikatorisch (z.B. zwartgras 'Gewächs', zwartmaskerduif 'Vogelart'). Die anderen Bildungen basieren auf einer possessiven Interpretation, so z.B. zwartkop (wörtl. 'schwarz' + 'Kopf'), d.h. 'Person mit schwarzem Haar; verschiedene Vögel mit schwarzem Kopf’. Diese Daten suggerieren, dass der Anteil von Possessivkomposita an der Gesamtzahl von A+N-Komposita im Niederländischen höher als im Deutschen ist, was sich aus der geringeren Nutzung der klassifikatorischen Komposition ergibt. Allerdings muss hier auch berück- 
sichtigt werden, dass beide Wörterbücher nicht ohne Weiteres vergleichbar sind. Im Duden werden veraltete Ausdrücke schneller gestrichen als in Van Dale, das nicht mehr gebrauchte Ausdrücke in der Regel mit dem Label verouderd 'veraltet' versieht und nur im Ausnahmefall löscht.

Einige niederländische Possessivkomposita können auch als Resultat eines Autonomisierungsprozesses des Erstglieds komplexer $(\mathrm{A}+\mathrm{N})+\mathrm{N}-\mathrm{Komposita}$ interpretiert werden (vgl. Kap. 2.4). So könnte das im LEXNEX-Korpus belegte roodwang 'Rotwangenschmuckschildkröte' als verkürzte Form aus roodwang(sier)schildpad entstanden sein, vgl. (103).

Maar dr. Rinus Hoogmoed van het Nationaal Natuurhistorisch Museum in Leiden denkt niet dat roodwangsierschildpadden uit het noorden van de VS [...] hier wel tot voortplanting zouden komen. Daarvoor is het landklimaat van de VS te verschillend van ons zeeklimaat.

Wel zijn er onbevestigde berichten dat roodwangen in Spanje wel jonkies krijgen. ${ }^{44}$ (Volkskrant, 6.11.1999)

Im LEXNEX-Korpus kommt roodwang(sier)schildpad 58-mal vor (teilweise auch in Koordinationsstrukturen mit geelwangschildpad oder getrennt geschrieben als roodwang schildpad). Die Variante roodwang wird 16-mal (davon zweimal als Diminutiv) verwendet. Diese kann wie in (103) als Variante der komplexeren Form im selben Text gebraucht werden, manchmal ist roodwang aber auch die einzige Bezeichnung:

(104) Zijn eerste schildpad, dat was behoorlijk schrikken. Karel Op de Beke hees hem met zijn hengel uit een visvijver. Toen er iets bewoog onder het kroos dacht hij nog met een botervette paling van doen te hebben. Maar nee, het was een kleine roodwang, hartstikke zielig. ${ }^{45}$ (Volkskrant, 9.8.2002)

\footnotetext{
44 „Aber Dr. Rinus Hoogmoed vom Nationalen Naturhistorischen Museum in Leiden glaubt nicht, dass die Rotwangenschmuckschildkröten aus dem Norden der USA [...] sich hier fortpflanzen würden. Dafür unterscheide sich das Landklima der USA zu sehr von unserem maritimen Klima. Allerdings gibt es unbestätigte Meldungen, wonach Rotwangen in Spanien doch Junge bekommen“ [Übersetzung: SFS].

45 „Seine erste Schildkröte, die jagte ihm schon einen ordentlichen Schreck ein. Karel Op de Beke holte sie mit seiner Angel aus einem Fischteich. Als sich unter der Entengrütze etwas rührte, dachte er, dass er es mit einem richtig fetten Aal zu tun habe. Aber nein, es war eine kleine Rotwange, wirklich jämmerlich“ [Übersetzung: SFS].
} 
Die Einheit roodwang erscheint hier als autonomes Lexem, dessen Verwendung durch die komplexe Wortbildung roodwang(sier)schildpad gefördert worden sein könnte. Aus synchroner Perspektive ist der Einfluss der komplexen Wortbildung vielleicht irrelevant, da roodwang den strukturellen Bildungsmöglichkeiten des Niederländischen entspricht und damit als reguläres $\mathrm{A}+\mathrm{N}-$ Kompositum gezählt werden kann. Diachron kann die zunehmende Autonomisierung der Erstkonstituente komplexer $(\mathrm{A}+\mathrm{N})+\mathrm{N}$-Bildungen aber dennoch relevant sein, wenn sie $\mathrm{zu}$ einer unterschiedlich starken Nutzung possessiver Komposita im Deutschen und

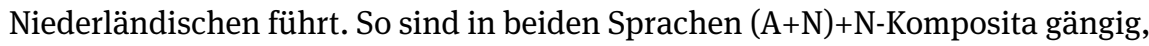
aber nur im Niederländischen scheinen die Erstkonstituenten z.T. als äquivalente Bezeichnungen verwendet zu werden. So sind neben den komplexen Bildungen auch die folgenden Bezeichnungen möglich:

(105) a. geelvintonijn - geelvin 'Gelbflossenthunfisch'

b. 'Sushitonijn, echt waar.' 'Ja, maar is het blauwvin of geelvin of skipjack...' 'Oh, dat weet ik niet hoor [...].' (VK, 12.7.2011)

(106) a. geelwangschildpad - geelwang 'Gelbwangenschmuckschildkröte'

b. „De roodwangschildpad is gewend aan een watertemperatuur van 20 tot 22 graden. De geelwang zelfs nog enkele graden hoger.“ (LC, 17.8.2005)

(107) a. zwartvoet-Indiaan - zwartvoet 'Schwarzfußindianer'

b. „Zij waren van groot belang als tolken in het contact met de indianen: de vredelievende Mandans en Minnetarees, de vechtlustige Sioux, de kalme Nez Percs en de opstandige Blackfeet. Met de laatsten kwam het later tot het enige zware incident, waarbij twee Zwartvoeten werden gedood.“(VK, 11.1.2003)

In den niederländischen Beispielen wird das Referenzkonzept im unmittelbaren sprachlichen Kontext genannt (in den Beispielen unterstrichen) und so die Interpretation der kürzeren Varianten vereinfacht. Die dem Niederländischen entsprechende Bezeichnung für zwartvoet, nämlich Schwarzfuß, ist auch im Deutschen gängig. Eine Überprüfung von A+N-Komposita mit gelb/rot/schwarz im ZEITKorpus zeigt jedoch, dass in anderen vergleichbaren Fällen fast ausnahmslos die komplexen Bezeichnungen verwendet werden: Gelbflossenthunfisch, Rotbauchunke, Schwarzhalstaucher und nicht ${ }^{\star}$ Gelbflosse, ${ }^{\star}$ Rotbauch, ${ }^{\star}$ Schwarzhals (eine Ausnahme ist Schwarznase für Schwarznasenschaf ). Eventuell liegt hier tatsächlich ein Unterschied zwischen beiden Sprachen vor, der genauer untersucht werden müsste. Allerdings ist er gradueller und nicht kategorischer Art. 
Zusammenfassend gesehen zeugt die Entwicklung der A+N-Verbindungen mit den drei genannten Farbadjektiven seit 1700 nicht von einschneidenden Veränderungen. Im gesamten Untersuchungszeitraum werden phrasale und morphologische $\mathrm{A}+\mathrm{N}$-Benennungseinheiten gebildet, wobei nur wenige nennenswerte Unterschiede im Sprachvergleich konstatiert werden können. Im Gegensatz zu Verbindungen mit den anderen, noch zu besprechenden Adjektiven wird eine große Anzahl von Bildungen in beiden Sprachen übereinstimmend versprachlicht, d.h. mit dem jeweiligen Adjektiv, einem bedeutungsentsprechenden Nomen und oft auch entweder als Phrase oder als Kompositum. Dies kann auf Sprachkontakt und Entlehnungsprozesse deuten (vgl. Kap. 6.5). Bisweilen konkurrieren Phrasen und Komposita auch bei der Benennung desselben Konzepts miteinander, v.a. im Deutschen (vgl. gelbes Fieber - Gelbfieber). Diese Konkurrenz tritt bei verschiedensten Adjektiven auf und wird deshalb in Kapitel 5.7 noch ausführlicher behandelt.

\subsubsection{2 bitter - bitter}

Die Bildungspräferenzen bei bitter - bitter sind weitaus deutlicher. Beispiele für morphologische Benennungen sind im Deutschen schon mit Beginn des 18. Jahrhunderts $\mathrm{zu}$ finden. Die Komposition ist in der Benennungsbildung bis zum heutigen Tage durchgängig sehr produktiv, fast alle klassifikatorischen Benennungseinheiten sind Komposita, vgl. Tabelle 5.13. Die wenigen syntaktischen Benennungen sind entweder metaphorischer Art oder erhalten Konkurrenz durch Komposita, z.B. das im 20. Jahrhundert aufkommende Bittermandel neben der bereits im 18. Jahrhundert verwendeten Phrase bittere Mandel (NL weiterhin bittere amandel).

Tab. 5.13: Verbindungen mit bitter im deutschen Primärmaterial

\section{Jahrhundert}

\section{Phrase}

bittere Mandel

'Bittermandel'

\section{Kompositum}

Bitterbier

Bitterdistel

Bitterholz

Bitterkalk

Bitterklee

Bitterkraut

'durch Hopfen o.Ä. bitter gemachtes Bier'
'anderer Name für Benediktendistel'
'Holz des Bitterholzbaumes'
'aus Kalksteinen gebrannter Kalk'
'best. Pflanzenart'
'best. Pflanzenart'




\begin{tabular}{ll} 
Bitterkresse & 'best. Pflanzenart' \\
Bittersalz & 'best. Mineral' \\
Bittersohle & 'Lauge, aus der ein Bittersalz gewonnen wird' \\
Bittertrank & 'bitter schmeckendes Getränk' \\
Bitterwasser & 'mit Bittersalz versetztes Wasser' \\
Bitterweide & 'best. Pflanzenart' \\
Bitterwein & 'Wermutwein' \\
\hline
\end{tabular}

19. Jahrhundert

\begin{tabular}{ll}
\hline $\begin{array}{l}\text { Phrase } \\
\text { bitteres Bier }\end{array}$ & $=$ 'Bitterbier' \\
\hline $\begin{array}{l}\text { Kompositum } \\
\text { Bitterbaum }\end{array}$ & 'Bitterholzbaum' \\
$\begin{array}{l}\text { Bittererde } \\
\text { Bitterstein }\end{array}$ & 'Kalkerde, Magnesia' \\
\hline 20. Jahrhundert & 'best. Steinsorte' \\
\hline Phrase & \\
- & \\
\hline Kompositum & \\
Bitterfäule & \\
Bitterkäse & 'Fruchtfäule, die bitteren Geschmack verursacht' \\
Bittermandel & 'Sauermilchkäse' \\
Bittermittel & 'Samenkern des Bittermandelbaums' \\
Bitterorange & 'Arzneimittel' \\
Bitterpilz & 'best. Frucht' \\
Bitterschwamm & 'Gallenröhrling' \\
Bitterspat & 'Gallenröhrling' \\
Bitterstoff & 'Magnesitmineral' \\
\hline
\end{tabular}

Auch im Niederländischen spielt die morphologische Benennungsbildung eine wichtige Rolle, vgl. Tabelle 5.14. Allerdings ist die Aussagekraft der Daten im Primärmaterial aufgrund der geringen Anzahl an Verbindungen zunächst begrenzt. In den verschiedenen historischen Textsammlungen (DBNL, LCA, Zitatsammlung des WNT) sind vor 1800 nur vereinzelt A+N-Komposita mit bitter belegt: in der DBNL nur bitterzout 'Bittersalz' (1791) und bitterkoekjens 'Bittermandelplätzchen' (1793), im LCA lediglich bitterzout (1782). Wirklich durchgesetzt hat sich die morphologische Benennungsbildung wohl erst nach 1800, wobei im 20. Jahrhundert auch klassifikatorische (eventuell fachsprachliche?) Phrasen als Benennungseinheiten auftreten. Ansonsten ist die Komposition ähnlich wie im Deutschen das dominante Benennungsverfahren. 
Tab. 5.14: Verbindungen mit bitter im niederländischen Primärmaterial

\section{Jahrhundert}

\begin{tabular}{|c|c|}
\hline $\begin{array}{l}\text { Phrase } \\
\text { bittere amandel }\end{array}$ & 'Bittermandel' \\
\hline $\begin{array}{l}\text { Kompositum } \\
-\end{array}$ & \\
\hline 19. Jahrhundert & \\
\hline $\begin{array}{l}\text { Phrase } \\
-\end{array}$ & \\
\hline $\begin{array}{l}\text { Kompositum } \\
\text { bitterkers } \\
\text { bitterkoekje } \\
\text { bitterzout }\end{array}$ & $\begin{array}{l}\text { 'best. Pflanzenart' } \\
\text { 'Bittermandelplätzchen' } \\
\text { 'Bittersalz' }\end{array}$ \\
\hline 20. Jahrhundert & \\
\hline $\begin{array}{l}\text { Phrase } \\
\text { bitter barbarakruid } \\
\text { bittere boleet } \\
\text { bittere kers } \\
\text { bittere scheefbloem } \\
\text { bittere veldkers } \\
\text { bittere vleugeltjesbloem }\end{array}$ & $\begin{array}{l}\text { 'best. Pflanzenart' } \\
\text { 'best. Pflanzenart' } \\
\text { 'best. Kressenart' } \\
\text { 'best. Pflanzenart' } \\
\text { 'best. Kressenart' } \\
\text { 'best. Pflanzenart' }\end{array}$ \\
\hline $\begin{array}{l}\text { Kompositum } \\
\text { bitteraarde } \\
\text { bitterbloem } \\
\text { bitterhout } \\
\text { bitterkalk } \\
\text { bitterklaver } \\
\text { bitterkruid } \\
\text { bitterspaat } \\
\text { bitterstof } \\
\text { bittervoorn } \\
\text { bitterwater } \\
\text { bitterwijn } \\
\text { bitterwilg } \\
\end{array}$ & $\begin{array}{l}\text { 'Magnesia' } \\
\text { 'best. Pflanzenart' } \\
\text { 'Bitterholz' } \\
\text { 'Dolomitmineral/-gestein' } \\
\text { 'best. Kleesorte' } \\
\text { 'best. Pflanzenart' } \\
\text { 'Bitterspat' } \\
\text { 'Bitterstoff' } \\
\text { 'Fischart' } \\
\text { 'Bitterwasser' } \\
\text { 'bitterer, medizinischer Wein' } \\
\text { 'Baumart' }\end{array}$ \\
\hline
\end{tabular}

In der Gegenwart kommen in beiden Sprachen neue Benennungseinheiten hinzu. Im Niederländischen beispielsweise hat das Referenzwörterbuch Van Dale das Wort bittersinaasappel 'Bitterorange' 2008 neu aufgenommen (mit dem Vermerk voorlopig 'vorläufig'). Im ZEIT-Korpus lässt sich für das Deutsche in den letzten 
zwei Jahrzehnten eine zunehmende Etablierung des Wortes Bitterschokolade erkennen, während der Gebrauch der Phrase marginal bleibt. Die starke Position der Komposition zeigt sich in beiden Sprachen auch daran, dass sie auch zur Bildung von Ad-hoc-Konzepten oder aus stilistischen Gründen verwendet wird. Während dies im Deutschen für die meisten untersuchten Adjektive gilt, ist dies im Niederländischen insgesamt seltener der Fall (vgl. Tab. 5.7-5.8). Für bitter liefert das LEXNEX-Korpus jedoch zwei schöne Beispiele:

(108) „We hebben ook getest hoe gevoelig die mensen überhaupt zijn voor bitter.“ Sommige mensen zijn echte 'bitterproevers', andere niet - dat is genetisch bepaald. „Misschien ondergaan bitterproevers ook eerder een smaakverandering. En zo niet, dan is dit toch de eerste keer dat het bittereffect in een lab bij proefpersonen wordt getest.“(VK, 12.2.2011) ${ }^{46}$

(109) Lof, spruiten, andijvie, ik haatte ze toen ik klein was. Maar ergens in mijn tienerjaren overschreed ik de bittergrens. Met koffie, omdat een meisje waarop ik verliefd was dat dronk. ${ }^{47}$ (VK, 7.12.2011)

Prinzipiell weisen das Deutsche und das Niederländische in Bezug auf bitter bitter also die gleichen Tendenzen auf.

\subsubsection{3 still - stil}

Weitgehend identisch verhalten sich das Deutsche und das Niederländische auch in Bezug auf Verbindungen mit still - stil. Beide Sprachen zeigen ein ähnliches Bedeutungsspektrum mit den drei Hauptbedeutungen 1. 'reglos, unbewegt' (wie in stille Luft), 2. 'leise' (wie in stilles Gebet) und 3. 'geheim' (wie in stille Hoffnung) sowie daran anschließende Bedeutungen wie 'ruhig, frei von Anspannung; wortlos'. Unabhängig von der jeweils realisierten Bedeutung wird die Benennungsbildung bei still - stil fast ausschließlich über Phrasen geleistet.

\footnotetext{
46 „Wir haben auch geprüft, wie empfindlich diese Menschen überhaupt für das Bittere sind.“ Einige sind wahre 'Bitterschmecker', andere nicht - das ist genetisch festgelegt. „Vielleicht durchleben Bitterschmecker auch eher eine Geschmacksveränderung. Und wenn nicht, dann ist es doch das erste Mal, dass der Bittereffekt in einem Labor bei Testpersonen überprüft wird“ [Übersetzung: SFS]. Die Form bitterproever 'Bitterschmecker' interpretiere ich hier als synthetisches Kompositum und zähle es somit nicht zu meinem Gegenstandsbereich.

47 „Chicorée, Rosenkohl, Endivien - ich hasste sie, als ich klein war. Aber irgendwann in meinen Teenagerjahren übertrat ich die Bittergrenze. Mit Kaffee, weil ein Mädchen, in das ich verliebt war, das trank“ [Übersetzung: SFS].
} 
Im deutschen Primärmaterial sind Komposita von Beginn an weitgehend marginalisiert, im Niederländischen sind sie - zumindest im Primärmaterial gar nicht vorhanden. Es gibt nur eine Ausnahme, stilleven 'bildliche Darstellung von Dingen des alltäglichen Lebens', das in seiner Betonung allerdings durch die Wörterbücher als variabel beschrieben wird (vgl. u.a. Van Dale 1984, Koenen 1986) und daher sowohl als Phrase als auch als (metonymisch $\mathrm{zu}$ interpretierendes) Kompositum eingestuft werden kann. Die Tabellen 5.15 und 5.16 enthalten alle im Primärmaterial gefundenen Verbindungen. Für das Niederländische sind im Primärmaterial des 18. Jahrhunderts keine Benennungseinheiten verzeichnet. Es werden lediglich Verbindungen wie stilleveger 'Person, die Toilettenhäuschen etc. reinigt' genannt, die eher als N+N-Verbindungen zu klassifizieren sind (vgl. WNT: STIL ${ }^{\mathrm{I}}$, 1938; mit stille als nominalisiertes Adjektiv bzw. Abkürzung des mittelniederländischen stillecamere 'Toilette, Toilettenzimmer'). Im Primärmaterial des 19. Jahrhunderts tauchen erste Verbindungen auf. Eine Analyse weiterer Wörterbücher zeigt aber, dass diese z.T. bereits Ende des 16. Jahrhunderts verwendet wurden, so u.a. stille mes 'stille Messe' sowie stille week 'Karwoche' und stille vrijdag 'Karfreitag' (vgl. Kiliaan 1599). Die (phrasale) Benennungsbildung mit stil war also bereits vor 1800 möglich.

Tab. 5.15: Verbindungen mit still im deutschen Primärmaterial

\section{Jahrhundert}

\begin{tabular}{|c|c|}
\hline \multicolumn{2}{|l|}{ Phrase } \\
\hline stilles Alter & ‘Greisenalter’ \\
\hline stille Beichte & 'Einzelbeichte' \\
\hline stiller Freitag & ‘Karfreitag’ \\
\hline stille Messe & 'Messe ohne Gesang und Ansprache' \\
\hline stille Woche & 'Karwoche' \\
\hline \multicolumn{2}{|l|}{ Kompositum } \\
\hline Stilllager & ‘Lager eines pausierenden Heeres’ \\
\hline Stillmesse & $=$ 'stille Messe' \\
\hline Stillpulver & 'Pulver, das beim Abbrennen nicht losknallt' \\
\hline \multicolumn{2}{|l|}{ 19. Jahrhundert } \\
\hline \multicolumn{2}{|l|}{ Phrase } \\
\hline stilles Gericht & '(hist.) geheimes Gericht in Westfalen bzw. Belgien' \\
\hline stille Jagd & 'Jagd ohne Schießen, nur mit Fallen, Netzen etc.' \\
\hline stiller Mann & 'tote Person' \\
\hline stille Pfeifen & ‘(Orgelbau) Pfeifen, die nur sanft tönen’ \\
\hline stilles Pulver & $=$ 'Stillpulver' \\
\hline stiller Teilhaber & 'Geschäftspartner ohne aktive Mitarbeit' \\
\hline
\end{tabular}




\begin{tabular}{|c|c|}
\hline $\begin{array}{l}\text { stiller Wein } \\
\text { stille Zeit } \\
\text { stille Zinken }\end{array}$ & $\begin{array}{l}\text { 'Wein ohne Kohlensäure' } \\
\text { 'umsatzschwache Zeit im Geschäft' } \\
\text { 'sanft tönendes Musikinstrument' }\end{array}$ \\
\hline Kompositum & \\
\hline $\begin{array}{l}\text { Stillflöte } \\
\text { Stillkampf } \\
\text { Stillleben }\end{array}$ & $\begin{array}{l}\text { '(Orgelbau) Flötenzug mit sanften Tönen' } \\
\text { 'ein im Stillen vor sich gehender Kampf' } \\
\text { 'zurückgezogenes Leben' }\end{array}$ \\
\hline
\end{tabular}

\section{Jahrhundert}

\section{Phrase}

stille Beteiligung

stille Brunft

stiller Gesellschafter

stille Gesellschaft

stilles Örtchen

stille Reserven

stille Rücklage

stille Teilhaberschaft

stille Verbrennung

stilles Wasser

\section{Kompositum}

Stillarbeit

Stillwein 'geschäftliche Beteiligung ohne aktive Mitarbeit' 'best. Brunft beim Rotwild'

'Geschäftspartner ohne aktive Mitarbeit'

'Gesellschaft, bei der jemand stiller Teilhaber ist'

'Toilette'

'Bestandteil des Eigenkapitals, der nicht in der Bilanz erscheint'

= 'stille Reserven'

'Teilhaberschaft ohne aktive Mitarbeit'

'ohne Flamme ablaufende Oxidation'

'Wasser ohne Kohlensäure; stehendes Gewässer'

'best. pädagogische Unterrichtsmethode'

= 'stiller Wein'

Tab. 5.16: Verbindungen mit stil im niederländischen Primärmaterial

\section{Jahrhundert}

\section{Jahrhundert}

\section{Phrase}

stil compagnon

stille knip

stille mis

stille tijd

stil(le) vennoot

stille verklikker

stille vrijdag

stille week 'stiller Teilhaber'

'geheimes Bordell'

'stille Messe'

'umsatzschwache Zeit im Geschäft'

'stiller Teilhaber'

'Geheimspion'

'Karfreitag'

'Karwoche'

\section{Kompositum}




\begin{tabular}{ll}
\hline 20. Jahrhundert & \\
\hline Phrase & \\
stille aanbidder & 'stiller Verehrer' \\
stille agent & 'Agent, der in Zivil arbeitet' \\
stil alarm & 'Alarminstallation, die nicht vor Ort, sondern bei der Polizei \\
& ausgelöst wird' \\
stille dood & 'Euthanasie' \\
stille getuige & 'zurückgebliebener Gegenstand o.Ä., der einen Vorfall etc. \\
& belegt' \\
stille markt & 'Marktsituation ohne Handel' \\
stil nummer & 'Geheimnummer' \\
stille omgang & 'Bezeichnung für diverse Gedenkumzüge' \\
stille reserve & 'stille Reserver, Rücklage' \\
stil spel & 'Schauspiel ohne Sprache' \\
stille spion & 'Geheimspion' \\
stille strand & 'Strandabschnitt außerhalb der normalen Badeplätze' \\
stille tocht & 'schweigender Gedenkumzug am 4. Mai' \\
stille uitslag & 'zusätzliches Gewicht beim Wiegen im Geschäft (veraltet)' \\
stille vennootschap & 'stille Teilhaberschaft' \\
stil()water & 'Übergang zwischen Ebbe und Flut; Wasser ohne Kohlensäure' \\
stille wijn & 'Wein ohne Kohlensäure' \\
stille zaterdag & 'Karsamstag' \\
\hline
\end{tabular}

\section{Kompositum}

-

Dieser erste Eindruck einer relativ starken Marginalisierung der Komposition wird durch Text- und Korpusuntersuchungen für beide Sprachen bestätigt. Im Deutschen ist die Komposition mit still im gesamten Beobachtungszeitraum kaum produktiv. Die DBLK verzeichnet im Zeitraum 1739-1920 lediglich zwei Bildungen, Stillager (Erstbeleg 1804-1805) und Stilleben (Erstbeleg 1795). Auch die DELEXLexika zeigen eine eindeutige Präferenz für phrasale Benennungseinheiten: Im Zeitraum 1806-1906 stehen 32 syntaktischen Benennungen nur zehn Komposita gegenüber. Diese sind zudem meist nur (temporäre) Konkurrenzvarianten zu etablierten Phrasen, vgl. z.B. stilles Gebet - Stillgebet, stilles Gericht - Stillgericht, stille Wut - Stillwut 'Wutkrankheit bei Tieren und Menschen (ähnlich wie Tollwut)'. Für Stillwasser und Stillwein finden sich im Primärmaterial ebenfalls phrasale Konkurrenten (stilles Wasser 'stehendes Gewässer' bzw. stiller Wein). Somit sind lediglich für Stillflöte 'Orgelpfeife', Stillprinzipiale 'Registerzug in der Orgel' und Stillager 'Zwischenlager von Briefen' (vgl. Pierer: Post) unabhängige Bildungen anzunehmen, die nicht im Zusammenhang mit etablierten Phrasen stehen. Auch im gegenwärtigen Deutsch lässt sich eine schwache Produktivität des Musters belegen, wie die geringe Anzahl an Hapaxen in Tabelle 5.7 zeigt. Nicht 
nur die Benennungsbildung im Speziellen, die Komposition mit still ist im Allgemeinen zu vernachlässigen. Gleichzeitig ist die phrasale Benennungsbildung produktiv.

Für das Niederländische gilt dasselbe: Die Komposition mit stil kann nicht als produktiv bezeichnet werden. Einige Treffer im MNW, dem Middelnederlandsch Woordenboek, weisen daraufhin, dass die Komposition im begrenzten Umfang im Mittelniederländischen (ca. 1150-1500) genutzt wurde (es gibt Einträge zu stilmes 'stille Messe/Stillmesse' und stilwaarheid 'stille, unausgesprochene Wahrheit'). Keine dieser Bildungen ist jedoch heutzutage etabliert. Für das Neuniederländische finden sich in der DBNL nur vereinzelte A+N-Komposita wie stilgebed 'Stillgebet; Gabengebet, das früher vom Priester still gebetet wurde’ (1897). Kuiper (1914) verzeichnet stilkruid 'Mittel, das weder Gutes noch Schlechtes bewirkt' (wörtl. 'still' + 'Kraut'), es handelt sich hier allerdings um Ausnahmen. Zahlreich sind hingegen Bildungen, die als Derivate zu analysieren sind, vgl. stilstand 'Stillstand', stilzitter 'Person, die still sitzen bleibt'. Sofern ein Benennungsbedarf für Verbindungen mit still/stil vorliegt, wird dieser gegenwärtig in beiden Sprachen phrasal realisiert. Dies ist aber bereits in den letzten 300 Jahren eher die Regel gewesen, so dass auch hier kein grundlegender Wandel bei den Realisierungspräferenzen erfolgt ist.

\subsubsection{4 tief-diep}

Dem Primärmaterial nach zu urteilen, ist die Benennungsbildung mit tief für das Deutsche erst langsam in Gang gekommen und umfasst für das 18. Jahrhundert noch relativ wenige A+N-Verbindungen. Erst im 19. und vor allem im 20. Jahrhundert werden $\mathrm{A}+\mathrm{N}$-Benennungseinheiten mit tief verstärkt gebraucht (vgl. Tab. 5.17). Im Niederländischen sind für das 18. Jahrhundert gar keine, für das 19. Jahrhundert ist nur eine Verbindung verzeichnet (diepe borden 'Suppenteller', wobei der Benennungscharakter diskutiert werden kann). Erst im 20. Jahrhundert kommt es zu einer Reihe von Bildungen, fast ausschließlich Komposita, die z.T. Konzepte aus dem Bauwesen bezeichnen (vgl. Tab. 5.18). In beiden Sprachen scheinen Phrasen von der Benennungsbildung nahezu ausgeschlossen.

Tab. 5.17: Verbindungen mit tief im deutschen Primärmaterial (20. Jh.)

\section{Jahrhundert}

\begin{tabular}{ll}
\hline $\begin{array}{l}\text { Phrase } \\
\text { tiefer Boden } \\
\text { tiefer Vokal }\end{array}$ & 'Boden, der so aufgeweicht ist, dass man darin einsinkt' \\
& '(Linguistik) Vokal, bei dem der Zungenrücken verhältnismäßig \\
& weit gesenkt ist' \\
\hline
\end{tabular}




\begin{tabular}{ll}
$\begin{array}{l}\text { Kompositum } \\
\text { Tiefangriff } \\
\text { Tiefbahnhof } \\
\text { Tiefbunker }\end{array}$ & 'Luftangriff im Tiefflug' \\
Tiefdruck & 'unterirdischer Bahnhof' \\
Tiefebene & 'unterirdischer Luftschutzbunker' \\
Tiefflug & 'besonderes Druckverfahren' \\
Tiefgarage & 'Flachland' \\
Tiefgeschoss & 'Flug in geringer Höhe' \\
Tiefgrab & 'unterirdische Garage' \\
& 'Unterirdisches Geschoss' \\
Tiefkraton & 'Glätzen' \\
& '(Geologie) bestimmter Teil der Erdkruste, der ozeanische \\
Tiefland & Becken bildet' \\
Tiefofen & $=$ 'Tiefebene' \\
Tiefparterre & 'best. Art von Industrieofen' \\
& 'Parterre, das eine halbe Treppe unterhalb des normalen \\
Tiefpumpe & Parterres liegt' \\
Tiefpunkt & 'Ölpumpe für große Tiefen' \\
Tiefschlag & 'tiefster Punkt auf einer Skala; negativer Höhepunkt' \\
& 'verbotener Schlag unterhalb der Gürtellinie im Boxen; \\
Tiefschnee & unfaires Verhalten' \\
Tiefschutz & 'tiefer, pulvriger Schnee' \\
Tiefsee & 'Schutz für Unterleib und Geschlechtsteile im Boxen' \\
Tiefstand & 'Teil der Ozeane, der besonders tief liegt' \\
Tiefstart & 'besonders tiefer Stand in einer Entwicklung' \\
Tiefstufe & '(Leichtathletik) Start aus hockender Haltung' \\
& '(Linguistik) Stufe des Ablautes bei nicht betonten Vokalen' \\
\hline
\end{tabular}

Tab. 5.18: Verbindungen mit diep im niederländischen Primärmaterial (20. Jh.)

\section{Jahrhundert}

\begin{tabular}{ll}
\hline $\begin{array}{l}\text { Phrase } \\
\text { diepe drive }\end{array}$ & 'best. Schlag im Golf' \\
\hline Kompositum & 'Tiefbau' \\
diepbouw & 'best. Druckverfahren' \\
diepdruk & 'Tieflöffel (Aufsatz am Bagger)' \\
dieplepel & 'besonders tief arbeitender Pflug' \\
diepploeg & 'Tiefschnee' \\
diepsneeuw & 'best. Art von Panzer' \\
dieptank & 'Schlitzwand' \\
diepwand & 'Tiefsee' \\
diepzee &
\end{tabular}


Es gibt zwei Besonderheiten bei den Verbindungen mit tief - diep. Erstens werden viele Bildungen im Niederländischen, v.a. in den Wörterbüchern von Van Dale, als Entlehnungen aus dem Deutschen eingestuft:

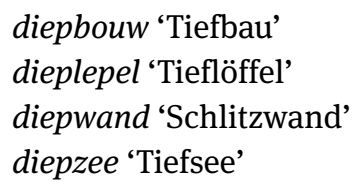

Tatsächlich ist dies aber nicht für alle Bildungen im gleichen Maße wahrscheinlich: Laut Wikipedia ist das Äquivalent zur niederländischen diepwand die deutsche Schlitzwand, also ein N+N-Kompositum (Wikipedia: ScHLITzWAND ${ }^{48}$ ). Die Verbindung diepzee ist dem WNT zufolge kein Germanismus, sondern auf das Englische zurückzuführen (vgl. WNT: DIEPZEE, 2001). Dass ein A+N-Kompositum nicht als endogene niederländische Bildung, sondern (oft pauschal) als Folge eines Sprachkontakts mit dem Deutschen gesehen wird, ist typisch für die Lexikografie des Niederländischen im 20. Jahrhundert und dient zum Teil der deutlichen Stigmatisierung des betroffenen Wortes. In Kapitel 6.4 wird auf gegen Germanismen gerichtete Tendenzen in der niederländischen Lexikografie und Sprachpflege genauer eingegangen.

Zweitens haben sich im Deutschen des 20. Jahrhunderts Komposita mit dem Superlativ tiefst als Erstglied etabliert, z.B. Tiefsttemperatur, Tiefstwert, Tiefstangebot, Tiefstkurs, Tiefstnotierung, Tiefstpreis, Tiefststand. Die Adjektive tief und diep weichen hier in ihrer Semantik voneinander ab: Das deutsche Adjektiv trägt die Bedeutung 'niedrig', während das niederländische Äquivalent in solchen Kontexten nicht diep, sondern laag 'niedrig' ist. Dementsprechend müsste tiefst- im Niederländischen durch laagst- ersetzt werden. Aber für laagst- als Erstglied (ebenso wie auch für diepst-) finden sich weder im LEXNEX-Korpus, in der DBNL noch in den WNT-Zitaten A+N-Komposita. Dem deutschen Tiefstpreis entspricht vielmehr die niederländische Phrase laagste prijs (oder das N+N-Kompositum bodemprijs, wörtl. 'Boden' + 'Preis'). Da in der Literatur davon ausgegangen wird, dass im Niederländischen nur monomorphemische Adjektive Erstglied eines A+N-Kompositums sein können und damit Superlative unzulässig sind (vgl. de Haas/Trommelen 1993: 377), handelt es sich hier wohl um eine generelle Bildungsrestriktion im Niederländischen: Adjektive im Superlativ bleiben von der Erstgliedposition im A+N-Kompositum ausgeschlossen.

48 http://nl.wikipedia.org/wiki/Diepwand, http://de.wikipedia.org/wiki/Schlitzwand (Stand: 1.3.2013). 
Die Verbindungspräferenzen mit den Adjektiven tief bzw. diep zeigen bis heute eine ähnliche Entwicklung. Die Komposition ist sehr stark vertreten, die Phrasenbildung hingegen kaum. Metakommentare in niederländischen Wörterbüchern legen nahe, dass Sprachkontakt mit dem Deutschen eine Rolle bei dieser Konvergenz gespielt haben könnte, allerdings unterstützen nicht alle genannten Belege diese These.

\subsubsection{Adjektive mit abweichender Entwicklung im Deutschen und Niederländischen}

Andere Adjektive weisen im Sprachvergleich unterschiedliche Verbindungspräferenzen auf, wobei diese sich z.T. erst im Laufe des Untersuchungszeitraums herausgebildet haben. Im Folgenden wird nacheinander die Entwicklung der Benennungsbildung bei geheim - geheim, kalt - koud, negativ - negatief und fremd - vreemd besprochen.

\subsubsection{1 geheim - geheim}

$\mathrm{Zu}$ Beginn des Untersuchungszeitraums sind in beiden Sprachen sowohl morphologische als auch syntaktische Benennungseinheiten etabliert:

(111) a. DE Geheimsiegel 'Herrschersiegel auf geheimen Dokumenten' geheimes Archiv 'Ort, an dem geheime Urkunden und Schriften aufbewahrt werden'

b. NL geheimkamer 'Raum für geheime, vertrauliche Beratungen' geheime raad 'geheimer Rat'

Während sich im Niederländischen diese Balance bis ins 20. Jahrhundert hält, findet im Deutschen ein deutlicher Wandel hin zur Komposition statt. Im Niederländischen werden auch phrasale Benennungseinheiten gebildet, die Äquivalente dazu entsprechen im Deutschen aber durchgehend Komposita, vgl. die folgenden Beispiele:

(112) a. DE Geheimpolizei - NL geheime politie (19. Jh.)

b. DE Geheimdienst - NL geheime dienst (20. Jh.)

c. DE Geheimagent - NL geheim agent (20. Jh.)

Im deutschen Primärmaterial sind für das 20. Jahrhundert nur vier eindeutige phrasale Benennungseinheiten verzeichnet: 
(113) a. geheime Polizei: wird (nur) im Duden (1999) als seltenes Synonym zu Geheimpolizei genannt; es scheint allerdings im 19. Jahrhundert die gängige Bezeichnung gewesen zu sein, vgl. Anmerkungen in den Lexika von Pierer (1857-1865), Meyer (1905-1909), Brockhaus (1906);

b. geheime Staatspolizei: 'politische Polizei zum Schutz der Einrichtungen u. leitenden Persönlichkeiten eines (bes. autoritär regierten) Staates' (Duden 1999: GEHEIM); wird allerdings mehrheitlich als Eigenname für die Geheime Staatspolizei des Nazi-Regimes verwendet;

c. geheimer Vorbehalt: rechtssprachlicher Terminus, 'stillschweigend abweichende Auslegung oder Umdeutung einer Aussage durch den Sprechenden, die Sprechende' (Brockhaus Wahrig 1980-1984: GEHEIM);

d. geheime Wahl: 'Wahl, bei der geheim bleibt, wie jede[r] einzelne Wählende gestimmt hat' (Duden Online 2012: GEHEIM) (als Kollokation bereits bei Heyne 1890-1895).

Die morphologische Benennungsbildung ist bereits seit dem 18. Jahrhundert produktiv und hat sich zunehmend ausgebreitet:

(114) a. 18. Jahrhundert

Geheimdeutung 'Hellseherei'

Geheimkammer 'Raum für geheime, vertrauliche Beratungen'

Geheimschreiber 'Sekretär'

b. 19. Jahrhundert

Geheimbote 'Bote, der vertrauliche Nachrichten überbringt'

Geheimkästchen 'Kästchen mit geheimen Fächern für Geld etc.'

Geheimkunst 'auf geheime Art, mit geheimen Kräften wirkende Kunst'

Geheimlehre 'nur Eingeweihten bekannte Lehre'

Geheimmittel '(Arznei-)Mittel mit geheimer Zusammensetzung'

Geheimsprache 'nur Eingeweihten verständliche Sprache'

c. 20. Jahrhundert

Geheimagent 'Agent eines Geheimdienstes'

Geheimakte 'Akte mit geheimen Inhalt'

Geheimdienst 'staatliche Organisation zur Beschaffung geheimgehaltenen Materials des Gegners'

Geheiminstruktion 'vertrauliche, nicht öffentliche Instruktion'

Geheimnummer 'nicht im Telefonbuch veröffentlichte Nummer'

Geheimtinte 'unsichtbare Tinte'

Geheimvertrag 'Vertrag, dessen Abschluss/Inhalt geheimgehalten wird' Geheimwaffe 'in ihrer Existenz oder Wirkkraft geheime Waffe' 
Benennungen mit geheim werden im Deutschen i.d.R. als Komposita realisiert. Damit korreliert auch eine allgemein sehr hohe Produktivität der A+N-Komposition mit geheim (vgl. auch Tab. 5.7). Beinahe die Hälfte aller 414 Types im ZEITKorpus (Zeitraum 1946-2009) sind Hapaxe (189 Einheiten, z.B. Geheimidiom, Geheimschatulle, Geheimkonzentrat). Bei den im Primärmaterial verzeichneten Komposita ist auch auffällig, dass in vielen Fällen kaum ein Bedeutungsunterschied zwischen Kompositum und einer entsprechenden Phrase festzustellen ist. So kommt im Duden (1999) bzw. Duden Online (2012) neben Geheimsitzung auch geheime Sitzung, neben Geheimabkommen auch geheimes Abkommen vor. Beide Komposita werden dabei explizit mit den Phrasen paraphrasiert:
a. Geheimsitzung - geheime (a) Sitzung
(Duden Online 2012: Geheimsitzung)
b. Geheimabkommen - geheimes (a) Abkommen
(Duden Online 2012: GeHEIMABKommeN)
c. geheim (a) = 'vor anderen, vor der Öffentlichkeit absichtlich verborgen gehalten; bewusst nicht bekannt gegeben, nicht für andere bestimmt' (Duden Online 2012: GEHEIM)

Der Unterschied zwischen Kompositum und Phrase besteht lediglich darin, dass das Kompositum die Bedeutung (a) von geheim realisiert, während die zweite vom Duden genannte Bedeutung (b) in seiner Art ein Geheimnis [d.h. etwas Unerforschtes] bleibend, in einer mit dem Verstand nicht erklärbaren Weise wirksam' (Duden Online 2012: GEHEIM) unberücksichtigt bleibt.

Eine recht produktive phrasale Benennungsinsel bilden im 18. und 19. Jahrhundert Bezeichnungen für Staatsämter mit der Kernphrase Geheimer Rat, z.B. geheimer Justizrat, geheimer Kammerrat, geheimer Staatsrat sowie die Abwandlungen geheimer Ratgeber und geheimes Ratskollegium (vgl. für viele ähnliche Bezeichnungen die verschiedenen DELEX-Lexika des 19. Jahrhunderts). Die Phrase geheimer Rat geht auf die ursprüngliche Bezeichnung heimlicher Rat zurück. Das Adjektiv geheim wird vom DWB (GEHEIM, 1897) als ,jüngere Schwesterbildung“ zu heimlich gesehen, das bereits im Althochdeutschen belegt ist, während geheim erst gegen Ende der mittelhochdeutschen Periode entsteht. Die Ersetzung der Phrase heimlicher Rat durch geheimer Rat vollzieht sich bereits vor 1700. Auch bei anderen Verbindungen, die zunächst noch mit heimlich gebildet werden, kommt es im Laufe der Zeit zur Verdrängung durch geheim, vgl. z.B. heimliche Wahl bei Kramer (17001702) > geheime Wahl bei Duden Online (2012). Neben die Phrase geheimer Rat tritt im Laufe der Zeit das Kompositum Geheimrat (erstmalig bei Campe 1807-1811 verzeichnet). In allen folgenden untersuchten Wörterbüchern des Primärmaterials (und auch im Duden Online 2012) werden beide Verbindungen als Synonyme geführt. 
Im Niederländischen ist das Verhältnis von phrasaler und morphologischer Benennung wie bereits erwähnt deutlich ausgeglichener. Für beide Verfahren finden sich in allen Jahrhunderten Beispiele, auch wenn die Wörterbücher insgesamt deutlich weniger Belege als im Deutschen angeben:

(116) 18. Jahrhundert

a. geheime raad 'geheimer Rat/Geheimrat'

b. geheimkoor 'Innenraum eines Tempels, der nicht von Laien betreten werden darf' geheimschrijver 'Sekretär'

(117) 19. Jahrhundert

a. geheime inkt 'unsichtbare Tinte' geheime politie 'Geheimpolizei'

c. geheimschrift 'Geheimschrift' geheimraad 'in Deutschland gebrauchter Titel'

(118) 20. Jahrhundert

a. geheim agent 'Geheimagent' geheim testament 'best. Form des Testaments'

b. geheimboek 'geheimes Rechnungsbuch' geheimtaal 'Geheimsprache'

Im Gegensatz zum Deutschen kann geheim nicht nur Adjektiv, sondern auch Nomen (het geheim 'das Geheimnis') sein. Die adjektivische Verwendung ist die ältere, wobei geheim als Entlehnung aus dem Deutschen gilt und im Niederländischen ebenfalls ältere Verbindungen mit heym und heymelick (wie heym-raed und heymelick ghemack bei Kiliaan 1599) ersetzt hat (> geheime raad; geheim gemak). Entlehnungen scheinen eine gewisse Rolle zu spielen, so wird das niederländische geheimschrijver (Hoogstraten 1704) als Übersetzung des lateinischen secretarius geführt. Ähnliches gilt für das erstmals in Van Dale (2005) aufgenommene geheimtip, das als Entlehnung bzw. Lehnübersetzung aus dem Deutschen bewertet wird. Bei vielen Sprechern muss geheimtip noch einen deutlich „fremden“ Charakter haben, wie sich aus Belegen im LEXNEX-Korpus ableiten lässt. Das Wort wird in der Regel durch für das Deutsche typische Großschreibung, den Gebrauch von Anführungszeichen oder explizite Referenz auf das Deutsche markiert, vgl. (119):

(119) a. 'Geen bijen, geen fruit' geldt sinds enkele dagen als de Geheimtipp van het festival. (LC, 19.6.2008) 
b. De andere was het Balos-strand bij Gramvoessa; een ongerept, verlaten paradijs, waar bijna geen toerist komt. Een echte 'geheimtip'. (LC, 17.9.2005)

c. Geheimtip, zoals de Duitsers dat zo mooi noemen ['wie die Deutschen das so schön nennen', SFS], is Langenargen, even voorbij Friedrichshafen. (LC, 3.7.2010)

Das Adjektiv geheim steht auch im Niederländischen für die Bildung neuer Komposita zur Verfügung. Im LEXNEX-Korpus (1997-2011) sind zehn Komposita verzeichnet, die nicht in Van Dale Online (2012) aufgenommen sind. Davon sind wiederum sechs Hapaxe: geheimafluisterprogramma 'geheimes Abhörprogramm', geheimcultus 'Geheimkult', geheimdiscipline 'Geheimdisziplin', geheimgast 'Geheimgast', geheimnummer 'Geheimnummer', geheimwet 'Geheimgesetz'. Dies deutet also auf eine gewisse Produktivität des Wortbildungsverfahrens, die sich auch in der Zunahme morphologischer Benennungseinheiten im 20. Jahrhundert widerspiegelt. Allerdings ist der Trend bei weitem nicht so deutlich ausgeprägt wie im Deutschen: Dort ist die Komposition das dominierende Benennungsmuster geworden, während die phrasale Benennungsbildung im Niederländischen deutlich stärker einzuschätzen ist.

\subsubsection{2 kalt - koud}

Prinzipiell scheint die Ausgangslage zu Beginn des 18. Jahrhunderts in beiden Sprachen ähnlich zu sein. Sowohl bei kalt als auch bei koud werden syntaktische und morphologische Benennungseinheiten gebildet, vgl. (120).

(120) a. DE Kaltmeißel 'Meißel, mit dem Eisen kalt bearbeitet werden kann' kalter Brand 'Gangrän (Krankheit)'

b. NL koudschaal 'Kaltschale', koude keuken 'kalte Speisen' (mit keuken 'Küche' in der lexikalisierten Bedeutung 'Essen')

Im 18. Jahrhundert wirken die Präferenzen relativ ausgeglichen, während für das 19. Jahrhundert aufgrund der geringen Datenmenge keine klare Tendenz erkennbar ist bzw. von keinem grundlegenden Unterschied zwischen beiden Sprachen ausgegangen werden kann. Eine größere Menge Benennungen verzeichnen die Wörterbücher beider Sprachen erst für das 20. Jahrhundert (vgl. Tab. 5.19 und 5.20), wobei im Deutschen morphologische und im Niederländischen phrasale Benennungseinheiten überwiegen, beide Sprachen hier also divergieren. 
Tab. 5.19: Verbindungen mit kalt im deutschen Primärmaterial (20. Jh.)

\begin{tabular}{|c|c|}
\hline Phrase & \\
\hline kalter Abszess & 'Abszess ohne Entzündung' \\
\hline kalter Blitz & 'beim Einschlag sich nicht entzündender Blitz' \\
\hline kaltes Büfett & ‘kalte Speisen zur Selbstbedienung’ \\
\hline kalter Krieg & $\begin{array}{l}\text { 'feindselige politische Auseinandersetzung zwischen Staaten } \\
\text { o.Ä., jedoch ohne Waffengewalt' }\end{array}$ \\
\hline kalter Krieger & $\begin{array}{l}\text { 'Politiker, der die Methoden des kalten Krieges befürwortet, } \\
\text { unterstützt' }\end{array}$ \\
\hline kaltes Licht & $\begin{array}{l}\text { '(Physik) Licht, das nicht durch hohe Temperaturen ausgelöst } \\
\text { wird' }\end{array}$ \\
\hline kalte Mamsell & $\begin{array}{l}\text { 'Angestellte, die sich um die kalten Speisen im Restaurant } \\
\text { kümmert' }\end{array}$ \\
\hline kalte Miete & ‘Miete ohne Neben- und sonstige Kosten’ \\
\hline kalte Pracht & $\begin{array}{l}\text { 'etwas Prachtvolles, das aber kalt, unbehaglich, ungemütlich } \\
\text { wirkt' }\end{array}$ \\
\hline kalte Progression & $\begin{array}{l}\text { '(Steuer) unverhältnismäßige Zunahme des Steuersatzes bei } \\
\text { geringfügig steigendem Einkommen’ }\end{array}$ \\
\hline kalter Schweiß & 'Angstschweiß' \\
\hline kalte Spur & '(Jagd) Spur, die älter als zwei Stunden ist' \\
\hline kalter Staatsstreich & ‘Staatsumsturz ohne Blutvergießen’ \\
\hline kalte Verpflegung & 'Verpflegung mit Brot, Aufschnitt etc.' \\
\hline
\end{tabular}

Kompositum

\begin{tabular}{ll}
\hline Kaltakquise & $\begin{array}{l}\text { 'Kundenakquise ohne vorherige (telefonische) Kontaktauf- } \\
\text { nahme' } \\
\text { Kaltanruf }\end{array}$ \\
'ohne Aufforderung erfolgender Telefonanruf zur Werbung \\
Von Kunden' \\
Kaltasphalt \\
Kaltaushärtung \\
'Emulsion von Bitumen in Wasser' \\
Kaltbrand & bei Raumtemperatur' \\
Kaltbrüter & 'kaltgewalzter Bandstahl' \\
Kaltfirnis & 'Tier, das sich nur während der kalten Jahreszeit fortpflanzt' \\
Kaltformgebung & 'best. Art von Firnis, der ohne Erwärmung gewonnen wird' \\
Kaltformung & $=$ 'Kaltformung' \\
Kaltfront & 'Umformen von Metallen bei Raumtemperatur' \\
Kaltgas & '(Meteorologie) Linie, die vordringende Kaltluft begrenzt' \\
Kaltgetränk & '(Technik) gereinigstes, meist abgekühltes Generatorgas' \\
Kaltglasur & 'Getränk, das kalt getrunken wird' \\
& 'glänzender Überzug, der nicht durch Einbrennen erzeugt \\
Kalthärtung & wird' \\
Kaltkaustik & '(Technik) Härten von Kunststoffen unter Zusatz von Säuren \\
bei Raumtemperatur' & 'medizinisches Verfahren zur Zerstörung krankhafter \\
& Gewebswucherungen'
\end{tabular}




$\begin{array}{ll}\text { Kaltkreissäge } & \text { 'best. Kreissäge, deren Sägeblätter meist mit Kühlmitteln } \\ & \text { vor Überhitzung geschützt werden' } \\ \text { Kaltleim } & \text { 'Leim, der bei Zimmertemperatur abbindet' } \\ \text { Kaltleiter } & \text { 'elektrischer Leiter mit größerer Leitfähigkeit im kalten } \\ & \text { Zustand' } \\ \text { Kaltluft } & \text { '(Meteorologie) kalte Luftmassen' } \\ \text { Kaltmamsell } & =\text { 'kalte Mamsell' } \\ \text { Kaltmetall } & \text { 'Legierung von geringer Wärmeleitfähigkeit' } \\ \text { Kaltmiete } & =\text { 'kalte Miete' } \\ \text { Kaltnadel } & \text { 'Stahl-, Radiernadel zur Herstellung von Kaltnadelradierungen' } \\ \text { Kaltphase } & \text { 'durch niedrige Durchschnittstemperatur gekennzeichnete } \\ & \text { Phase in der Entwicklung des Klimas' } \\ \text { Kaltreserve } & \text { 'abgeschaltetes, aber nicht stillgelegtes Kraftwerk' } \\ \text { Kaltsatz } & \text { '(Druck) Satzarten, die nicht aus einer flüssigen Metalllegie- } \\ & \text { rung hergestellt werden' } \\ \text { Kaltstart } & \text { '1. (KFZ) Start mit kaltem Motor bei niedrigen Temperaturen; } \\ & 2 .(\text { EDV) das Booten' } \\ \text { Kaltteer } & \text { 'best. Sorte Teer, die auch im kalten Zustand verarbeitet } \\ & \text { werden kann' } \\ \text { Kaltverfestigung } & \text { '(Technik) bei der Kaltformung metallischer Werkstoffe } \\ & \text { eintretende Verfestigung' } \\ \text { = 'Kaltformung' } \\ \text { Kaltverformung }\end{array}$

Die Recherche in diachronen Textsammlungen legt nahe, dass die Komposition und damit indirekt auch die morphologische Benennungsbildung mit kalt im Deutschen noch in der ersten Hälfte des 19. Jahrhunderts wenig verbreitet ist. Die DBLK liefert für den Zeitraum 1739-1920 nur drei Treffer (Kalthaus, Kaltsinn, Kaltwasser), von denen zwei bereits im 18. Jahrhundert lexikografisch fixiert sind (zudem kann Kaltsinn als Rückbildung zu kaltsinnig analysiert werden). Auch in den DELEX-Lexika sind neue Bildungen erst ab Mitte des 19. Jahrhunderts anzutreffen, u.a. in Pierer (1857-1865; z.B. Kaltbruch, Kaltmeißel, Kaltnadel, Kaltschlächter, Kaltschmied). Ein weiteres Indiz für die geringere Produktivität sind zeitweilige Konkurrenzen zwischen Phrase und Kompositum, bei denen sich untypischerweise (vgl. Kap. 5.7) nicht die Komposita durchsetzen (vgl. die Erläuterungen zu Kaltbrand, Kaltfieber, Kaltschweiß, Kaltpiss im DWB: KalTBRAnD, 1873). Auch im 20. Jahrhundert konkurrieren Phrase und Kompositum oftmals miteinander, u.a. kalte Miete - Kaltmiete, kalte Mamsell - Kaltmamsell. 
Tab. 5.20: Verbindungen mit koud im niederländischen Primärmaterial (20. Jh.)

\begin{tabular}{ll}
\hline Phrase & \\
\hline koude bakker & 'Verkäufer nicht selbst gebackener Backwaren' \\
koude bouw & '(Bienenzucht) best. Ausrichtung der Waben im Bienenstock' \\
koud buffet & 'kaltes Büfett' \\
koud dak & 'Dach mit Wärmeisolation' \\
koude drukte & 'Brimborium, Theater' \\
koude feiten & 'sachliche, neutrale Gegebenheiten' \\
koude fusie & '(Physik) kalte Fusion' \\
koude gewassen & 'Pflanzen, die in nicht erwärmten Treibhäusern wachsen' \\
koud geweer & 'Gewehr ohne identifizierbare Seriennummer' \\
koud gezwel & 'Wucherung, die sich ohne Anzeichen eines Fiebers ausbreitet' \\
koude grond & '(Landwirtschaft) Boden, der nicht künstlich erwärmt wird' \\
kouwe kak & 'Hochnäsigkeit' \\
koude kassen & 'Kalthäuser, nicht erwärmte Treibhäuser' \\
koude kernfusie & '(Physik) kalte Kernfusion' \\
koude lichtstraal & 'ultraviolette Strahlen' \\
koude lunch & 'Lunch mit kalten Speisen' \\
koude oorlog & 'kalter Krieg' \\
koude smid & 'Schmied der ohne Feuer oder Hitze arbeitet' \\
koud vuur & 'kalter Brand (Krankheit), Gangrän' \\
\hline Kompositum & \\
\hline koudbeitel & 'Kaltmeißel' \\
koudbewerking & 'Kaltformung' \\
koudemail & 'kalt aufgetragene Emaille, Glasur' \\
koudlak &
\end{tabular}

Im Niederländischen ist eine stärkere Nutzung morphologischer Benennungseinheiten ausgeblieben. Zwar sind in den diachronen Korpus- und Textsammlungen einige weitere Verbindungen belegt, vgl. das im LCA 1929 belegte koudasfalt 'Kaltasphalt' und das im LCA und LEXNEX-Korpus mehrfach belegte koudschuim 'Kaltschaum' (erstmals 1976 im LCA, v.a. in Werbeanzeigen). Koudasfalt kann allerdings auch als Phrase interpretiert werden, da es in anderen Quellen auseinandergeschrieben wird, so z.B. im LEXNEX-Korpus, wo keine Belege für die Schreibungen koudasfalt bzw. koud-asfalt existieren, sondern lediglich 22 Treffer für koud asfalt verzeichnet sind. Koudschuim scheint in erster Linie durch die Verwendung in komplexen Bildungen wie koudschuimvulling 'Kaltschaumfüllung', -matrassen '-matratzen', koudschuimgevulde 'mit Kaltschaum gefüllte' in Gebrauch gekommen zu sein. Die meisten Treffer mit koudschuim im LCA ab den 1970er Jahren sind tatsächlich komplexe Wortbildungen, erst in den 1990er Jah- 
ren wird das Wort verstärkt ohne weitere Zusätze verwendet. Es handelt sich möglicherweise um einen Beispielfall der in Kapitel 2.4 beschriebenen Autonomisierung von Erstgliedkonstituenten in polymorphemischen Komposita. Zwei andere in den WNT-Zitaten belegte Bildungen sind koud-front 'Kaltfront' und koudkleum 'etwa: Frostbeule' (wörtlich 'kalt' + 'Person, die friert'), die inzwischen jedoch durch koufront bzw. koukleum ersetzt wurden (Van Dale 2005), d.h. Formen, die zumindest formal $\mathrm{N}+\mathrm{N}$-Komposita entsprechen (mit dem Nomen de kou 'die Kälte').

Vereinzelt ist es wie im Deutschen zu Konkurrenzen zwischen Phrasen und Komposita gekommen, z.B. koude schaal - koudschaal, koude bakker - koudbakker, koud vuur - koudvuur. Bis auf koudvuur sind beide Formen aber entweder nahezu gleichzeitig aus dem Wortschatz verschwunden oder die Phrase hat sich langfristig durchgesetzt (vgl. Kap. 5.7).

Insgesamt scheinen sich das Deutsche und das Niederländische in Hinblick auf Verbindungen mit kalt - koud also v.a. im Verlauf der letzten 150 Jahre auseinander entwickelt zu haben.

\subsubsection{3 negativ - negatief}

Das Adjektiv negativ - negatief gehört nicht zum Erbwortschatz des Deutschen oder Niederländischen, sondern ist aus dem Französischen entlehnt. Im Deutschen ist die Betonung variabel (entweder auf der ersten oder der letzten Silbe); im Niederländischen wird immer die letzte Silbe betont.

In den hier untersuchten deutschsprachigen Wörterbüchern ist negativ erstmalig im WDG (1967-1982) verzeichnet, obwohl es bereits in deutschen Quellen des ausgehenden 18. Jahrhundert belegt werden kann, z.B. bei Lessing (1780; DBLK). Einige morphologische Bildungen mit negativ stammen aus der Zeit vor 1900, z.B. Negativlehre (1780; DBLK), wohl ein philosophischer Fachbegriff bei Kant, oder Negativpartikel ('Negationspartikel') bei Pierer (TsCHEREMISSISCHE SPRACHE, 1857-1865). Um die Jahrhundertwende tauchen eine ganze Reihe von Bildungen mit Benennungsfunktion auf, allerdings sind diese als N+N-Komposita einzustufen (z.B. Negativfilm) mit Negativ in der Bedeutung 'negatives Bild eines belichteten Fotofilms'. Später wird die A+N-Komposition aber sehr produktiv, vor allem mit negativ in der Bedeutung 'ungünstig, nachteilig; schlecht', vgl. die Beispiele in (121):

Negativbeispiel, Negativbilanz, Negativimage, Negativpresse, Negativrekord, Negativschlagzeile, Negativserie, Negativtrend etc. 
Es scheint sich hierbei um eine Innovation des 20. Jahrhunderts zu handeln, da aktuellere Wörterbücher sehr viele entsprechende Verbindungen verzeichnen, während in keiner der Quellen des 18. oder 19. Jahrhunderts Bildungen dieses Typs belegt sind.

Einen zweiten Trend bei Benennungseinheiten mit negativ offenbaren die deutschen Lexika des 19. und frühen 20. Jahrhunderts, nämlich die Bildung fachsprachlicher Ausdrücke, darunter die folgenden Beispiele (vgl. die Lexika von Herder 1854-1857, Pierer 1857-1865 und Meyer 1905-1909):

(122) a. negative Elektrizität 'Elektrizität mit wenigen positiv geladenen Elementarteilchen'

b. negative Feststellungsklage 'best. Klageart, um das Nichtbestehen eines Rechtsverhältnisses nachzuweisen'

c. negative Philosophie 'eine den Wahrheiten der geoffenbarten Religion widersprechende Philosophie'

d. negativer Pol '(Elektrophysik) Minuspol'

e. negative Zahlen 'alle Zahlen unter Null'

Diese Bildungen werden in der Regel phrasal realisiert. Dies gilt auch für die meisten erst im 20. Jahrhundert entstandenen Fachbegriffe. Nur wenige sind als Komposita versprachlicht, u.a. Negativtestament (Rechtswesen) und Negativsteuer (Wirtschaft). Im Deutschen herrscht bei negativ also über weite Strecken eine Komplementarität zwischen Phrase und Kompositum vor, die zum einen mit dem Status der Verbindung (gemein- vs. fachsprachlich) und zum anderen mit dem Bedeutungsspektrum von negativ in Verbindung gebracht werden kann. Nur im Falle der Adjektivbedeutung 'ungünstig, nachteilig; schlecht' sind überhaupt Dubletten im Wörterbuch verzeichnet (z.B. negativer Rekord - Negativrekord).

Im Niederländischen ist die Phrasenbildung ebenfalls bereits im 19. Jahrhundert und frühen 20. Jahrhundert vertreten, wie die folgenden Beispiele zeigen (vgl. Kuipers 1912-1918; WNT: NEGATIEF, 1911).
a. negatieve electriciteit 'negative Elektrizität'
b. negatieve getallen 'negative Zahlen'
c. negatieve grootheden 'negative Größen'
d. negatieve katalysator 'Stoff, der eine Reaktion verlangsamt'

Die gewählten niederländischen Wörterbücher des 20. Jahrhunderts verzeichnen ausschließlich phrasale Benennungseinheiten mit einem intuitiv fachsprachlichen Charakter (negatieve arbeid '(Physik) negative Arbeit'; negatieve bestandsdelen '(Wirtschaft) Passiva'). Im Gegensatz dazu etablieren sich keine mor- 
phologischen Benennungseinheiten im Niederländischen, die eindeutig als $\mathrm{A}+\mathrm{N}$-Verbindungen $\mathrm{zu}$ charakterisieren sind. So sind beispielsweise negatiefretouche 'Retuschieren von Negativen' (WNT: NEGATIEF, 1911) und negatiefdruk 'Druckmethode, bei dem helle Bilder auf dunklem Untergrund gefertigt werden' (Van Dale 1961) wohl als N+N-Komposita zu analysieren. Die einzige Ausnahme ist das 2009 in Van Dale Online aufgenommene und als vorläufig markierte negatieflijst 'Liste von Tieren, die nicht ohne Genehmigung von Privatpersonen gehalten werden dürfen'.

Im Gegensatz zum Deutschen sind Verbindungen mit negatief in der Bedeutung 'ungünstig, nachteilig; schlecht' nicht gängig. Prinzipiell kann das Adjektiv zwar in dieser Bedeutung verwendet werden, vgl. (124). Die Verbindungen sind aber nicht lexikalisiert bzw. kann die zugrundeliegende Bedeutung auch anders versprachlicht werden, vgl. (125)-(126) (Beispiele aus dem EUROPARL-Korpus, vgl. Koehn 2005).

(124) a. DE [...] so dass wir den Fehler, den wir mit diesem Gebäude gemacht haben und der für zahlreiche Negativschlagzeilen gesorgt und dem Ansehen des Parlaments sehr geschadet hat, nicht wiederholen.

b. NL [...] dat we niet dezelfde fouten maken als bij dit gebouw, dat veel negatieve publiciteit heeft opgeleverd en het Parlement in diskrediet heeft gebracht.

(125) a. DE Ich denke, wenn der Hof so viele Spielräume bei der Auslegung seines Berichtes lässt, dann bekommen wir immer Negativschlagzeilen.

b. NL Als het verslag van de Rekenkamer zoveel ruimte voor interpretatie laat, denk ik dat wij altijd slechte publiciteit zullen krijgen.

(126) a. DE Wir wissen auch, daß es ständig Negativschlagzeilen über dieses Parlament gibt [...].

b. NL We zijn er ons echter ook van bewust dat dit Parlement constant wordt achtervolgd en ondermijnd door afbrekende publiciteit [...].

Im Deutschen hat sich also ein besonders produktives morphologisches Verfahren mit einer spezifischen Bedeutung gebildet, die im Niederländischen zwar prinzipiell möglich ist, aber bisher nicht in $\mathrm{A}+\mathrm{N}-$ Verbindungen lexikalisiert wurde. Dadurch hat sich im Laufe des Untersuchungszeitraums nur im Deutschen ein weitgehend komplementäres Benennungsmuster ausgebildet: fachsprachlich syntaktische und gemeinsprachlich morphologische Benennungsbildung. 


\subsubsection{4 fremd - vreemd}

Für das deutsche fremd gilt nicht nur, dass für das gesamte 18. Jahrhundert keinerlei morphologische Benennungseinheiten im Primärmaterial zu finden sind. Die A+N-Komposition mit fremd als Erstglied ist überhaupt bis ins 19. Jahrhundert hinein unproduktiv, d.h., auch textbedingte Verkürzungen komplexer syntaktischer Ausdrücke sind nicht anzutreffen. Erst zur Mitte des 19. Jahrhunderts verzeichnen Wörterbücher erste morphologische Benennungseinheiten und tauchen Komposita in den Korpora und diachronen Textsammlungen auf, z.B. Fremdwort (Erstbeleg DBLK: 1832), Fremdherrschaft (Erstbeleg DBLK: 1835). Es handelt sich dabei noch um vereinzelte Bildungen. Richtig produktiv wird das Muster in der Benennungsbildung erst im 20. Jahrhundert und es kommt zu einer Vielzahl von Bildungen, u.a.:

Fremdsprache, Fremdkörper, Fremdkapital, Fremdeinwirkung, Fremdleistung, Fremdverschulden etc.

Dass nicht nur die morphologische Benennungsbildung, sondern die gesamte $\mathrm{A}+\mathrm{N}-$ Komposition mit fremd hochproduktiv geworden ist, zeigt sich an der großen Anzahl von Hapaxen im ZEIT-Korpus im Zeitraum 1946-2009. Mehr als die Hälfte aller Types sind Hapaxe (192 von 328), d.h. Bildungen, die nur ein einziges Mal im Korpus auftauchen, vgl. einige Beispiele in (128):

Fremdanzeige, Fremdäußerung, Fremdberuf, Fremdereignis, Fremdgarantie, Fremdinformation, Fremdklischee, Fremdkomponente, Fremdlärm, Fremdpersonal, Fremdprovision, Fremdschuld, Fremdstudie, Fremdursache

Diese Produktivität betrifft dabei oftmals eine bestimmte Bedeutung von fremd, nämlich 'einem anderen gehörend; einen anderen, nicht die eigene Person, den eigenen Besitz betreffend'. Bildungen wie in (128) sind natürlich bei weitem nicht alle als Benennungseinheiten einzustufen. Auffällig ist vielmehr, dass viele Bildungen oftmals ad hoc durch etablierte Ausdrücke mit eigen (wie in Eigenkapital) und selbst (wie in Selbstbild) motiviert sind. Vgl. die folgenden Beispiele aus dem ZEIT-Korpus, wo der Zusammenhang sogar im unmittelbaren sprachlichen Kontext gegeben wird:

(129) a. Möglicherweise ist es dies, was die (im Eigen- und Fremdversuch erprobte) mesmerisierende Wirkung dieser Erzählung ausmacht [...]. (ZEIT, 29.9.1995) 
b. Die plötzlich aufflackernde, ziemlich hysterische Debatte [...] hat doch krasse Züge der Selbstbespiegelung und Fremdbezichtigung: Jeder, der dabei war, erzählt dem anderen, dass entweder er selber oder dass sogar alles anders gewesen war. (ZEIT, 23.1.2001)

Oder das Hapax ist eine Analogiebildung zu einem etablierten Kompositum:

$$
\begin{aligned}
& \text { Die Haute Couture ist in Deutschland ein Fremdwort und eine Fremd- } \\
& \text { sache. „Großschneider?“ O weh! „Modeschöpfer?“ Da wären wir schon } \\
& \text { wieder mitten im Schöpferischen, auf den Spuren des Prometheus. } \\
& \text { (ZEIT, 18.10.1963) }
\end{aligned}
$$

Vergleicht man die Anzahl morphologischer und syntaktischer Benennungseinheiten im Deutschen, fällt auf, dass es praktisch kaum zur Bildung phrasaler Benennungseinheiten mit fremd gekommen ist. Das fremde Wort 'Fremdwort' ist laut DWB (WoRT, 1960) Mitte des 17. Jahrhunderts als Fachterminus bei Sprachtheoretikern etabliert, inzwischen in dieser Bedeutung aber durch Fremdwort ersetzt (die Phrase ist nicht im Primärmaterial verzeichnet; vgl. aber NL vreemd woord, eine Phrase!). Adelung (1793-1801), Campe (1807-1811) und Heyne (18901895) verweisen auf die Phrase fremdes Licht, das folgendermaßen definiert wird: '[Licht] bey den Mahlern, welches noch von dem Hauptlichte verschieden ist' (Adelung, FREMD). Es handelt sich jedoch um Einzelfälle.

Das Niederländische unterscheidet sich demgegenüber in zweierlei Hinsicht. Zum einen ist die morphologische Benennungsbildung im Niederländischen nie produktiv geworden. Im Primärmaterial ist kein einziges Kompositum mit vreemd verzeichnet. Lediglich das WNT verzeichnet drei Bildungen als Lemmata: vreemdmeester (ohne Bedeutungserklärung; belegt als freemtmeesters (1519)) und die beiden Regionalismen vreemdgoed 'fremde, schlechte Leute' (vor 1899) und vreemdhaar 'jemand mit sonderbaren Manieren' (1955) (hier allerdings mit einer possessiven Interpretation!). Es ist jedoch unklar, ob es sich hier um verbreitete Benennungen oder um Ad-hoc-Bildungen handelt. Die im Deutschen besonders häufige Bedeutung von fremd 'einem anderen gehörend; einen anderen, nicht die eigene Person, den eigenen Besitz betreffend' existiert zwar auch im Niederländischen (z.B. vreemde bestanddelen 'Fremdstoff'). Nichtsdestoweniger werden i.d.R. A+N-Phrasen mit vreemd oder sogar anderen Modifikatoren gebildet, da auch die phrasale Benennungsbildung mit vreemd nur eingeschränkt produktiv ist. Im Primärmaterial sind für den gesamten Untersuchungszeitraum nur wenige Phrasen (so z.B. vreemd woord, vremde bestanddelen) verzeichnet. 
(131) a. DE Fremdkörper - NL vreemd lichaam, vreemd voorwerp

b. DE Fremdstoff - NL vreemde bestanddelen
a. DE Fremdbestäubung - NL kruisbestuiving, xenogamie
b. DE Fremdfinanzierung - NL externe financiering

Dass die Komposition mit vreemd im heutigen Niederländisch nicht völlig ausgeschlossen ist, zeigen Gelegenheitsbildungen im LEXNEX-Korpus, vgl. vreemdparkeerder 'nicht-ortsansässige Person, die ihr Auto in einer fremden Parkzone parkt':

B. en w. willen de parkeerschijf voortaan ook verplicht stellen in de Oranjewijk ten westen van het Emmaplein [...]. Bewoners mogen voor f25 een ontheffing kopen. Zij hebben over de vreemdparkeerders veelvuldig geklaagd bij de gemeente. ${ }^{49}$ (LC, 26.11.1998)

Eine DBNL-Volltextsuche belegt sporadische Bildungen (vreemdwoord, 1888; vreemdlanden, 1893; vreemdlachje, 1894; vreemdlichaam, $1920^{50}$ ), vreemdwezen, 1933). Ein (seltenes) Beispiel für eine durch den Kontext initiierte Bildung ist vreemdbeoordeling in (134):

Ongeveer een week na deze zelfbeoordeling werd iedere pp. gekonfronteerd met dezelfde lijst, nu zogenaamd door een ander ingevuld [...]. De helft van de 40 aanduidingen op deze vreemdbeoordeling was in overeenstemming met de zelfbeoordeling, de andere helft dus niet. ${ }^{51}$ (DBNL, 1978)

Keine dieser Bildungen wird allerdings als lexikalische Einheit im Wörterbuch aufgeführt, so dass hinsichtlich der morphologischen Benennungsbildung von

49 „B[ürgermeister] und G[esetzgeber] wollen die Parkscheibe im Oranje-Viertel westlich des Emma-Platzes zur Pflicht machen. [...] Anwohner dürfen für 25 Gulden eine Befreiung kaufen. Sie haben sich vielfach bei der Gemeinde über die Fremdparker beklagt“ [Übersetzung: SFS].

50 Das Wort vreemdlichaam 'Fremdkörper' tritt mehrmals, aber ausschließlich bei dem flämischen Autor Paul Van Ostaijen auf, der längere Zeit in Berlin gelebt hat, u.a. auch zur Zeit des Erstbelegs für vreemdlichaam. Eventuell handelt es sich also um eine vom Deutschen beeinflusste Individualbildung.

51 „Ungefähr eine Woche nach dieser Selbsteinschätzung wurde jede Testperson mit derselben Liste konfrontiert, nun angeblich durch eine andere Person ausgefüllt [...]. Die Hälfte der $40 \mathrm{Be}-$ merkungen auf dieser Fremdeinschätzung stimmte mit der Selbsteinschätzung überein, die andere Hälfte also nicht“ [Übersetzung: SFS]. 
einer großen Divergenz zwischen dem Deutschen und dem Niederländischen ausgegangen werden muss. Obwohl morphologische Benennungen mit vreemd im Niederländischen prinzipiell möglich sind, kommen diese sehr selten vor und sind langfristig - und wenn überhaupt - phrasale Benennungseinheiten die Regel (z.B. vreemd woord 'Fremdwort'). Im Deutschen hat sich hingegen eine produktive morphologische Benennungsbildung mit fremd sowie ein generell hochproduktives $\mathrm{A}+\mathrm{N}-$ Kompositionsmuster entwickelt.

\subsubsection{Vorläufiges Fazit}

Die historisch-vergleichende Analyse der Benennungsbildung bei zehn qualitativen Adjektiven hat gezeigt, dass die Unterschiede zwischen dem Deutschen und dem Niederländischen in der klassifikatorischen Benennungsbildung je nach Adjektiv unterschiedlich stark ausgeprägt sind. Die Ergebnisse lassen sich folgendermaßen zusammenfassen:

1. Das Adjektiv hat einen deutlichen Einfluss auf die Realisierung einer Verbindung als Phrase oder Kompositum. Einige Adjektive bevorzugen eindeutig die Phrasenbildung (z.B. DE still, NL stil, vreemd), andere Adjektive in erster Linie die Komposition (z.B. DE bitter, fremd, NL bitter). Bei einer dritten Gruppe von Adjektiven lässt sich zeigen, dass sie häufig sowohl in Phrasen als auch Komposita auftreten, dies gilt v.a. für die Farbadjektive.

2. Für den Großteil der Adjektive sind die Präferenzen von Beginn des Untersuchungszeitraums an relativ stabil (z.B. gelb - geel, bitter - bitter, still - stil). Nur bei DE kalt und geheim gibt es Anzeichen dafür, dass die Komposition die Phrasenbildung im Laufe der Zeit zunehmend verdrängt. Andere Adjektive treten wiederum zu Beginn des Untersuchungszeitraums kaum in Benennungseinheiten auf (z.B. fremd - vreemd, NL diep, negatief). Wenn diese aber im Laufe der Jahrhunderte verstärkt gebraucht werden, entwickeln sie in der Regel sehr schnell stabile Präferenzen. So werden mit DE fremd fast ausschließlich morphologische, mit NL negatief hingegen phrasale Benennungseinheiten gebildet. Keinesfalls lässt sich aber für alle Adjektive ein gemeinsamer systematisch verlaufender Entwicklungstrend erkennen. Jedes Adjektiv scheint eine eigene Entwicklung zu verfolgen.

3. Die formale Realisierung von Benennungen unterscheidet sich im Deutschen und Niederländischen sowohl qualitativ als auch quantitativ. So sind im Deutschen deutlich mehr Adjektive mit einem eindeutigen Kompositumsbias zu finden. Im Niederländischen ist die Phrasenbildung bei den meisten Adjektiven hingegen zumindest eine gleichwertig genutzte Alternative oder sogar dominant. Darüber hinaus sind im Deutschen einzelne Adjektive in einer 
spezifischen Bedeutung in der morphologischen Benennungsbildung besonders produktiv geworden (z.B. DE fremd 'einen anderen, nicht die eigene Person, den eigenen Besitz betreffend'). Diese sind zwar auch im Niederländischen zu finden, oft aber nicht in A+N-Verbindungen lexikalisiert. Konzeptuelle Entsprechungen werden formal anders realisiert (vgl. DE Fremdbestäubung - NL kruisbestuiving, wörtl. 'Kreuz'+'Bestäubung').

4. Die Stärke der morphologischen Benennungsbildung korreliert mit der allgemeinen Produktivität der A+N-Komposition. Ist die Komposition mit einem bestimmten Adjektiv als solche kaum produktiv, sind auch morphologische Benennungseinheiten sehr selten (vgl. still - stil, das fast ausschließlich in phrasalen Benennungseinheiten realisiert wird). Allerdings muss dies nicht mit der intensiveren Nutzung des syntaktischen Benennungsverfahrens einhergehen, wie am Beispiel von NL vreemd deutlich wurde. In den Wörterbüchern sind zwar keine morphologischen Einheiten zu finden, es existieren allerdings nur wenige phrasale Benennungseinheiten. Der Bedarf an Benennungen mit vreemd ist demnach offensichtlich im Niederländischen nicht in derselben Weise wie im Deutschen vorhanden.

5. Die Bildungen mit DE negativ zeigen, dass hier fachsprachlich eine eindeutige Präferenz für Phrasenrealisierungen besteht. Dies deutet darauf hin, dass sich Beobachtungen aus der Allgemeinsprache nicht immer nahtlos auf die Fachsprache übertragen lassen (vgl. zu Bildungstendenzen in Fachsprachen noch einmal Kap. 4.6), sondern einer eingehenden Untersuchung bedürfen. Bei anderen Adjektiven kommt es teils zur Phrasenbildung (vgl. DE kalte Progression, geheimer Vorbehalt, NL bitter barbarakruid, bittere scheefbloem), teils zur Komposition (vgl. DE Kaltkaustik, Kaltkreissäge, NL diepdak, dieplepel), so dass fraglich scheint, ob fachsprachliche Benennungsbildung immer eine besondere Präferenz zur Phrasenbildung hat.

6. Es kommt zu Konkurrenz- und Verdrängungsprozessen, die im Deutschen wesentlich stärker ausgeprägt sind als im Niederländischen. Morphologische Benennungseinheiten treten neben phrasale Verbindungen (vgl. DE geheimer Rat - Geheimrat) oder ersetzen diese langfristig (z.B. DE gelbes Fieber > Gelbfieber; vgl. Kap. 5.7).

\subsection{Benennungsbildung bei Relationsadjektiven seit 1700}

Relationsadjektive unterscheiden sich von qualitativen Adjektiven dadurch, dass sie inhärent klassifikatorisch modifizieren (vgl. Kap. 2.3.2). Demnach besteht kein grundsätzlicher semantischer Unterschied zwischen Bildungen wie nationaler 
Staat und Nationalstaat, so lange keine der beiden Verbindungen eine Bedeutungsveränderung/-spezialisierung erfahren hat. Der einzige Unterschied ist eine möglicherweise variierende Gebrauchsfrequenz (im Deutschen ist Nationalstaat konventionalisiert). Relationsadjektive mit endbetontem (nicht-nativem) Suffix können im Deutschen die Modifikatorposition eines Kompositums besetzen, während dies im Niederländischen die Ausnahme darstellt. Es stellt sich die Frage, wie stark diese Beschränkung tatsächlich ist und ob sie nur für die unmittelbare Gegenwartssprache oder darüber hinaus auch für die Vergangenheit gilt. Im Folgenden soll daher die Entwicklung von Bildungen mit sozial - sociaal und zivil - civiel beschrieben werden.

Beide Adjektive wurden über das Französische ins Deutsche bzw. Niederländische entlehnt. Das französische social geht wiederum auf das Lateinische socialis 'kameradschaftlich, von den Bundesgenossen' zurück, das eine Derivation des Nomens socius 'Bundesgenosse, Kamerad, Geschäftspartner' darstellt (vgl. EWN: SOcIAAL). Das Adjektiv zivil - civiel hat über das Französische seine Ursprünge im lateinischen civilis 'bürgerlich, Staats-' und ist von civis 'Bürger' (vgl. EWN: CIVIEL) abgeleitet. Da sich die Entwicklung bei beiden Adjektiven weitgehend ähnelt, werden sie zusammen behandelt.

Im Deutschen ist sozial laut Kluge (1995: 773) vor dem 18. Jahrhundert aus dem Französischen entlehnt worden. Im deutschen Primärmaterial ist das Adjektiv dennoch erst im WDG (1967-1982) verzeichnet. Daher lohnt sich zunächst ein Blick in das DWB (1905), in dem sozial folgendermaßen definiert wird:

SOZIAL, adj. was die menschliche gesellschaft, das zusammenleben der menschen und seine staatlich-rechtliche ordnung wie die wirtschaftlichen verhältnisse betrifft: der soziale zustand eines landes, volkes, die soziale lage eines standes $u$. ähnl. (DWB: sozIAL, 1905; Hervorhebung im Original)

Bereits zu Beginn des 20. Jahrhunderts sind eine Reihe von morphologischen und syntaktischen Verbindungen etabliert. Das DWB nennt die folgenden:

(136) a. die soziale Frage, der complex von problemen, der die wirtschaftlichen und politischen zustände, namentlich die lage der unteren schichten, der lohnarbeiterklasse, betrifft (Hervorhebung im Original)

b. die soziale Bewegung, bewegung zur besserung der wirtschaftlichpolitischen zustände, zur verwirklichung der gerechtigkeit in der ordnung der gesellschaft, speciell zur hebung der arbeiterklasse (Hervorhebung im Original) 
(137) a. s o z i a l d e m o k r a t i e, die politische partei, die eine umgestaltung der gesellschaftsordnung und productionsweise im sinne des sozialismus (s. das.) anstrebt (Hervorhebung im Original)

b. s o z i a $1 \mathrm{p}$ o $1 \mathrm{i} \mathrm{t}$ i k, der theil der politik, der die wirtschaftlichen verhältnisse zum gegenstande und ihre besserung zum zweck hat (DWB: SOZIAL, 1905; Hervorhebung im Original)

Benennungen können also phrasal und morphologisch realisiert werden. Beide Optionen sind schon seit etwa Mitte des 19. Jahrhunderts anhand von Beispielen aus den DELEX-Lexika belegbar, vgl. in Herder (1854-1857) die drei Verbindungen Socialpolitik, Socialroman und sociale Revolution 'die Vernichtung alles Rechts, aller Einrichtungen, welche durch Familie, Gemeinde, Staat und Kirche begründet worden sind' (Herder: ARMENwESEN). Diese Entwicklung setzt sich auch im 20. Jahrhundert fort, vgl. einige Beispiele im Primärmaterial:

(138) Brockhaus Wahrig (1980-1984)

a. sozialer Wohnungsbau

b. Sozialplan

(139) Duden (1999)

a. soziale Einrichtungen

b. Sozialstatistik

(140) Duden Online (2012)

a. soziale Sicherheit

b. Sozialsystem

Allerdings sind zumindest in den Wörterbüchern deutlich mehr Komposita als Phrasen verzeichnet. Auch das ZEIT-Korpus (1946-2009) verzeichnet mehrere hunderte morphologische Types mit sozial als Erstglied.

Im Niederländischen taucht das Adjektiv sociaal im Primärmaterial erstmals bei Sicherer/Akveld (1870) auf (zusammen mit den Bildungen socialisme, socialismus, socialist). Im WNT, dem niederländischen Äquivalent des DWB, werden in einem Eintrag von 1932 die folgenden Verbindungen genannt:

(141) a. De (EEN) Sociale Revolutie, de (een) revolutie die niet slechts de politieke, maar ook de maatschappelijke verhoudingen omwentelt ${ }^{52}$

52 „Die (eine) Soziale Revolution, die (eine) Revolution, die nicht nur die politischen, sondern auch die gesellschaftlichen Verhältnisse umwälzt“ [Übersetzung: SFS]. 
b. De Sociale QUAESTIE, [...] het vraagstuk van de eischen en rechten der onderliggende klassen, inzonderheid der arbeidersklasse. ${ }^{53}$ (WNT: SOCIAAL, 1932; Hervorhebung im Original)

In zwei gesonderten Einträgen verzeichnet das WNT parallel die Wortbildungen sociaaldemocratie 'Sozialdemokratie' und sociaaldemocraat 'Sozialdemokrat', die als Lehnwörter aus dem Deutschen klassifiziert werden. In der Tat haben beide Verbindungen einen weitgehenden Ausnahmecharakter: Abgesehen von ihnen werden alle in den Wörterbüchern des 20. Jahrhunderts verzeichneten $\mathrm{A}+\mathrm{N}$ Benennungen mit sociaal phrasal realisiert, z.B. sociale beweging 'soziale Bewegung', sociale partners 'soziale Partner/Sozialpartner', sociale politiek 'Sozialpolitik', sociale woningsbouw 'sozialer Wohnungsbau'.

Die Befunde zu zivil - civiel zeigen ein ähnliches Bild. Für das Deutsche sind im Primärmaterial sowohl Phrasen als auch Komposita zu finden, im Niederländischen ausschließlich Phrasen (vgl. die folgenden Beispiele):

(142) a. ziviler Ungehorsam 'Widerstand gegen eine als ungerecht empfundene Politik, der zwar gesetzeswidrig, aber gewaltlos erfolgt' (Duden Online 2012: ZIVIL) ziviler Notstand 'Naturkatastrophe'

b. Zivildienst 'Ersatzdienst für Wehrdienstverweigerer' Zivilehe 'Ehe, die im Standesamt geschlossen wurde'

(143) a. civiele staat 'Familien-, Personenstand' civiele verdediging 'Gesamtheit der nichtmilitärischen Aufgaben zum Schutz der Bevölkerung im Verteidigungsfall' civiele luchtvaart 'zivile (d.h. nicht zu militärischen Zwecken gebrauchte) Luftfahrt/Zivilluftfahrt'

b. (keine Bildungen im Gebrauch)

Die Daten der gegenwartssprachlichen Korpora des Deutschen (ZEIT, LEXNEX) bestätigen diese Divergenz. Komposita mit zivil als Erstglied sind im ZEIT-Korpus sehr häufig, unter ihnen auch eine Reihe von Hapaxen, z.B. Zivilbüro, Zivilkarriere, Zivilneurose. Im Niederländischen gibt es hingegen kaum Belege für die $\mathrm{A}+\mathrm{N}-$ Komposition mit civiel.

53 „Die soziale Frage, [...] die Frage nach den Forderungen und Rechten der unteren Klassen, vor allem der Arbeiterklasse“ [Übersetzung: SFS]. 
Laut DWB ist die Komposition mit zivil als Erstglied im Deutschen erst im 19. und 20. Jahrhundert intensiviert worden:

[...] dem 19. und 20. jh. gehört die mehrzahl der im 16. und 17. jh. vereinzelten, im 18. jh. immer noch spärlichen zivil-zss. an (s. d.); insbesondere das neuzeitliche heereswesen und die groszen kriege des 19./20. jhs. haben zahlreiche dieser bildungen in umlauf gesetzt [...] (DWB: zIVIL, 1956; Hervorhebung im Original)

Es handelt sich also ähnlich wie bei Komposita mit sozial im Deutschen um eine Entwicklung des 19. und 20. Jahrhunderts, wobei Bildungen mit zivil schon etwas früher belegt sind: Im Bilder-Conversations-Lexikon (1837-1841) ist erstmals ein Lemma mit einem Kompositum mit zivil (nämlich Civilrecht) verzeichnet. Davor sind im Conversations-Lexikon (1809-1811) bereits eine Reihe von Wortbildungen im Volltext zu finden (u.a. Civilangelegenheiten, Civilbehörde, Civilpersonen etc.). Im Gegensatz dazu kennt weder das WNT eindeutige Beispiele für niederländische $\mathrm{A}+\mathrm{N}-$ Komposita mit civiel noch sind in den NLLEX-Lexika des ausgehenden 19. und beginnenden 20. Jahrhunderts entsprechende Bildungen verzeichnet.

Diese eindeutige Situation - das Deutsche erlaubt Komposition und Phrasenbildung, im Niederländischen sind ausschließlich Phrasen zulässig - wird durch einen nicht geringen Teil an phrasalen Benennungseinheiten mit Schwa-Apokope verkompliziert, vgl. die im Primärmaterial $\mathrm{zu}$ findenden Verbindungen in (144)-(145):

(144) a. het sociaal fonds 'Sozialfonds', het sociaal kapitaal 'Sozialkapital'

b. de sociaal geneeskundige 'Sozialarzt', de sociaal geograaf 'Sozialgeograph', de sociaal psycholoog 'Sozialpsychologe', de sociaal raadsman 'Sozialberater', de sociaal rechercheur 'Sozialdetektiv', de sociaal werker 'Sozialarbeiter'

(145) a. het civiel bestuur 'Zivilverwaltung'

b. de civiel ingenieur 'Zivilingenieur', de civiel technicus 'Ziviltechniker'

Die Beispiele in (144a) bzw. (145a) entsprechen Typ 1, die Beispiele in (144b) bzw. (145b) Typ 2 der in Kapitel 4.4.2 aufgeführten Klassifikation von Phrasen mit Schwa-Apokope. Fälle des Typs 2 (Titel- und Berufsbezeichnungen) sind bereits Mitte des 20. Jahrhunderts verzeichnet und insofern ein verkomplizierender Faktor, da sie in einigen Wörterbüchern analog zu den Entlehnungen sociaaldemocrat bzw. sociaaldemocratie als (mit Bindestrich) zusammen geschriebene Verbindungen aufgenommen wurden. 
(146) a. Koenen (1966); Van Dale (1984); Koenen (1986):

sociaal-directeur, sociaal-geneeskundige, sociaal-geograaf, sociaalpsycholoog

b. Koenen (1909) - Koenen (1986): civiel-ingenieur

c. Koenen (1986): civiel-technicus

Erst in Van Dale (2005) werden all diese Verbindungen getrennt geschrieben (außer sociaal-directeur, das nicht mehr verzeichnet wird). ${ }^{54}$ Zwar handelt es sich um Phrasen mit Schwa-Apokope, dennoch neigen Sprecher manchmal zur Zusammenschreibung solcher Bildungen, vgl. die folgenden Belege mit sociaal aus dem LEXNEX-Korpus in (147): ${ }^{55}$

sociaalantropoloog '-anthropologe', sociaalassistent '-arbeiter', sociaaldarwinist '-darwinist', sociaalfilosoof '-philosoph', sociaalgeograaf '-geograph', sociaalgeriaters '-geriater', sociaalgeneeskundige '-arzt', sociaalhistoricus '-historiker', sociaalpsycholoog (-loge) '-psychologe', sociaal-pedagoog '-pädagoge', sociaaltherapeute '-therapeut', sociaalverpleegkundige '-pfleger', sociaalwetenschapper '-wissenschaftler', sociaalwerker '-arbeiter' (daneben sind im Korpus auch entsprechende Bezeichnungsformen mit Suffix für die weibliche Berufsbezeichnung zu finden)

Solche Korpusbelege vermitteln den Eindruck, dass das Niederländische doch über eine Reihe von Komposita mit sociaal als Erstglied verfüge, da die Betonung als überprüfbares Kriterium ausfällt (und sicher untersuchenswert ist) und beide Wörter zusammen oder mit Bindestrich geschrieben werden. Die Zusammenschreibung gilt im Übrigen auch für eine Reihe von Bildungen, die keine Berufsbezeichnungen darstellen:

(148) a. [...] en bovendien in kringen waar sociaalcontact ['soziale Kontakte', SFS] met Duitsers iemand automatisch 'fout” maakte. (NRC, 27.3.2003)

b. 'Na ons de zondvloed' heeft niets van doen met sociaalliberalisme ['Sozialliberalismus', SFS], niets met liberalisme, niets met conservatisme, niets met groenrechts en niets met rentmeesterschap. (LC, 14.9.2010)

54 Die Getrenntschreibung entspricht der offiziellen Rechtschreibung des Niederländischen, festgelegt im Groene Boekje (einsehbar im Internet unter www.woordenlijst.org).

55 Der einzige relevante Treffer für civiel war civieltechnici. 
c. Het gonst van de geruchten dat Skype zou gaan samenwerken met sociaalnetwerk ['soziales Netzwerk', SFS] Facebook (500 miljoen gebruikers). (NRC, 7.10.2010)

d. Ik heb ze gezegd: ik respecteer het sociaalplan ['Sozialplan', SFS] dat tot 2011 van kracht is. (NRC, 29.1.2007)

e. Al jaren is hij teamleider en coördinator van een sociaalpension ['Pensionsunterkunft für sozial benachteiligte Personen', SFS] van het Leger in Amsterdam-Zuid, een tehuis voor vijftig voormaligdaken thuislozen [...]. (VK, 22.12.2005)

f. In de jaren vijftig nam hij ook afstand van het sociaalrealisme ['Sozialrealismus', SFS] en ontwikkelde een lyrische en fantastische toon [...]. (VK, 8.8.2001)

Auch diese Belege bleiben formal mehrdeutig. Die Zusammenschreibung suggeriert einen möglichen Kompositionsstatus. Der syntaktische Kontext ist aber nicht immer eindeutig (in einigen Fällen würde die Flexionsendung regulär ausfallen, z.B. bei sociaalcontact) bzw. es kann nicht ausgeschlossen werden, dass es sich lediglich um Phrasen mit Schwa-Apokope (des Typs 1, also A+N-Verbindungen mit het-Nomen, die ggf. eine Bedeutungsspezialisierung erfahren haben) handelt, die entgegen der geltenden Norm zusammen geschrieben werden. Nur die Fälle in (149), ebenfalls Suchresultate im LEXNEX-Korpus, sind dann tatsächlich potenzielle Komposita, da sie weder Bildungen des Typs 1 (es sind keine hetNomen) noch des Typs 2 (es handelt sich nicht um Personen-/Berufsbezeichnungen) sind:

de sociaaldienst 'sozialer Dienst', de sociaaleconomie 'Sozialwirtschaft', de sociaalpedagogie 'Sozialpädagogik', de sociaalpolitiek 'Sozialpolitik'

Dies sind allerdings Einzelfälle, eventuell gefördert durch die Existenz etablierter komplexer Adjektive wie sociaal-economisch 'sozialökonomisch', sociaal-politiek 'sozialpolitisch' etc. (vgl. auch civiel-rechtelijk und civiel-technisch). Es kann also weiterhin angenommen werden, dass die Komposition mit Relationsadjektiven im Niederländischen nahezu ausgeschlossen ist. Funktionsbezeichnungen mit Schwa-Apokope wie in (144b) und (145b) sind allerdings sehr frequent - in der Tat sogar frequenter als Verbindungen mit den untersuchten qualitativen Adjektiven (vgl. hierzu Kap. 5.4).

Die historische Entwicklung von Verbindungen mit sozial - sociaal und zivil - civiel bestätigt den gegenwartssprachlichen Zustand im Deutschen und Niederländischen. Im Deutschen sind von Beginn an (also etwa Anfang bis Mitte des 19. Jahrhunderts) sowohl phrasale als auch morphologische Benennungseinhei- 
ten möglich. Im Niederländischen ist allein die phrasale Realisierung üblich, wobei hier Phrasen mit Schwa-Apokope eine besondere Rolle spielen. Sobald es sich um eine Berufs- bzw. Titelbezeichnung handelt, weisen entsprechende A+NVerbindungen eine Schwa-Apokope auf. Hier ist die Annahme eines eigenen (Sub-)Konstruktionsschemas plausibel (vgl. dazu Kap. 5.5).

\subsection{Phrasen mit Schwa-Apokope als dritter Weg?}

Wie im letzten Abschnitt deutlich wurde, sind im historischen Primärmaterial des Niederländischen neben Komposita und regulären Phrasen auch eine Reihe von Phrasen mit Schwa-Apokope belegt. Problematisch ist bisweilen, dass es sich zwar um Phrasen handelt, diese aber aufgrund des Flexionsausfalls und der in Wörterbüchern häufigen Zusammenschreibung Wortbildungen zu sein scheinen. Dies legt zunächst nahe, dass es sich um reguläre Konkurrenzsituationen zwischen Phrase und Kompositum handelt, vgl. die folgenden Beispiele:

(150) a. het rode weeskind (Van Dale 1961, 1984, 2005)

het roodweeskind (Van Dale 2005)

b. rood koper (Hoogstraten 1704 bis Van Dale 2005)

roodkoper (Sicherer/Akveld 1870 bis Van Dale 2005)

c. stil water (Van Dale 1924, 1961, 1984, 2005)

stilwater (Van Dale 1924, 1961, 1984, 2005)

d. geel bloedloogzout (Van Dale 1924, 1961, 1984, 2005)

geelbloedloogzout (Van Dale 1961, 1984)

Angaben zur Betonung in neueren Wörterbüchern zeigen allerdings, dass in all diesen Beispielen die Hauptbetonung auf dem Nomen liegt, d.h., es handelt sich hier um die phrasalen Benennungseinheiten (der Deutlichkeit halber getrennt geschrieben) rood wéeskind, rood kóper, stil wáter, geel blóedloogzout. Auffällig ist, dass fast alle Phrasen mit Schwa-Apokope im Primärmaterial ein het-Nomen als Kopf haben, also nur Verbindungen des Typs 1 darstellen (vgl. Kap. 4.4.2). Die einzige systematische Ausnahme stellen Personen-/Berufsbezeichnungen mit den Relationsadjektiven dar, die bereits in Kapitel 5.3 behandelt wurden (z.B. de sociaal geograaf).

Bei einigen Bildungen lässt sich zeigen, dass die Schwa-Apokope nicht von Beginn an die etablierte Form war, sondern dass sie zunächst mit der regulären Phrase konkurrierte. Ein Beispiel hierfür ist die Entwicklung von geheim agent 'Geheimagent' (mit Schwa-Apokope), das erstmalig in Van Dale (1924) verzeichnet ist. Die Verbindung konnte offenbar zunächst auch in regulärer Form verwen- 
det werden. So ist die Titelübersetzung eines Romans von Joseph Conrad, The Secret Agent, in der Übersetzung aus dem Jahre 1979 noch De geheime agent, in der Version aus dem Jahre 1997 aber De geheim agent. Auch eine Recherche in verschiedenen niederländischen Tages- und Wochenzeitungen seit 1994 zeigt, dass trotz der inzwischen deutlichen Präferenz für die Variante mit Schwa-Apokope die reguläre Form noch bis zu einem gewissen Grad verwendet wird, vgl. Tabelle 5.21 (agente ist das Femininum zu agent; Recherche am 12.9.2012).

Tab. 5.21: Verbindungen mit geheim und agent(e) in niederländischen Zeitungen seit 1994 (VK, NRC, LC, GA)

\begin{tabular}{llclc}
\hline Status & Singular & Frequenz & Plural & Frequenz \\
\hline P regulär & geheim agent $(e)$ & 47 & geheime agenten & 268 \\
P mit Schwa-Apokope & geheim- $\emptyset$ agent $(e)$ & 1381 & geheim- $\emptyset$ agenten & 638 \\
\hline
\end{tabular}

Auch bei sociaal werker 'Sozialarbeiter' legen Wörterbücher eine Entwicklung von der regulären Phrase zur Phrase mit Schwa-Apokope nahe. Erstmalig in Van Dale (1961) wird auch in den folgenden Wörterbüchern im Primärmaterial - Koenen (1966), Van Dale (1984) und Koenen (1986) - nur die Phrase sociale werker bzw. sociale werkster ('Sozialarbeiterin') verzeichnet. In Van Dale (2005) wird erstmals vom sociaal werker, sociaal werkster (neben der geschlechtsneutralen Form sociaal werkende) gesprochen. Bei allen anderen Verbindungen mit sociaal scheint die Realisierung mit Schwa-Apokope aber von Beginn an die Norm gewesen zu sein.

Die Konkurrenz zwischen regulären Phrasen bzw. Komposita und Phrasen mit Schwa-Apokope ist - bei qualitativen Adjektiven - ein relativ seltenes Phänomen im Primärmaterial, wenn man dazu die Menge an regulären phrasalen Bildungen ins Verhältnis setzt. Vereinzelte Beispiele finden sich für Verbindungen mit zwart, rood, geel, stil, geheim, für die daher angenommen wird, dass es sich um Einzelfälle handelt, die durch Lexikalisierung eine klassifikatorische Bedeutung erhalten bzw. eine Schwa-Apokope erworben haben. Lediglich für sociaal ergibt sich ein produktiver Subtyp. Bei civiel sind im Primärmaterial nur zwei Verbindungen mit Schwa-Apokope belegt, die allerdings ebenfalls als Berufsbezeichnungen verwendet werden. Eventuell ist der Benennungsbedarf einfach geringer als für Bildungen mit sociaal. Mit Ausnahme der Relationsadjektive scheinen Phrasen mit Schwa-Apokope also keine dritte, systematisch genutzte Option für die Benennungsbildung im Niederländischen geworden zu sein (vgl. auch die Diskussion in 6.3.2). 


\subsection{Konstruktionalisierungs- und Schematisierungsprozesse seit 1700}

In diesem Abschnitt sollen die Ergebnisse der vorgestellten Fallstudien in Beziehung zu den in Kapitel 4.5 angenommenen Konstruktionsschemata für die klassifikatorische $\mathrm{A}+\mathrm{N}$-Benennungsbildung im Deutschen und Niederländischen gesetzt werden. Dort war die Annahme, dass für beide Sprachen jeweils zwei lexikalisch unterspezifizierte Schemata für die klassifikatorische A+N-Benennungsbildung angenommen werden können. Außerdem wurde von einer großen Anzahl Mikro-Konstruktionen ausgegangen, die lexikalisch vollständig spezifizierte Benennungseinheiten darstellen und taxonomisch mit den höhergestellten Schemata verbunden sind (vgl. Abb. 4.5 am Beispiel des Deutschen). In den Abbildungen 5.3 und 5.4 wird dies um die Erkenntnisse ergänzt, die sich aus der historischen Untersuchung der $\mathrm{A}+\mathrm{N}-$ Verbindungen für die klassifikatorische Benennungsbildung seit 1700 ergeben haben. Dadurch ergibt sich ein wesentlich differenzierteres Bild.

Die historischen Daten zeigen, dass in der linguistischen Beschreibung für einige der untersuchten Adjektive lexikalisch teilspezifizierte Subschemata angenommen werden können, die sich zu unterschiedlichen Zeitpunkten vor oder während des Untersuchungszeitraums entwickelt haben. Die Subschemata (z.B. $\mathrm{NL}\left[\operatorname{stil}_{\mathrm{AP}} \mathrm{N}\right]_{\mathrm{N}}{ }^{0}$ ) sollen besonders produktive Bildungsprozesse abbilden (vgl. Booij 2010: 51-52), denn die vorliegenden Daten zeigen, dass für einige Adjektive die Frage einer Konkurrenz von Phrase und Kompositum überhaupt nicht zu stellen ist. Vielmehr zeichnen sie sich durch sehr klare Präferenzen zugunsten der einen oder anderen Strategie aus, wobei diese Präferenzen z.T. auch durch semantische oder pragmatische Beschränkungen charakterisiert werden können (bei DE negativ liegt beispielsweise eine komplementäre Verteilung zwischen fachsprachlichem und gemeinsprachlichem Gebrauch sowie ein besonders produktives Subschema in der Bedeutung 'nachteilig, schlecht' vor). Subschemata werden nur dann angenommen, wenn die untersuchten Daten sehr deutlich auf eine Präferenz hinweisen (indem etwa 80\% der Bildungen entweder morphologisch oder syntaktisch realisiert werden). Zudem ist $\mathrm{zu}$ unterscheiden zwischen Adjektiven, die schon vor der Annahme eines produktiven Subschemas in A+N-Benennungseinheiten auftreten, zunächst aber noch keine deutlichen Präferenzen zeigen (dies gilt z.B. für DE geheim, für das bereits im 17. Jahrhundert Verbindungen belegt sind), und solchen Adjektiven, die erst im Laufe der Zeit überhaupt in $\mathrm{A}+\mathrm{N}-$ Verbindungen in Erscheinung treten, dann aber umgehend und nahezu ausschließlich in einem bestimmten Konstruktionsmuster auftreten (vgl. DE fremd, NL diep). 

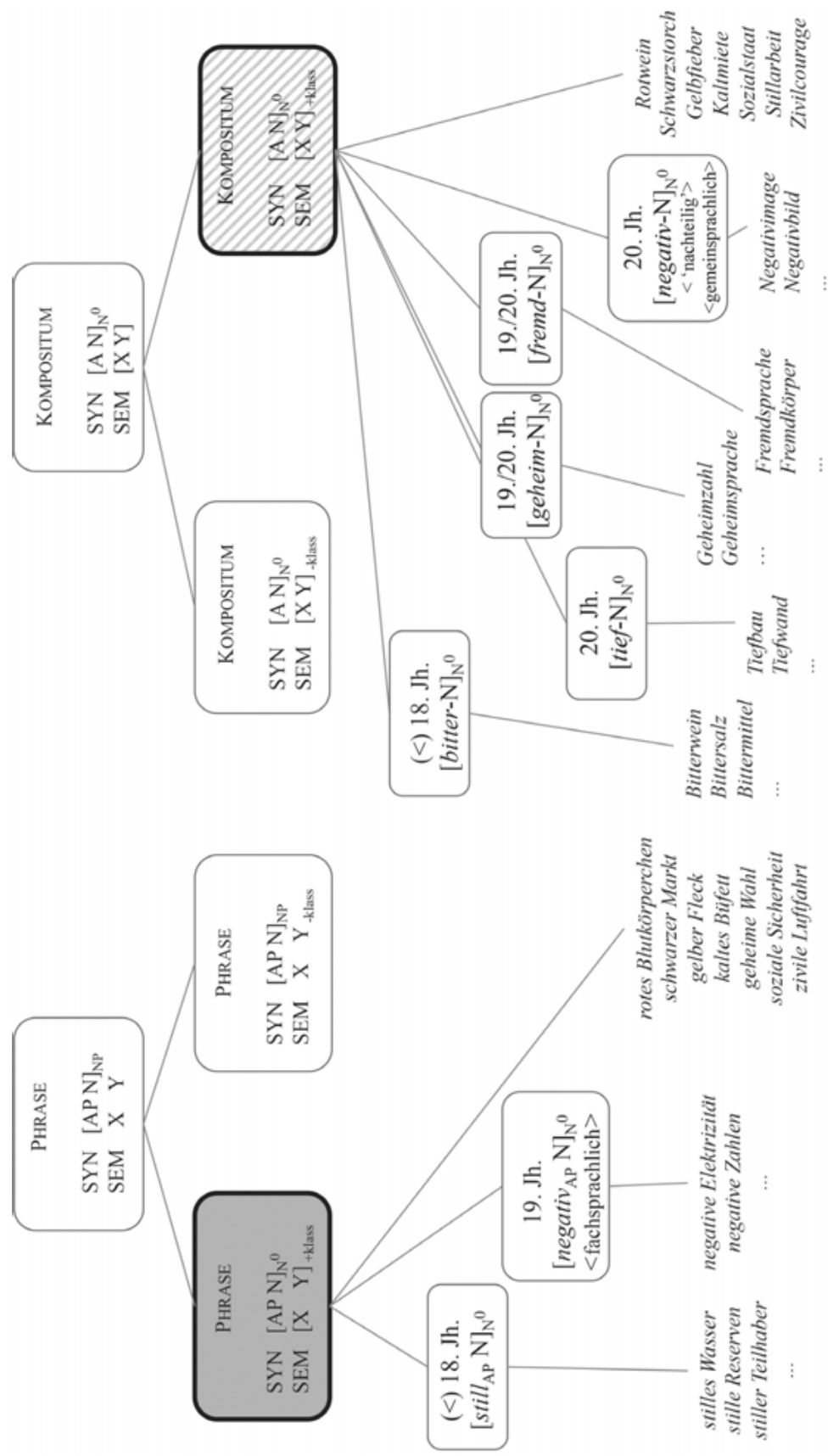

Abb. 5.3: Schemahierarchien im Deutschen 

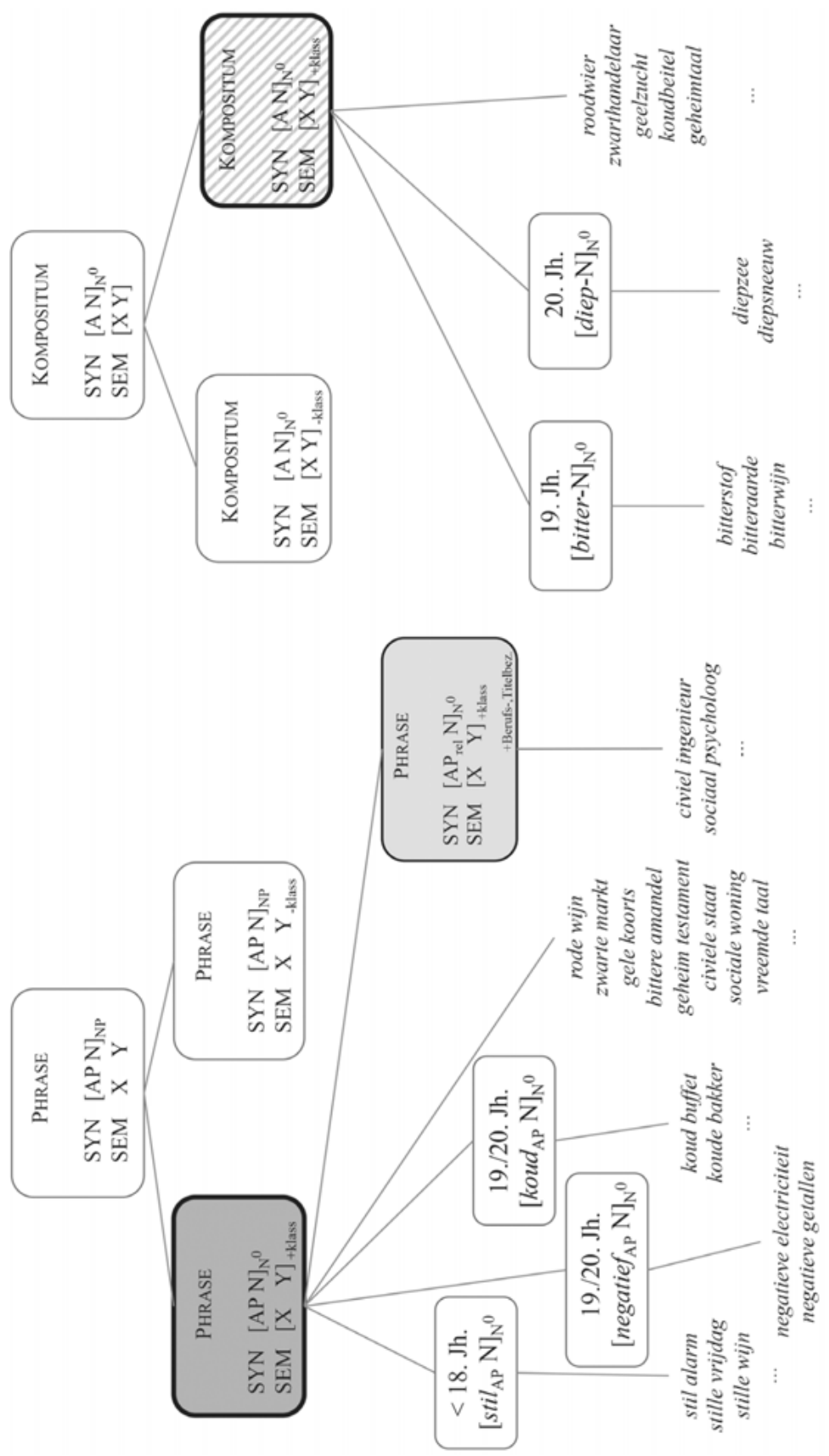

Abb. 5.4: Schemahierarchien im Niederländischen 
Die Entstehung dieser Subschemata kann als schematization bezeichnet werden, d.h. als „one kind of a more general phenomenon one could dub constructionalization, i.e. the kind through which partially or fully schematic constructions arise“ (Noël 2006: 17; Hervorhebung im Original). Die Schemata stellen Verallgemeinerungen über Sets von Mikro-Konstruktionen dar, die im Laufe der Zeit gebildet und lexikalisiert wurden und die Sprecher aufgrund von morphologischen und/oder semantischen Parallelen unbewusst als ähnlich empfinden (vgl. Bybee 1995: 430; Traugott 2014: 6).

In den Abbildungen 5.3 und 5.4 ist die Entstehung der angenommenen Subschemata unterschiedlich datiert. Für still - stil gilt z.B. die Annahme, dass bereits vor 1700 deutliche Realisierungspräferenzen bestehen, während sich diese für andere Adjektive erst in der Folge herausbilden. Da die Daten nur auf einer qualitativen Analyse beruhen, ist sicherlich Vorsicht geboten. Beispielsweise ist die Annahme von Subschemata für NL bitter und koud weniger naheliegend als für stil oder diep, da phrasale Verbindungen mit bitter bzw. Komposita mit koud durchaus im Niederländischen existieren. Nur eine genaue quantitative Analyse könnte diese Annahmen untermauern. Meines Erachtens stellen die angenommenen Subschemata jedoch eine brauchbare erste Annäherung an die komplexe Realität der diachronen Entwicklung der A+N-Verbindungen und ihrer gegenwärtigen Distribution dar. Darüber hinaus bedeutet die Annahme von Subschemata nicht, dass Ausnahmen nicht möglich seien (vgl. z.B. DE Stillarbeit oder NL negatieflijst). Diese werden im Modell aber direkt auf die allgemeinen Konstruktionsmuster für klassifikatorische A+N-Komposition bzw. A+N-Phrasenbildung zurückgeführt. Gleiches gilt auch für Adjektive, für die bezüglich ihrer Bildungspräferenzen keine eindeutigen Aussagen getroffen werden können (d.h. für die untersuchten Farbadjektive schwarz - zwart, rot - rood, gelb - geel sowie für DE kalt, sozial, zivil und NL geheim). Hier sind Komposition und Phrasenbildung weiterhin gleichberechtigte Bildungsverfahren. Einige Adjektive spielen kaum eine Rolle, z.B. NL vreemd, das im Niederländischen lediglich in wenigen phrasalen Benennungseinheiten auftritt. Für die Relationsadjektive gilt, dass sie im Niederländischen zwar eindeutig phrasale Bildungspräferenzen zeigen (zur Annahme eines zusätzlichen Subschemas, vgl. unten). Allerdings werden die Präferenzen als Inputbeschränkung des allgemeinen Schemas der klassifikatorischen $\mathrm{A}+\mathrm{N}$ Komposition im Niederländischen interpretiert, so dass keine eigenen phrasalen Subschemata für sociaal und civiel, die durchweg phrasale Benennungseinheiten ausbilden, angenommen werden. Für NL negatief wird hingegen ein eigenes phrasales Subschema angenommen, da - wie in Kapitel 4.6 besprochen - nicht klar ist, ob die Tatsache, dass mehrsilbige Adjektive i.d.R. nicht in niederländischen Komposita auftreten, nur eine Gebrauchsnorm oder eine strukturelle Beschränkung des Wortbildungsmusters widerspiegelt. 
Im Sprachvergleich fällt auf, dass sich die für die Gegenwart festgestellten divergierenden Präferenzen zwischen dem Deutschen und dem Niederländischen auch in der historischen Entwicklung widerspiegeln. Im Untersuchungszeitraum kann für das Deutsche von der Entwicklung einer Reihe von Subschemata für die $\mathrm{A}+\mathrm{N}-$ Komposition ausgegangen werden, während die Entwicklung im Niederländischen insgesamt ausgeglichener ist. Während auf der Ebene allgemeiner Schemata nicht von einem grundlegenden Wandel gesprochen werden kann - beide Konstruktionsmuster bleiben in beiden Sprachen über die Jahrhunderte hinweg produktiv - zeigen sich auf der Ebene lexikalisch teilspezifizierter Schemata einige Unterschiede. Ein weiterer Kontrast ist die Annahme eines zusätzlichen Subschemas für phrasale A+N-Verbindungen im Niederländischen, die sich durch drei Besonderheiten auszeichnen: 1. Der adjektivische Slot wird durch morphologisch komplexe Relationsadjektive wie die untersuchten sociaal oder civiel besetzt (daher die Markierung $\mathrm{A}_{\text {rel }}$ ); 2. Am Adjektiv entfällt die Flexionsendung - $e$ (SchwaApokope); 3. Die Verbindungen sind Berufs- bzw. Titelbezeichnungen. Wie in Kapitel 5.3 argumentiert, kann hier von einem produktiven Konstruktionsschema ausgegangen werden, aus denen Bildungen wie sociaal psycholoog oder civiel ingenieur hervorgegangen sind. Für Verbindungen mit monomorphemischem, qualitativem Adjektiv und Schwa-Apokope wird hingegen angenommen, dass diese nicht Resultat eines produktiven Musters zur Bildung klassifikatorischer Einheiten sind. Vielmehr handelt es sich bei diesen Verbindungen meines Erachtens um lexikalisierte Einzelfälle (vgl. Kap. 5.4). Ob dieses Schema bereits zu Beginn des Untersuchungszeitraums oder erst für das letzte Jahrhundert angenommen werden kann, kann nicht eindeutig entschieden werden; daher ist die Entstehung des Schemas in Abbildung 5.4 nicht zeitlich bestimmt. Fast alle Berufs-/Titelbezeichnungen mit sociaal und civiel und Schwa-Apokope stammen zwar aus dem 20. Jahrhundert, aber es ist nicht klar, ob eine Untersuchung der Bildungspräferenzen am Beispiel anderer Relationsadjektive hier zu zeitlich abweichenden Ergebnissen führen würde.

In den vorliegenden Übersichten steht die Entwicklung klassifikatorischer $\mathrm{A}+\mathrm{N}-$ Verbindungen im Mittelpunkt. In den folgenden Abschnitten soll die Diskussion um die historische Entwicklung der $\mathrm{A}+\mathrm{N}-$ Verbindungen ergänzt und anhand des Materials Thesen zu Korrelationen zwischen Form und Bedeutung, die in Kapitel 4.6 erläutert wurden, auf ihre historische Richtigkeit überprüft werden. Außerdem werden die erwähnten Univerbierungsprozesse genauer betrachtet. Wandel äußert sich nämlich nicht nur in Form von (Sub-)Schematisierungsprozessen, sondern findet auch auf der Ebene der Mikro-Konstruktionen statt. 


\subsection{Entwicklung der A+N-Verbindungen unter semantischen Gesichtspunkten}

In diesem Abschnitt wird die historische Entwicklung der A+N-Verbindungen aus semantischer Sicht behandelt. In Kapitel 4.6 wurden einige gegenwärtig stabile Korrelationen zwischen Form und Bedeutung vorgestellt. Die Validität dieser Korrelationen wird in diesem Abschnitt anhand der erhobenen Daten überprüft. Es geht dabei erstens um die Korrelation zwischen metaphorischer Bedeutung und phrasaler Struktur bzw. possessiver Bedeutung und morphologischer Struktur, zweitens um die Korrelation zwischen der Form und den einzelnen Bedeutungen polysemer Adjektive und drittens um die internen Modifikationsrelationen in Phrasen und Komposita.

\subsubsection{Metaphorische und metonymische Verbindungen}

Die vorliegenden Daten zeigen, dass die gegenwärtig vorhandene Korrelation zwischen metaphorischen bzw. metonymischen Verbindungen und einer syntaktischen bzw. morphologischen Struktur bereits im 18. Jahrhundert etabliert und seitdem stabil geblieben ist. Vgl. einige Beispiele in (151)-(152):

(151) Phrasen mit metaphorischer Interpretation

a. DE bittere Pille 'etwas sehr Unangenehmes', gelber Engel 'Mitarbeiter der Straßenwacht des ADAC', kalte Dusche 'Ernüchterung', rote Laterne '(Sport) Letzter in der Tabelle, Rangfolge etc.'

b. NL bittere pil 'bittere Pille', koude douche 'kalte Dusche', rode draad 'roter Faden', zwart goud 'Kohle; Mineralöl' (wörtl. 'schwarzes Gold')

(152) Komposita mit metonymischer/possessiver Interpretation

a. DE Bitterwurzel 'gelber Enzian', Gelbkreuz 'Senfgas', Kaltblut 'als Zugund Lastpferd geeignetes schweres, starkes Pferd mit ruhigem Temperament', Rothaut '(abwertend; scherzhaft) nordamerikanischer Ureinwohner', Schwarzhemd 'italienischer Faschist'

b. NL bitterblad 'Stumpfblättriger Ampfer' (wörtl. 'bitter'+'Blatt'), geelbek 'Vogel mit gelbem Schnabel’ (wörtl. 'gelb’‘'Schnabel'), koudschaal 'Kaltschale', roodkorst 'Edamer Käse mit rotgefärbter Rinde' (wörtl. 'rot'+'Rinde'), zwartstip 'Pflanzenkrankheit, die zu schwarzen Tupfen führt' (wörtl. 'schwarz’+'Tupfen')

Phrasen mit einer metonymischen bzw. possessiven Interpretation sind sehr selten. (153) enthält alle im Material gefundenen eindeutig interpretierbaren Belege: 
(153) a. DE gelber Schnabel 'junger unerfahrener Mensch' (gegenwartssprachlich: Gelbschnabel), kalte Schale 'kalte Wein-, Biersuppe, die in Schalen serviert wurde' (gegenwartssprachlich: Kaltschale), schwarze Zunge 'Krankheit, bei der die Zunge schwarz wird' (Brockhaus Wahrig: SCHWARZ)

b. NL rode baard 'Mann mit rotem Bart' (ausschließlich in Des Roches 1786), koude schaal 'Kaltschale', zwartemantel 'Seidenschwanz (Singvogel)' (wörtl. 'schwarzer Mantel') $)^{56}$

Auch für diese Phrasen gelten die Bezeichnungsbereiche, die für Possessivkomposita typisch sind: Personen, Pflanzen, Tiere oder auch Krankheiten.

Komposita mit einer rein metaphorischen Bedeutung sind im Material ähnlich selten:

a. DE Rotmaus 'Lemming'

b. NL zwartjoekel '(Schimpfwort für) Menschen von dunkler Hautfarbe' (wörtl. 'schwarz'‘'Köter'); bitterappel 'Koloquinte, Kürbisgewächs, das einem Apfel gleicht' (wörtl. 'bitter'+'Apfel'); geelbal 'gelb-rundliche Kartoffelsorte' (wörtl. 'gelb’+'Ball'); roodtijger 'rotgetigertes Pferd' (wörtl. 'rot'+'Tiger')

Etwas häufiger im Material sind Possessivkomposita, denen zugleich eine metaphorische Bedeutungsrelation zugrunde liegt, z.B. Gelbschnabel 'junger unerfahrener Mensch' nach dem Bild eines jungen Vogels, der einen gelben Schnabel hat (vgl. auch NL geelbek), Rotkugel 'Pilzsorte mit roter, kugeliger Kappe' etc. Zusammenfassend kann nichtsdestoweniger von einer stabilen Korrelation von metaphorischer Bedeutung und Phrase einerseits sowie metonymischer/possessiver Bedeutung und Wortbildung in beiden Sprachen über die Jahrhunderte hinweg gesprochen werden.

Eine Besonderheit bei der Entwicklung der Possessivkomposita scheinen auf dem ersten Blick Angaben in Campes „Wörterbuch der deutschen Sprache“ (18071811) nahezulegen, die in Widerspruch zu einer u.a. von Simoska (1999: 168) genannten Verknüpfungspräferenz im Deutschen stehen. Diese Verknüpfungspräferenz besagt, dass ein A+N-Possessivkompositum, das auf Personen verweist und bei dem das Nomen einen Körperteil o.Ä. bezeichnet, keine (zusätzliche) klassifikatorische Interpretation hat. Im Widerspruch hierzu werden bei Campe

56 Zwartemantel wird offiziell zusammen geschrieben, das Adjektiv ist allerdings flektiert und auch die Betonung entspricht einem phrasalen Muster. 
vielfach Komposita mit einer possessiven Lesart zusätzlich auch mit einer klassifikatorischen Lesart aufgeführt, vgl. (155)-(156):

(155) Schwarzauge (Campe 1807-1811)

a. 'schwarzes Auge'

b. 'Geschöpf mit schwarzen Augen; Name für verschiedene Vogel- und Schneckenarten'

(156) Schwarzbart (Campe 1807-1811)

a. 'schwarzer Bart'

b. 'eine Person mit schwarzem Barte'

c. 'eine Art Papageien'

d. '[als Schwarzbärtchen] Name des Bluthänfling, Rothänfling, Flachsfinks'

Die rein klassifikatorische Lesart der Komposita in (155)-(156) kommt fast ausschließlich in Campes Wörterbuch vor (manchmal auch bei Heyne 1890-1895, der Angaben aus Campe übernimmt). Es ist deshalb nicht deutlich, ob diese Verwendungsweise eine (zeitweise gültige) systematische Möglichkeit im Deutschen war bzw. eine (zunehmende) Auflösung der von Simoska genannten Verknüpfungspräferenz darstellt. Heutzutage gibt es tatsächlich einige Komposita wie Langhaar '(bei Hunden und Katzen) Fell mit langen Haaren; (selten) lange Kopfhaare, Frisur mit langen Haaren' (Duden Online 2012: LANGHAAR), die possessiv und klassifikatorisch interpretiert werden können. Im Primärmaterial finden sich allerdings - abgesehen von den Daten bei Campe und vereinzelten Beispielen bei Heyne - kaum Beispiele, die auf eine systematische Auflösung dieser Präferenz hinweisen. Ausnahmen sind:

(157) Schwarzmantel (Kramer 1700-1702)

a. 'Mantel nero, Casacca nera'(= 'Schwarzer Mantel, schwarze Uniform')

b. 'Uno che lo porta'(= 'eine Person, die ihn [d.h. den Schwarzmantel, SFS] trägt')

(158) Schwarzhemd (Duden Online 2012)

a. 'schwarzes Hemd als Teil der Uniform faschistischer Organisationen, bes. in Italien'

b. '(meist Pl.) Träger des Schwarzhemds'

Weitere Beispiele sind Rotnase 'rote Nase, u.a. gerötet von der Wärme etc.' bei Kramer (1700-1702) und Rotkopf 'Kopf eines rothaarigen Menschen' im Duden (1999) bzw. Duden Online (2012). Insgesamt handelt es sich aber zumindest bei Benennungseinheiten um Einzelfälle. Da die Zuschreibung von klassifikatorischer und 
possessiver Lesart bei Campe so regelmäßig ist und praktisch jedes Kompositum mit einer possessiven Lesart betrifft, wird hier davon ausgegangen, dass es sich entweder um eine nicht verallgemeinerbare Wahrnehmung des Verfassers oder um eine aus unbekannten Gründen getroffene lexikografische Konvention handelt. Nur bei Komposita, die - abgesehen von Campe und Heyne - in mindestens einem weiteren Wörterbuch auch eine klassifikatorische Lesart aufweisen, ist die Annahme beider Lesarten plausibel. Dies kommt allerdings wie bereits erwähnt selten vor.

Im kreativen Sprachgebrauch ist die Verwendung von A+N-Komposita, in denen das Nomen einen Körperteil etc. bezeichnet, mit einer klassifikatorischen Interpretation häufiger. So verweist Simoska (1999: 168-169) auf Beispiele aus der Werbesprache wie Rotnase (siehe oben) und Blaßgesicht. Sie nennt auch historische Beispiele, die die zumindest zeitweilig mögliche klassifikatorische Interpretation solcher der Form nach typischen Possessivkomposita stützen, z.B. Dickbein aus dem DWB ('Oberschenkel'; das Wort ist allerdings weder im DWDS -Kernkorpus noch im ZEIT-Korpus belegt):

\section{DICKBEIN, $\mathrm{n}$.}

1. das bein von der hüfte bis zum knie, diech, schenkel femur [...] auch das dicke bein, eine musketenkugel hatte mich am dicken bein gestreift CHR. WEISE Erznarren 70.

2. eine münze [...] (DWB: DickBEIN, 1860; Hervorhebung im Original)

Tatsächlich ist dick in Dickbein eine volksetymologische Umdeutung des mittelhochdeutschen Nomens diech 'Schenkel' und damit ursprünglich kein Adjektiv (vgl. Duden Online 2012: DiCKBEIN). Es ist demnach nur aus synchroner Sicht als $\mathrm{A}+\mathrm{N}$-Kompositum mit klassifikatorischer Lesart einzustufen. Interessanterweise wird im DWB-Eintrag als Formvariante auch die Phrase das dicke Bein geführt, die gemäß der oben genannten Verknüpfungspräferenz als normkonformer gelten müsste. Dickbein ist also kein überzeugender Beleg für eine klassifikatorische Interpretation. Auch die anderen von Simoska genannten Bildungen, nämlich Breitschädel, Fettbauch, Schiefhals, Spitzkopf und Stumpfnase, stützen ihre These nur zum Teil. Für Breitschädel habe ich gar keinen Eintrag im DWB, für Fettbauch und Schiefhals nur Einträge mit eindeutig possessiver Lesart oder mehrdeutigen Belegen gefunden. Lediglich Spitzkopf und Stumpfnase lassen laut DWB eine klassifikatorische Lesart zu. Im Übrigen existieren auch im Niederländischen zumindest im Primärmaterial keine lexikalisierten Komposita mit possessiver und gleichzeitig klassifikatorischer Lesart. Das Kompositum zwarthemd 'Schwarzhemd' (erstmals in Van Dale 1961) beispielsweise wird nur als Bezeichnung für italienische Faschisten geführt, nicht aber für ihre Uniformhemden (vgl. hingegen (158)). 
Die Korrelation zwischen possessiver Bedeutung und morphologischer Form war und ist in beiden Sprachen also ebenso stabil wie die Korrelation zwischen metaphorischer Bedeutung und phrasaler Form. Eine zusätzliche klassifikatorische Lesart bei den Possessivkomposita ist prinzipiell möglich, aber nicht verbreitet. Damit bestätigt sich, dass der Bereich der klassifikatorischen Verbindungen für die Frage nach dem Verhältnis von Variation und Wandel auch in den letzten drei Jahrhunderten am relevantesten war und immer noch ist.

\subsubsection{Formkorrelationen bei polysemen Adjektiven}

Die meisten der untersuchten Adjektive tragen mehrere, voneinander abgrenzbare Bedeutungen. Zumeist sind diese Bedeutungen in beiden Sprachen identisch, in Einzelfällen können sie allerdings auch abweichen wie bei DE fremd NL vreemd: Im Niederländischen hat das Adjektiv neben den auch im Deutschen gängigen Bedeutungen (1. 'nicht dem eigenen Land oder Volk angehörend'; 2. 'einem anderen gehörend; einen anderen, nicht die eigene Person, den eigenen Besitz betreffend'; 3. 'unbekannt; nicht vertraut; ungewohnt', vgl. Duden Online 2012: FREMD) ebenfalls die Bedeutung 'komisch, sonderbar, wunderlich', die im Deutschen jedoch veraltet ist.

Im vorliegenden Primärmaterial sollte genauer analysiert werden, ob einzelne Adjektivbedeutungen mit einer Präferenz für die morphologische oder syntaktische Benennungsbildung korrelieren und ob sich dieses Verhältnis seit 1700 gewandelt hat. Dabei hat sich schnell gezeigt, dass eine solche Analyse mit dem vorliegenden Material schwierig ist, da die Belegmenge hierfür zu klein ist. Aufgrund dessen werden im Folgenden nur einige besonders auffällige Beispiele besprochen.

Generell lässt sich sagen, dass die Distribution von Kompositum und Phrase in einigen Aspekten durchaus regelmäßig ist und zwar so, wie es von Barz (1996) bereits vorausgesagt wurde: Metaphorische Verwendungsweisen von Adjektiven korrelieren durchweg mit phrasaler Form. Die metaphorische Bedeutung 'unheilvoll, düster, böse' ist bei schwarz bzw. zwart fast ausnahmslos in phrasalen Benennungseinheiten anzutreffen, vgl. die Beispiele in (160):

(160) a. DE schwarzer Humor, schwarze Magie, schwarzer Freitag

b. NL zwarte humor, zwarte magie, zwarte vrijdag

Die einzige Ausnahme ist das Kompositum Schwarzkunst, das zeitweilig in der gleichen Bedeutung wie schwarze Kunst, schwarze Magie verwendet wurde, 
heutzutage aber zumindest in Wörterbüchern nur mit der Bedeutung 'Kupferstech-' bzw. 'Schabkunst' geführt wird. Im ZEIT-Korpus gibt es noch einige wenige Belege für die Lesart als 'schwarze Magie':

Die Produktionsweise erinnert an Schwarzkunst und Goldmacherei. Es glüht und qualmt, dann zischt es und knallt, und am Ende hält der Meister ein Stück Metall ans Licht. (ZEIT, 18.11.2004)

Im Niederländischen existiert im Primärmaterial kein Beispiel für eine solche Verwendungsweise, wobei allerdings auch weniger morphologische Benennungseinheiten belegt sind. Bei einigen Verbindungen ist die genaue Bedeutung von schwarz - zwart nicht eindeutig bestimmbar, z.B. bei schwarzer Kasten - zwarte doos (Lehnübersetzungen von EN black box, d.h. Flugschreibern, die jedoch i.d.R. nicht schwarz sind).

Auch Verbindungen mit bitter bieten interessante Beobachtungen. In beiden Sprachen hat bitter die folgenden vier Bedeutungen (vgl. Duden Online 2012 bzw. Van Dale Online 2012, leicht modifiziert):

(162) a. 'einen sehr herben (bis ins Unangenehme gehenden) Geschmack aufweisend'

b. 'schmerzlich; als verletzend, kränkend empfunden, z.B. eine bittere Enttäuschung'

c. i. 'verbittert, z.B. die Erfahrung hat ihn bitter gemacht';

ii. 'beißend, scharf, z.B. bittere Ironie'

d. i. 'stark, groß, schwer, z.B. bittere Kälte';

ii. 'sehr (bei Verben), z.B. etw. bitter bereuen'

Die erste Bedeutung kann ohne Weiteres in etablierten Phrasen und Komposita mit Benennungsfunktion auftreten. Alle anderen Bedeutungen sind fast ausschließlich in Phrasen, meist Kollokationen, zu finden. Nur in Einzelfällen existieren im Deutschen Komposita, in denen bitter als Erstglied auftritt und eine andere Bedeutung als die in (162a) hat, vgl. (163)-(164) (wobei beide Verbindungen - gemessen an den hohen Trefferzahlen bei einer Googlesuche, 3.4.2013 allerdings nicht völlig unüblich sind).

(163) Sogar die Sowjetunion erstrebte nach dem Zweiten Weltkrieg die Anerkennung ihrer Eroberungen in Osteuropa und erhielt sie 1975 auf der KSZE-Konferenz in Helsinki. Damals nahm Moskau mit Bittermiene den so genannten Korb drei entgegen, der die Achtung der Menschenrechte in Europa einforderte. (ZEIT, 2.12.1999) 
[...] diese Brusttöne, die manchmal von so tief unten kamen, daß man sich fragte, warum sie nicht den kürzeren Weg wählten, die spitzen Schreie der Betroffenheit, die Zähren des Bittersinns, und dann das satte Grinsen. (ZEIT, 8.4.1994)

Selbst wenn es sich bei Bittermiene und Bittersinn um lexikalisierte Bildungen handeln sollte, betrifft dies nur zwei von 48 Types mit bitter als Erstglied im ZEIT-Korpus. Mit anderen Worten: Die hauptsächlich in Komposita realisierte Bedeutung ist 'herber Geschmack'. Im Niederländischen scheint der Zusammenhang zwischen Adjektivbedeutung und Form noch stärker zu sein. Unter allen im LEXNEX-Korpus und LCA gefundenen Komposita (lexikalisierte und okkasionelle Verbindungen) sind ausschließlich Komposita mit bitter in der Bedeutung 'herber Geschmack' zu finden (vgl. die Beispiele (108)-(109) in Kap 5.2.1) Auch bei neuen Benennungseinheiten wie bittersinaasappel 'Bitterorange' hat bitter diese Bedeutung. Das Niederländische ist hier also weniger permissiv als das Deutsche.

Das niederländische Adjektiv rood in der Bedeutung 'politisch, ideologisch links' scheint nur in phrasalen Benennungseinheiten vorzukommen, vgl. rooie rakker 'überzeugter, militanter Sozialist' (rooie ist eine Aussprachevariante von rode, der flektierten Form von rood), rode jeugd 'in sozialistischen/kommunistischen Verbänden organisierte Jugendliche'. Dies zeigt sich auch bei Eigennamen wie het Rode Leger 'Rote Armee' oder het Rode Plein 'der Rote Platz' (in Moskau). Diese sind zwar nicht unmittelbar Gegenstand dieser Untersuchung, verdeutlichen aber einen weiteren Einflussfaktor, nämlich die Rolle des Sprachkontakts für die Bildung von Benennungseinheiten. Im Russischen, das als Quelle für die Bezeichnung in anderen Sprachen gedient haben dürfte, wird die A+N-Phrase Krasnaja Ploščcad' verwendet. Im Deutschen, Englischen und Französischen wird die Bezeichnung (analog zum Niederländischen) ebenfalls phrasal als Roter Platz, Red Square und Place Rouge realisiert. Sprachkontakt und Lehneinflüsse sind bei der Frage nach der Korrelation von Form und Adjektivbedeutung, genau genommen sogar bei der allgemeineren Frage nach der Distribution von Phrase und Kompositum, also nicht zu vernachlässigen (vgl. hierzu auch Kap. 6.5).

\subsubsection{Indirekte Modifikationsrelationen bei Phrasen und Komposita}

Wie in Kapitel 4.3 bereits dargestellt, kann in der semantischen Struktur einer Adjektiv-Nomen-Verbindung zwischen fünf verschiedenen Modifikationsrelationen unterschieden werden. Von diesen fünf Relationen wird laut Schlücker (2014) 
nur die direkte Modifikationsrelation systematisch in A+N-Phrasen realisiert, in Komposita hingegen seien auch indirekte Modikationsrelationen systematisch zulässig, vgl. (165)..$^{57}$

(165) a. direkte Modifikationsrelation: Kleinkind, saure Sahne

b. indirekte Modifikationsrelation:

Rundbrief 'Brief, der rundgeschickt wird'

Schnellgericht 'Gericht, das schnell zubereitet werden kann'

Scharfschütze 'Schütze, der scharf schießt'

Einige Ausnahmen zu dieser Regel sind laut Schlücker (2014: 126) die Phrasen kompletter Preis, depressive Neurose, nervöser Magen, möblierter Herr (vgl. auch Zifonun/Hoffmann/Strecker 1997: 1996). Auch im vorliegenden Primärmaterial weisen einige Komposita indirekte Modifikationsrelationen auf:

(166) DE

a. Bitterfäule 'Fruchtfäule mit runden, braunen, zuletzt eintrocknenden Faulstellen, die den Früchten einen bitteren Geschmack geben' (Brockhaus Wahrig 1980-1984)

b. Fremdbesitz '(Rechtsspr.) Besitz, den jmd. für sich nutzen kann, ohne Eigentümer zu sein (z.B. Mietwohnung)' (Duden 1999)

(167) NL

a. koudslachter 'Abdecker; der tote (und damit auch kalte) Tiere häutet' (wörtl. 'kalt'+'Schlachter')

b. roodgieter 'Kupfergießer' (wörtl. 'rot'+'Gießer')

Allerdings gibt es auch eine ganze Reihe von Phrasen im historischen Primärmaterial, für die eine implizite Modifikationsstruktur angenommen werden kann:

(168) a. DE gelbes Fieber 'Gelbfieber'

gelbe Sucht 'Gelbsucht'

kaltes Büfett 'Büfett mit zur Selbstbedienung angerichteten kalten Speisen'

kalte Mamsell 'für Zubereitung und Ausgabe der kalten Speisen zuständige Angestellte in einem Restaurant o.Ä.'

kalte Platte 'Platte mit kalt angerichteten Speisen'

57 Der fünfte, von Schlücker (2014) aufgeführte semantische Typ (Possessivkomposita) wird hier nicht berücksichtigt. 
b. NL geheim testament 'Testament, das dem Notar versiegelt übergeben wird und dessen Inhalt daher nicht bekannt ist' gele koorts 'Gelbfieber' koude bakker 'Verkäufer von nicht selbst gebackenen Backwaren' koud buffet 'kaltes Büffet' koude (kern)fusie 'kalte Kernfusion' koude smid 'Schmied, der ohne Feuer arbeitet'

Indirekte Modifikationsrelationen sind bei Phrasen also auf den ersten Blick keine absoluten Ausnahmen. Im Primärmaterial weisen vor allem Verbindungen mit gelb/geel und kalt/koud indirekte Modifikationsrelationen auf. Einige andere Beispiele, die neben einer direkten zumindest auch eine indirekte Interpretation zulassen, sind DE geheime Polizei (nicht die Polizei, sondern ihre Tätigkeiten bleiben geheim) oder NL geheim agent 'Geheimagent' (wenn nicht die Tätigkeit, aber einzelne Aktionen geheim bleiben).

Interessanterweise lässt sich für einen Teil dieser Verbindungen nachweisen, dass sie im Laufe der Zeit durch Komposita verdrängt werden - ein Wandel, der in erster Linie für das Deutsche gilt: gelbes Fieber > Gelbfieber, kalte Miete > Kaltmiete. Indirekte Modifikationsrelationen kommen also durchaus bei Phrasen vor, werden aber oftmals durch Komposita mit der gleichen Bedeutung verdrängt, so dass aus gegenwärtiger Sicht der Eindruck entstehen kann, dass es sich um ein seltenes Phänomen (v.a. im Deutschen) handele. Allerdings müssen hier auch andere Faktoren eine Rolle spielen, da einige Phrasen wie DE kaltes Büfett oder NL gele koorts durchaus stabil sind. Außerdem kann die Annahme, dass indirekte Modifikationsrelationen bei Phrasen nur unsystematisch vorkommen, nur einzelsprachlich gültig sein. Da im Niederländischen trotz der prinzipiellen Möglichkeit zur Komposition weitaus mehr Phrasen als im Deutschen vorkommen, scheint es logisch, dass die indirekte Modifikationsrelation dort häufiger in Phrasen anzutreffen und prinzipiell stabiler ist.

Schließlich ist auch der Verdrängungsprozess durch Komposita nicht nur bei Phrasen mit indirekter Modifikationsrelation $\mathrm{zu}$ beobachten, sondern betrifft ebenso Phrasen mit einer direkten Modifikationsrelation (wie rotes Wild $>$ Rotwild). Die Ersetzung phrasaler durch morphologische Benennungseinheiten stellt also ein allgemeineres Phänomen dar und wird im folgenden Abschnitt ausführlich behandelt. 


\subsection{Konkurrierende Benennungseinheiten}

Die auffälligste Veränderung bei der Entwicklung der A+N-Verbindungen seit dem 18. Jahrhundert bezieht sich auf die Konkurrenz syntaktischer und morphologischer Einheiten bei der Benennung gleicher Konzepte. Für eine ganze Reihe von Konzepten können im Primärmaterial Dubletten belegt werden, d.h. Phrasen und Komposita mit identischem Adjektiv und Nomen, die die gleiche Bedeutung haben bzw. hatten und als Benennungseinheiten fungier(t)en, vgl. z.B.:

$\mathrm{DE}$

gelbes Fieber - Gelbfieber

schwarzer Tee - Schwarztee

(170) $\mathrm{NL}$

koude schaal - koudschaal 'Kaltschale'

zwarte handelaar - zwarthandelaar'Schwarzhändler'58

Die Ko-Existenz beider Formen ist meist von begrenzter Dauer, langfristig verdrängt eine die andere Form. Dies gilt insbesondere dann, wenn die Benennungseinheiten eine deutliche Bedeutungsspezialisierung erfahren haben. In der Mehrheit der Fälle verdrängt die morphologische Benennungseinheit die syntaktische. Dies gilt insbesondere für das Deutsche und bestätigt Erbens These, wonach im Deutschen eine „strukturelle Tendenz zur U n i v e r b i e r u n g [...], d.h. das Bestreben, statt einer umständlichen, mehrgliedrigen Zeichenkette ein einziges komplexes Wort als grammatischen Baustein im Satz und als Benennung der bezeichneten Sache zu gewinnen“ (Erben 2006: 25; Hervorhebung im Original) bestehe. Das Deutsche wird immer wieder im Lichte starker Univerbierungstendenzen beschrieben (vgl. auch Fleischer 1997). Im begrenzteren Umfang scheint dies auch für das Niederländische zu gelten (siehe unten). Univerbierung ist ein zentrales Konzept dieser Arbeit und wird in Bezug auf die Unterschiede zwischen dem Deutschen und dem Niederländischen in Kapitel 6.2 detaillierter behandelt. An dieser Stelle werden zunächst die Entwicklung der Dubletten im Primärmaterial und Unterschiede zwischen dem Deutschen und dem Niederländischen beschrieben.

58 NL koude schaal und zwarte handelaar werden in den verwendeten Wörterbüchern zusammen geschrieben. Aus Gründen der Einheitlichkeit werden sie hier ebenso wie andere Phrasen getrennt geschrieben. 
Vorsicht ist bei der Analyse angebracht, da sich einige potenzielle Beispiele für Univerbierungstendenzen im Wortschatz bei genauerer Untersuchung nicht als Verdrängung einer Phrase durch ein Kompositum erweisen, sondern es im Zuge der Neubildung eines Kompositums zu einer Bedeutungsspezialisierung kommt. Ein Beispiel für einen solchen Prozess ist die Entwicklung von fremde Sprache und Fremdsprache im Deutschen. Beide Verbindungen sind im Duden Online (2012) verzeichnet, wobei fremde Sprache als Kollokation eingestuft werden kann (mit fremd in der Bedeutung 'nicht dem eigenen Land oder Volk angehörend; eine andere Herkunft aufweisend'), aber bereits in Kramer (1700-1702) belegt ist. Fremdsprache, eine Neubildung des ausgehenden 19., frühen 20. Jahrhunderts, wird hingegen als 'fremde Sprache, die sich jemand nur durch bewusstes Lernen aneignet; Sprache, die nicht jemandes Muttersprache ist' beschrieben (Duden Online 2012: Fremdsprache). Da die Phrase in ihrer Bedeutung allgemein bleibt, sind trotz der spezialisierten Bedeutung beide Verbindungen in vielen Kontexten austauschbar:

(171) a. Sprachgrenzen sind letztlich nur zu überwinden, wenn die Leute fremde Sprachen lernen. Die bisher nur kläglichen Leistungen der automatischen Übersetzung stellen kein Versprechen dar, daß ihnen der Computer diese Mühe je abnehmen könnte. (ZEIT, 6.5.1999)

b. Sprachgrenzen sind letztlich nur zu überwinden, wenn die Leute Fremdsprachen lernen. [...] (eigene Umformung)

Eine Ersetzung durch Fremdsprache ist hier ohne Probleme möglich; vgl. hingegen die folgende Gegenüberstellung beider Verbindungen:

Für den Dichter, von dem hier die Rede sein soll, ist Deutsch eine fremde Sprache, jedoch keine Fremdsprache. Es war seine Muttersprache, doch heute ist Hebräisch die Sprache seiner Gedichte und Träume. (ZEIT, 1.2.1991)

Phrase und Kompositum sind also nicht prinzipiell bedeutungsgleich; vielmehr hängt ihre Interpretation vom Kontext ab, so dass sie sogar in Opposition zueinander treten können. Die Phrase fremde Sprache, so zeigt sich, ist viel flexibler in ihrer Bedeutung und kann neben der Bedeutung von Fremdsprache auch andere Bedeutungen von fremd ausdrücken. Nicht immer lassen sich also zwei formale Dubletten als Konkurrenten betrachten. 


\subsubsection{Globale Entwicklung von $\mathrm{A}+\mathrm{N}-$ Konkurrenzen}

In diesem Abschnitt sind in zwei Tabellen alle Dublettenpaare im deutschen und niederländischen Primärmaterial aufgeführt. Dubletten müssen zwei Bedingungen erfüllen: 1. Auf Grundlage der Bedeutungsbeschreibung ist anzunehmen, dass sie die gleiche Bedeutung haben; 2. Der Benennungsstatus als solcher ist zumindest in einem Teil der Quellen zweifelsfrei anzunehmen (vgl. die genannten Kriterien in Kap. 5.1). ${ }^{59}$

Sofern eine Form die andere verdrängt (d.h., ausschließlich die dominante Form wird in wenigstens zwei folgenden Wörterbüchern verzeichnet oder ein Metakommentar legt eine entsprechende Entwicklung nahe), wird sie typografisch durch Fettdruck hervorgehoben. In allen anderen Fällen handelt es sich entweder um aktuelle Konkurrenzsituationen oder beide Begriffe sind kurz nacheinander aus dem Gebrauch verschwunden (hier annäherungsweise gemessen am Vorkommen in etablierten Wörterbüchern). Bei weniger geläufigen Verbindungen wird die Bedeutung kurz umschrieben. Der weitere Kommentar dient der groben Orientierung bei der Entwicklung der Konkurrenz. ${ }^{60}$

\subsubsection{Konkurrierende Bildungen im Deutschen}

Im Deutschen sind konkurrierende A+N-Verbindungen im gesamten Zeitraum sehr häufig und treten bei fast allen untersuchten Adjektiven auf, vgl. Tabelle 5.22.

Die Wörterbuchanalyse legt nahe, dass im Normalfall Phrasen durch Komposita verdrängt werden. Dies gilt im Deutschen für etwa $4 / 5$ aller Fälle, in denen es $\mathrm{zu}$ einer Entscheidung gekommen ist. Bei fünf Paaren setzt sich die Phrase langfristig durch und zwar bei geheimer Vorbehalt, kaltes Fieber, kalte Pisse, rote Ruhr, stille Messe, wobei für jede Phrase unterschiedliche Ursachen angenommen werden könnten. Die Phrase geheimer Vorbehalt ist fachsprachlich; auf die (allerdings nicht unumstrittene) Annahme, dass Fachsprachen verstärkt zu phrasaler Realisierung tendieren, wurde in Kapitel 4.6 hingewiesen. Die Komposita Kaltfieber und Kaltpisse konkurrieren mit entsprechenden Phrasen zu einem Zeitpunkt, als die Komposition mit kalt noch wenig verbreitet ist. Außerdem scheint bei klassifikatorischen Krankheitsbezeichnungen eine Tendenz zur Phrasenbil-

59 Aufgrund dieser Kriterien konnte eine ganze Reihe von Bildungen nicht in die folgenden Tabellen aufgenommen werden, da meines Erachtens nicht immer beide Bedingungen erfüllt waren. Sie sind im Anhang aufgeführt.

60 Für eine visuelle, chronologische Übersicht nach Wörterbüchern vgl. ebenfalls den Anhang. 
dung zu bestehen (vgl. auch die rote Ruhr). Die morphologische Benennungsbildung mit still schließlich ist stets marginal geblieben, insofern erklärt sich die dauerhafte Nicht-Etablierung von Stillmesse scheinbar von selbst. Es handelt sich hier allerdings um reine Ad-hoc-Erklärungen, ein systematischer Trend ist nicht erkennbar. Bedeutungsdifferenzierungen scheinen kaum relevant zu sein, lediglich für schwarze Kunst - Schwarzkunst kommt es laut Primärmaterial zur Differenzierung.

Tab. 5.22: Dubletten im deutschen Primärmaterial seit $1700^{61}$

\begin{tabular}{|c|c|c|}
\hline Phrase & Kompositum & Kommentar \\
\hline bittere Mandel & Bittermandel & $\begin{array}{l}\text { P seit 18. Jh, K erst im 20. Jh.; noch nicht } \\
\text { entschieden }\end{array}$ \\
\hline geheime Polizei & Geheimpolizei & $\begin{array}{l}\text { P zu Beginn des 20. Jh. noch gängig; im PM nur } \\
\text { im Duden (1999) mit der Bemerkung „selten“ } \\
\text { verzeichnet }\end{array}$ \\
\hline geheimer Rat & Geheimrat & $\begin{array}{l}\text { beide seit } 200 \text { Jahren etabliert, weitgehend } \\
\text { synonym }\end{array}$ \\
\hline geheime Tinte & Geheimtinte & P nur bei Campe, $\mathrm{K}$ ab BH Wahrig durchgängig \\
\hline geheimer Vorbehalt & Geheimvorbehalt & K nur in BH Wahrig, $\mathrm{P}$ durchgängig ab BH Wahrig \\
\hline gelbes Fieber & Gelbfieber & P von Heyne bis BH Wahrig; $K$ ab WDG durchgängig \\
\hline gelbes Holz & Gelbholz & $\begin{array}{l}\text { 'Holzsorte', die gelb färbt; allerdings nicht klar, ob } \\
\text { heutiges K noch dieselbe Holzsorte bezeichnet }\end{array}$ \\
\hline gelber Körper & Gelbkörper & $\begin{array}{l}\text { (Medizin) corpus luteum; P nur bei Campe; } \\
\text { K erstmals bei BH Wahrig }\end{array}$ \\
\hline gelbe Rübe & Gelbrübe & 'Möhre'; Gebrauch inzwischen regional \\
\hline gelber Schnabel & Gelbschnabel & 'Grünschnabel'; P nur bei Heyne erwähnt \\
\hline gelbe Sucht & Gelbsucht & $\begin{array}{l}\text { 'Krankheit'; von Adelung bis Heyne }(=19 . \text { Jh.) } \\
\text { auch P im PM, K bereits um } 1700 \text { belegt }\end{array}$ \\
\hline kaltes Fieber & Kaltfieber & $\begin{array}{l}\text { P dominiert, inzwischen sind beide Bezeichnun- } \\
\text { gen veraltet }\end{array}$ \\
\hline kaltes Lager & Kaltlager & beide Formen kurz nacheinander veraltet \\
\hline kalte Mamsell & Kaltmamsell & im PM noch nicht entschieden \\
\hline kalte Miete & Kaltmiete & im PM noch nicht entschieden \\
\hline kalte Pisse & Kaltpisse & P setzt sich durch, inzwischen aber veraltet \\
\hline kalte Schale & Kaltschale & K setzt sich im 20. Jh. durch \\
\hline kaltes Silber & Kaltsilber & beide Formen kurz nacheinander verschwunden \\
\hline
\end{tabular}

61 In Tabelle 5.22 und 5.24 werden in der Spalte Kommentar folgende Abkürzungen verwendet: $\mathrm{P}=$ Phrase, $\mathrm{K}=$ Kompositum, $\mathrm{PM}=$ Primärmaterial, $\mathrm{BH}$ Wahrig = Brockhaus Wahrig. Die Wörterbücher werden nach Titel bzw. Verfasser verzeichnet. Vgl. Tabelle 5.2 bzw. 5.3 in Kapitel 5.1 für eine chronologische Übersicht der Wörterbücher. 


\begin{tabular}{|c|c|c|}
\hline Phrase & Kompositum & Kommentar \\
\hline negativer Rekord & Negativrekord & $\mathrm{P}$ und $\mathrm{K}$ in $\mathrm{BH}$ Wahrig; sonst nur $\mathrm{K}$ verzeichnet \\
\hline rotes Gold & Rotgold & $\begin{array}{l}\text { ‘Gold-Kupferlegierung’; nur kurzzeitige Konkur- } \\
\text { renz im 20. Jh. }\end{array}$ \\
\hline roter Kohl & Rotkohl & $\begin{array}{l}\text { ‘Gemüsesorte’; P in der 1. Hälfte 18. Jh., dann } \\
\text { abgelöst von K }\end{array}$ \\
\hline rotes Kupfererz & Rotkupfererz & $\begin{array}{l}\text { 'Mineral'; P nur bei Campe, K bei Campe, danach } \\
\text { erst wieder ab BH Wahrig }\end{array}$ \\
\hline roter Milan & Rotmilan & $\begin{array}{l}\text { 'Vogelart'; Konkurrenz im PM noch nicht } \\
\text { entschieden }\end{array}$ \\
\hline rote Ruhr & Rotruhr & $\begin{array}{l}\text { ‘Krankheit'; Konkurrenz im 18. Jh., danach } \\
\text { ausschließlich P }\end{array}$ \\
\hline roter Wein & Rotwein & $\begin{array}{l}\text { 'Weinsorte'; beide Verbindungen bis heute im } \\
\text { WB; P nur (noch) Kollokation? }\end{array}$ \\
\hline rotes Wild & Rotwild & $\begin{array}{l}\text { ‘Hirsche, Rehe’; ab } 1800 \text { P langsam durch K } \\
\text { abgelöst }\end{array}$ \\
\hline rotes Wildbret & Rotwildbret & 'Rotwild’; Formen verschwinden kurz nacheinander \\
\hline schwarzes Blech & Schwarzblech & $\begin{array}{l}\text { ‘unverzinntes Blech’; ab } 1800 \text { P langsam durch K } \\
\text { abgelöst }\end{array}$ \\
\hline schwarzes Brot & Schwarzbrot & $\begin{array}{l}\text { 'Roggenbrot'; Konkurrenz im PM noch nicht } \\
\text { entschieden; unklar, ob P im } 20 \text {. Jh. nur noch } \\
\text { Kollokation }\end{array}$ \\
\hline schwarze Ente & Schwarzente & $\begin{array}{l}\text { ‘Entenart'; beide Begriffe nur bei Campe } \\
\text { verzeichnet }\end{array}$ \\
\hline schwarzes Erz & Schwarzerz & $\begin{array}{l}\text { 'Mineral’; Konkurrenz bis Beginn 19. Jh., danach } \\
\text { K noch einmal bei BH Wahrig }\end{array}$ \\
\hline schwarzer Falke & Schwarzfalke & $\begin{array}{l}\text { 'Vogelart'; beide Begriffe nur bei Campe } \\
\text { verzeichnet }\end{array}$ \\
\hline schwarzes Geld & Schwarzgeld & $\begin{array}{l}\text { ‘illegales Geld’; noch nicht entschieden: P und K } \\
\text { im Duden (1999), nur K im Duden Online (2012) }\end{array}$ \\
\hline schwarzes Holz & Schwarzholz & $\begin{array}{l}\text { 'Nadelholz'; in der gleichen Bedeutung ver- } \\
\text { schwinden beide Formen zeitgleich; K später in } \\
\text { anderer Bedeutung ('Ebenholz') }\end{array}$ \\
\hline schwarzes Konto & Schwarzkonto & $\begin{array}{l}\text { ‘illegales Konto’; beide neu in Duden Online } \\
\text { (2012) }\end{array}$ \\
\hline schwarzer Kümmel & Schwarzkümmel & $\begin{array}{l}\text { 'Gewürzpflanze'; K allerdings auch noch mit } \\
\text { anderer Bedeutung }\end{array}$ \\
\hline schwarze Kunst & Schwarzkunst & $\begin{array}{l}\text { Konkurrenz in der Bedeutung 'schwarze Magie' } \\
\text { bis Beginn 19. Jh.; danach Bedeutungsdifferen- } \\
\text { zierung laut PM: P = 'schwarze Magie', K= } \\
\text { 'Kupferstechkunst; Schabkunst' }\end{array}$ \\
\hline schwarzes Kupfer & Schwarzkupfer & $\begin{array}{l}\text { 'ungereinigtes Kupfer’; Formen verschwinden } \\
\text { kurz nacheinander }\end{array}$ \\
\hline schwarzer Markt & Schwarzmarkt & Konkurrenz ab WDG bis einschl. Duden Online \\
\hline
\end{tabular}
(2012) 


\begin{tabular}{|c|c|c|}
\hline Phrase & Kompositum & Kommentar \\
\hline schwarze Pappel & Schwarzpappel & $\begin{array}{l}\text { 'Baumart'; ab } 1800 \text { P zunehmend durch K } \\
\text { verdrängt }\end{array}$ \\
\hline schwarzer Tee & Schwarztee & $\begin{array}{l}\text { 'Teesorte/-getränk’; P seit 19. Jh., K erstmals } \\
\text { in Duden Online (2012) }\end{array}$ \\
\hline schwarzes Wild & Schwarzwild & $\begin{array}{l}\text { 'Wildschweine'; Konkurrenz im 19. Jh., danach } \\
\text { nur noch K }\end{array}$ \\
\hline schwarzes Wildbret & Schwarzwildbret & $\begin{array}{l}\text { 'Schwarzwild'; beide Formen verschwinden } \\
\text { kurz nacheinander }\end{array}$ \\
\hline schwarze Wurzel & Schwarzwurzel & $\begin{array}{l}\text { ‘Gemüsesorte’; P nur bei Heyne verzeichnet, } \\
\text { ansonsten immer K }\end{array}$ \\
\hline stille Messe & Stillmesse & $\begin{array}{l}\text { P fast durchgängig ab } 1700 \text { verzeichnet; K nur } \\
\text { temporär bei Kramer und Campe }\end{array}$ \\
\hline stilles Pulver & Stillpulver & K nur bei Kramer, $\mathrm{P}$ nur bei Campe verzeichnet \\
\hline sozialer Beruf & Sozialberuf & $\begin{array}{l}\text { ‘Beruf ausgerichtet auf Unterstützung hilfsbe- } \\
\text { dürftiger Menschen’; bei BH Wahrig bis Duden } \\
\text { Online (2012) beide Formen verzeichnet }\end{array}$ \\
\hline soziale Leistung & Sozialleistung & $\begin{array}{l}\text { ‘unterstützende Leistungen für Arbeitnehmer’; } \\
\text { konkurrieren im 20. Jh. }\end{array}$ \\
\hline zivile Bevölkerung & Zivilbevölkerung & $\begin{array}{l}\text { 'nicht-militärischer Teil der Bevölkerung’; } \\
\text { Konkurrenz im Duden (1999) und Duden Online } \\
\text { (2012) }\end{array}$ \\
\hline zivile Ehe & Zivilehe & $\begin{array}{l}\text { K ab WDG, Konkurrenz mit P im Duden (1999), } \\
\text { Duden Online (2012) }\end{array}$ \\
\hline zivile Luftfahrt & Zivilluftfahrt & $\begin{array}{l}\text { 'nicht-militärische Luftfahrt'; erst nur P, Konkur- } \\
\text { renz mit K im Duden (1999) und Duden Online } \\
\text { (2012) }\end{array}$ \\
\hline ziviles Recht & Zivilrecht & $\begin{array}{l}\text { 'Privatrecht'; Konkurrenz im WDG, Duden (1999), } \\
\text { Duden Online (2012) }\end{array}$ \\
\hline zivile Verteidigung & Zivilverteidigung & $\begin{array}{l}\text { ‘Maßnahmen zum Schutz der Bevölkerung'; P nur } \\
\text { in BH Wahrig, K durchgängig im 20. Jh. }\end{array}$ \\
\hline
\end{tabular}

Aus methodischer Sicht besteht der Einwand, dass einige der in den Wörterbüchern verzeichneten Varianten im Gebrauch eher marginal waren, d.h., die angenommene Konkurrenz zwischen Phrase und Kompositum ist eher eine Fiktion bzw. war nur sehr eingeschränkt vorhanden. Hieraus ergibt sich die Relevanz von Korpusstudien, die Aufschluss über den tatsächlichen Gebrauch von Phrase und Kompositum geben können. In Kapitel 5.7.2 erfolgt dies für Verbindungen mit schwarz - zwart. Leider handelt es sich dabei um die einzige (wenn auch exemplarische) Fallstudie, da die Tokenfrequenzen in den verwendeten Korpora und Textsammlungen bei vielen anderen Verbindungen (wie z.B. bei kalte Mamsell/Kaltmamsell oder kalte Miete/Kaltmiete) für aussagekräftige Resultate $\mathrm{zu}$ niedrig sind. Lediglich für Bildungen mit zivil kann das ZEIT-Korpus aussage- 
kräftige Tokenfrequenzen liefern: ${ }^{62}$ Bei zivil + Bevölkerung/Ehe/Recht sind (fast) ausschließlich Komposita im Korpus belegt. Bei zivil+Verteidigung wird in etwa einem Drittel der Fälle auch die Phrase verwendet. Nur bei zivil+Luftfahrt geht der Trend zumindest in den letzten zwei Jahrzehnten zur Phrase (vgl. Tab. 5.23). Der allgemeine Trend zur Komposition ist also auch bei den Relationsadjektiven präsent.

Tab. 5.23: Tokenfrequenzen zivile Luftfahrt - Zivilluftfahrt (ZEIT-Korpus, 1946-2009)

\begin{tabular}{lcc}
\hline & zivile Luftfahrt & Zivilluftfahrt \\
\hline $1946-1949$ & 0 & 0 \\
$1950-1959$ & 11 & 16 \\
$1960-1969$ & 15 & 19 \\
$1970-1979$ & 16 & 22 \\
$1980-1989$ & 12 & 25 \\
$1990-1999$ & 23 & 14 \\
$2000-2009$ & 27 & 10 \\
\hline
\end{tabular}

\subsubsection{Konkurrierende Bildungen im Niederländischen}

Gegenüber dem Deutschen sind Konkurrenzen zwischen Phrase und Kompositum im Niederländischen seltener, wenngleich nicht ausgeschlossen. Tabelle 5.24 umfasst alle Dubletten im Primärmaterial für das Niederländische:

Tab. 5.24: Dubletten im niederländischen Primärmaterial seit $1700^{63}$

\begin{tabular}{lll}
\hline Phrase & Kompositum & Kommentar \\
\hline bittere kers & bitterkers & 'best. Sorte Kresse'; P nur bei Koenen (1909) \\
geel koper & geelkoper & 'Messing'; 18. Jh. nur P, dann ab 19. Jh. auch K \\
gele oker & geeloker & 'Mineral'; P im 20. Jh. nur in Van Dale (2005), \\
& & Kin Koenen (1937, 1966, 1986) \\
geheime middelen & geheimmiddelen & 'Geheimmittel', P nur bei Sicherer/Akveld
\end{tabular}

62 Aufgrund der immens hohen Trefferzahlen für Bildungen mit sozial und der notwendigen manuellen Überprüfung jedes einzelnen Beispiels hinsichtlich der Semantik (potenziell mögliche qualitative Lesarten!) wurde von einer Korpusanalyse der Dubletten mit sozial abgesehen. 63 Vgl. Fußnote 61. 


\begin{tabular}{|c|c|c|}
\hline Phrase & Kompositum & Kommentar \\
\hline koude bakker & koudbakker & $\begin{array}{l}\text { 'Verkäufer nicht-selbstgefertigter Backwaren’; } \\
\text { K nur bei Sicherer/Akveld, ansonsten P }\end{array}$ \\
\hline koude schaal & koudschaal & $\begin{array}{l}\text { 'Kaltschale’; bis Sicherer/Akveld beide Formen } \\
\text { verzeichnet, in Van Dale (1924) noch einmal P; } \\
\text { beide inzwischen veraltet }\end{array}$ \\
\hline koudvuur & koudvuur & $\begin{array}{l}\text { ‘Gangrän’; Konkurrenz im 18. Jh., P da bereits } \\
\text { mit Schwa-Apokope }\end{array}$ \\
\hline rode aarde & roodaarde & $\begin{array}{l}\text { ‘Kreidesorte’; im 20. Jh. beide Formen neben- } \\
\text { einander im PM }\end{array}$ \\
\hline rode baard & roodbaard & 'Mann mit rotem Bart'; P nur bei Weiland \\
\hline rode gloeihitte & roodgloeihitte & $\begin{array}{l}\text { 'best. Wärmegrad von Eisen'; in allen Van Dale } \\
\text { des 20. Jh. P und K in Konkurrenz }\end{array}$ \\
\hline rood ijzersteen & roodijzersteen & $\begin{array}{l}\text { 'Mineral'; K bei Sicherer/Akveld, ansonsten P } \\
\text { und K in allen Van Dale }\end{array}$ \\
\hline rode vos & roodvos & $\begin{array}{l}\text { 'rothaarige Person'; nur bei Des Roches }(K) \text { und } \\
\text { Weiland }(P)\end{array}$ \\
\hline rood wild & roodwild & $\begin{array}{l}\text { ‘Rotwild’; Sicherer/Akveld bis Van Dale (1961) } \\
\text { nur P; Van Dale (1984) und Koenen (1986) } \\
\text { P und K; Van Dale (2005) K }\end{array}$ \\
\hline zwarte handelaar & zwarthandelaar & $\begin{array}{l}\text { 'Schwarzhändler’; nur P in Van Dale (1961); ab } \\
\text { Koenen (1966) P und K }\end{array}$ \\
\hline zwart snot & zwartsnot & $\begin{array}{l}\text { 'Pflanzenkrankheit'; P erstmals in Van Dale } \\
\text { (1924); P und K in Van Dale }(1961,1984,2005)\end{array}$ \\
\hline zwart wild & zwartwild & $\begin{array}{l}\text { 'Schwarzwild'; P von Sicherer/Akveld bis Koenen } \\
\text { (1986); K ab Koenen (1986) }\end{array}$ \\
\hline
\end{tabular}

Allein auf Grundlage der Wörterbücher lassen sich für das Niederländische nur wenige Tendenzen bei der Entwicklung der $\mathrm{A}+\mathrm{N}$-Konkurrenzen ableiten. Nur bei drei Paaren kann eine eindeutige Entwicklung zugunsten des Kompositums festgestellt werden, nämlich bei bitterkers, geheimmiddel und koudvuur. Allerdings sind die phrasalen Einheiten jeweils nur in einem Wörterbuch belegt. Dies könnte ein Hinweis darauf sein, dass sie entweder wenig etabliert oder bereits deutlich vor 1700 verbreitet waren. Die Phrase koud vuur wird zudem nur mit SchwaApokope geführt, so dass nicht ganz ausgeschlossen werden kann, dass es als (getrennt geschriebenes) Kompositum aufgefasst wurde. Die einzige Phrase, die sich im Primärmaterial eindeutig durchgesetzt hat, ist koude bakker. Aber auch hier ist das Kompositum überhaupt nur in einem Wörterbuch, nämlich in Sicherer/ Akveld (1870), verzeichnet. 
Für alle anderen Dublettenpaare ist eine Prognose schwierig, da entweder beide Begriffe relativ schnell nacheinander verschwinden oder auch in den aktuellen Wörterbüchern immer noch als Varianten geführt werden (vgl. beispielsweise die sehr stabile lexikografische Konkurrenz von geel koper - geelkoper). Zum Teil hängt dies mit der stärkeren Neigung der Redaktion der Wörterbücher von Van Dale (etwa im Vergleich zu den Koenen-Wörterbüchern oder zum Duden) zusammen, lexikalische Einheiten nicht zu streichen, sondern weiter zu verzeichnen und ggf. mit einer Markierung (veraltet) zu versehen. Mehr noch als im Deutschen ist hier also eine Korpusanalyse unverzichtbar, um tatsächliche Trends $\mathrm{zu}$ identifizieren. Für diejenigen Verbindungen, die noch in Wörterbüchern des späten 20. Jahrhunderts verzeichnet sind, wurden daher die Tokenfrequenzen im LEXNEX-Korpus überprüft, vgl. Tabelle 5.25. Bis auf zwarte()handelaar zwarthandelaar 'Schwarzhändler' sind die Trefferzahlen aber sehr niedrig, so dass die Frequenzen bestenfalls als Indikatoren dienen können. Demnach kann bei einigen Paaren vorsichtig von einer Tendenz zum Kompositum gesprochen werden (bei rode aarde, roodwild, zwarthandelaar, zwartwild). Andere Dublettenpaare wie rode gloeihitte - roodgloeihitte, rood ijzersteen - roodijzersteen, rode olm - roodolm, zwart snot - zwartsnot sind jedoch kaum bzw. gar nicht im Korpus belegt. Für gele oker - geeloker gibt es nur vier Treffer im Korpus (davon drei Phrasen und ein Kompositum), für die die Zuordnung einer konkreten Bedeutung aus dem Kontext heraus aber nicht möglich ist.

Tab. 5.25: Ausgewählte Dubletten im Niederländischen (LEXNEX-Korpus, 1997-2011; * = Schätzung)

\begin{tabular}{lll}
\hline Dubletten & LEXNEX & Kommentar \\
\hline $\begin{array}{l}\text { geel koper } \\
\text { geelkoper }\end{array}$ & $\begin{array}{l}11 \text { Treffer } \\
7 \text { Treffer }\end{array}$ & Tendenz unklar \\
\hline $\begin{array}{l}\text { rode aarde } \\
\text { roodaarde }\end{array}$ & $\begin{array}{l}\text { 150 Treffer* } \\
0 \text { Treffer }\end{array}$ & $\begin{array}{l}\text { Phrase etabliert; genaue Bedeutung bei } \\
\text { vielen Belegen aber unklar }\end{array}$ \\
\hline $\begin{array}{l}\text { rood wild } \\
\text { roodwild }\end{array}$ & 0 Treffer & Tendenz zum Kompositum \\
\hline zwarte handelaar & 9 Treffer & \\
zwarthandelaar & 10 Treffer & Kompositum etabliert \\
\hline zwart wild & 270 Treffer* & \\
zwartwild & 1 Treffer & Tendenz zum Kompositum \\
\hline
\end{tabular}




\subsubsection{Konkurrenzen im Vergleich}

Konkurrenzsituationen im Deutschen sind deutlich häufiger als im Niederländischen. Außerdem treten Dubletten im Deutschen bei fast jedem Adjektiv auf (außer bei tief und fremd), während im Niederländischen nur die Hälfte aller Adjektive Konkurrenzpaare aufweist. Konkurrenzsituationen führen im Deutschen mehrheitlich zur Verdrängung der phrasalen durch die morphologische Benennungseinheit. Es ist hingegen wesentlich seltener der Fall, dass sich eine phrasale Verbindung langfristig gegen ein Kompositum durchsetzt. Hierbei müssen genaugenommen zwei Szenarien unterschieden werden: Im ersten Szenario ist die Phrase bereits etabliert, als das Kompositum auftritt, oder erscheint etwa gleichzeitig mit dem Kompositum. Hier setzt sich die Phrase manchmal langfristig durch, vgl. z.B. die Entwicklung von DE kaltes Fieber vs. Kaltfieber und kalte Pisse vs. Kaltpisse.

In einem zweiten Szenario ist zunächst nur das Kompositum die etablierte Einheit, wird aber allmählich von einer neuen phrasalen Einheit verdrängt. Hierfür gibt es im Primärmaterial der beiden Sprachen keinerlei Beispiele. Lediglich das WNT verweist auf zwei Fälle im Niederländischen mit rood:
a. roodhond > rodehond 'Röteln' (vgl. WNT: RODEHOND, 1920)
b. roodolm > rode olm 'Krankheit des Holzes' (vgl. WNT: RoodoLM, 1920)

Hüning (2010) nennt noch andere Beispiele für diese Entwicklung, nämlich goetdaet > goede daad 'gute Tat' und zoetwijn > zoete wijn 'Süßwein'. Mit Blick auf die vorliegenden Daten handelt es sich ingesamt gesehen jedoch um eine Randerscheinung.

Auch wenn bei der Konkurrenz von Phrase und Kompositum also keinesfalls ein Automatismus von der Phrase hin zum Kompositum angenommen werden darf, ist ein Wandel in diese Richtung sehr viel wahrscheinlicher. Dies spricht meines Erachtens für eine besondere Benennungsqualität von Komposita, die einzelsprachlich unterschiedlich stark ausgeprägt sein kann. Relevant ist hier eventuell die formale Prägnanz der Wortbildung (vgl. Barz 1988a: 20). In Kapitel 6.2 stehen die Entwicklung von Dubletten und der als Univerbierung bezeichnete Prozess der Verdrängung syntaktischer Einheiten durch Wortbildungen im Mittelpunkt. Dort wird gezeigt, dass möglicherweise auch Faktoren des Sprachgebrauchs eine Rolle bei der Ent- und Abwicklung solcher Konkurrenzen spielen können. 


\subsubsection{Fallstudie mit schwarz/zwart}

Anhand der Wörterbuchdaten lassen sich einige allgemeine Trends ableiten, die durch Korpus- und Textanalysen überprüft werden müssen. Im Zuge der Untersuchung hat sich allerdings gezeigt, dass historische Korpora und Textsammlungen i.d.R. viel zu klein sind, um über Jahrzehnte oder gar Jahrhunderte hinweg aussagekräftige Tokenfrequenzen für die meisten Dublettenpaare zu erhalten. Eine Ausnahme stellen A+N-Verbindungen mit schwarz - zwart in der Bedeutung 'illegal, ohne behördliche Genehmigung' dar. Bei diesen Verbindungen kann auf moderne Text- und Korpusmaterialien zurückgegriffen werden, da sich diese Bedeutung in attributiver Verwendung oder als Erstglied eines Kompositums erst im 20. Jahrhundert im Deutschen und Niederländischen etabliert hat. Zudem finden sich viele der Verbindungen in Zeitungsartikeln $\mathrm{zu}$ den Themen Politik, Gesellschaft und Wirtschaft wieder und diese stellen den Großteil der verwendeten modernen Korpusquellen. Im Folgenden sollen daher am Beispiel der Verbindungen mit schwarz - zwart wesentliche Punkte der Entwicklung von Dubletten erläutert und Unterschiede zwischen dem Deutschen und dem Niederländischen aufgezeigt werden.

Die Bedeutung 'illegal, ohne behördliche Genehmigung' bei schwarz - zwart in attributiven Wendungen ist eine Innovation des 20. Jahrhunderts. Bis zu diesem Zeitpunkt werden im Zusammenhang mit dem Adjektiv in beiden Sprachen nur zwei Bedeutungen in Nominalphrasen bzw. A+N-Komposita realisiert: 'dunkle Farbe' und 'pessimistisch, traurig, böse, gemein' sowie daran anschließende metaphorische Bedeutungen. Im Gegensatz hierzu verzeichnen sowohl Duden Online (2012) als auch Van Dale (2005) eine große Menge an A+N-Verbindungen - Kollokationen und Benennungseinheiten - mit schwarz bzw. zwart in der Bedeutung 'illegal', vgl. die Beispiele in (174)-(175) (in beiden Sprachen versprachlichte Konzepte sind fettmarkiert):

(174) Bildungen mit schwarz 'illegal' im Duden Online (2012)

a. Phrasen: schwarze Börse, schwarzes Geld, schwarzes Geschäft, schwarzes Konto, schwarzer Markt

b. Komposita: Schwarzbau, Schwarzgeld, Schwarzgeschäft, Schwarzhandel, Schwarzhändler, Schwarzkauf, Schwarzkonto, Schwarzmarkt, Schwarzschlachtung, Schwarzsender 
(175) Bildungen mit zwart 'illegal' in Van Dale (2005)

a. Phrasen: zwarte boekhouding (boekhouding = 'Buchhaltung'), zwart geld ('Schwarzgeld'), zwarte goederen (goederen = 'Güter'), zwarte handel ('Schwarzhandel'), zwarte handelaar ('Schwarzhändler'), zwarte loon (loon = 'Lohn'), zwarte markt ('Schwarzmarkt'), zwarte prijzen (prijs $=$ 'Preis')

b. Kompositum: zwarthandelaar ('Schwarzhändler')

Die Bedeutung hat sich also offensichtlich erst im Laufe des 20. Jahrhunderts in Nominalphrasen und Komposita verbreitet. Etymologisch geht sie laut Kluge (1995: 748) wohl auf das Verb schwärzen zurück (vgl. auch die Bedeutungszuschreibung bei SchwäRzER (DWB, 1899) als 'Schmuggler, Schleichhändler'), das bereits im 18. Jahrhundert gebraucht wurde und so viel wie 'schmuggeln' bedeutet. In der Folge muss das Adjektiv diesen Bedeutungsaspekt übernommen haben:

[...] von geschmuggelten waaren sagt man: schwarz herein (über die grenze) kommen, vielleicht weil man bei nacht zu schmuggeln pflegt [...], so dasz schwarz hier gewissermaszen prädicativisch im sinne von 'dunkel, in der dunkelheit' stände, oder weil die schmuggler sich das gesicht schwärzen, um sich unkenntlich zu machen. (DWB: SCHWARZ, 1899)

Dem „Etymologisch Woordenboek van de Nederlandse Taal“ zufolge hat das Niederländische diese Bedeutung aus dem Deutschen entlehnt. Die ersten Verwendungen mit zwart als attributivem Modifikator in der beschriebenen Bedeutung im LCA stammen aus den 1940er Jahren. Im DWDS-Kernkorpus, einem Referenzkorpus der deutschen Sprache im 20. Jahrhundert, tritt das Adjektiv in einer $\mathrm{A}+\mathrm{N}-$ Verbindung bereits 1921 auf (und zwar im Kompositum Schwarzmarkt).

Wie in (174)-(175) deutlich, gibt es gegenwärtig mehrere Dubletten im Deutschen, nämlich schwarzer Markt - Schwarzmarkt, schwarzes Geld - Schwarzgeld, schwarzes Konto - Schwarzkonto, während im Niederländischen lediglich das Paar zwarte handelaar - zwarthandelaar auftritt. Für alle Dubletten wurden die Tokenfrequenzen im ZEIT-Korpus (1946-2009) bzw. im Leeuwarder Courant Archief (1940-2009) ermittelt. Dabei spiegeln die ermittelten Daten einen Trend wider, den die Wörterbücher noch nicht anzeigen (vgl. Tab. 5.22 bzw. 5.24), nämlich den zunehmenden Gebrauch der Wortbildungen Schwarzmarkt und zwarthandelaar (vgl. Tab. 5.26 bzw. 5.27). ${ }^{64}$

64 Die Tokenfrequenzen basieren auf Suchanfragen im ZEIT-Korpus, die allerdings des Öfteren Wiederholungen enthielten und deshalb manuell überprüft werden mussten. Die Gesamtanzahl an Treffern entspricht also nicht den „Brutto“-Angaben im ZEIT-Korpus. 
Tab. 5.26: Tokenfrequenzen schwarzer Markt - Schwarzmarkt (ZEIT-Korpus, 1946-2009)

\begin{tabular}{llc}
\hline & schwarzer Markt & Schwarzmarkt \\
\hline $1946-1949$ & 158 & 19 \\
$1950-1959$ & 48 & 26 \\
$1960-1969$ & 39 & 18 \\
$1970-1979$ & 91 & 48 \\
$1980-1989$ & 77 & 196 \\
$1990-1999$ & 41 & 232 \\
$2000-2009$ & 14 & 193 \\
\hline
\end{tabular}

schwarzer Markt $\square$ Schwarzmarkt

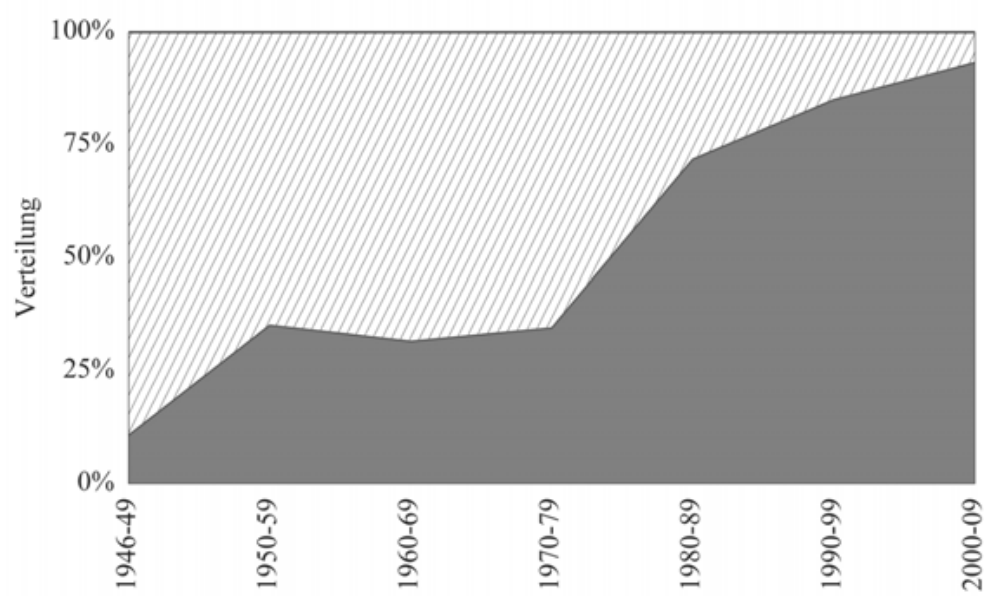

Abb. 5.5: schwarzer Markt vs. Schwarzmarkt (ZEIT-Korpus, 1946-2009)

Tab. 5.27: Tokenfrequenzen zwarte()handelaar - zwarthandelaar (LCA, 1940-2009)

\begin{tabular}{lclc}
\hline & zwarte handelaar & zwartehandelaar & zwarthandelaar \\
\hline $1940-1949$ & 104 & 9 & 53 \\
$1950-1959$ & 22 & 2 & 15 \\
$1960-1969$ & 6 & 2 & 21 \\
$1970-1979$ & 9 & 1 & 55 \\
$1980-1989$ & 5 & 5 & 45 \\
$1990-1999$ & 3 & 0 & 103 \\
$2000-2009$ & 1 & 0 & 54 \\
\hline
\end{tabular}




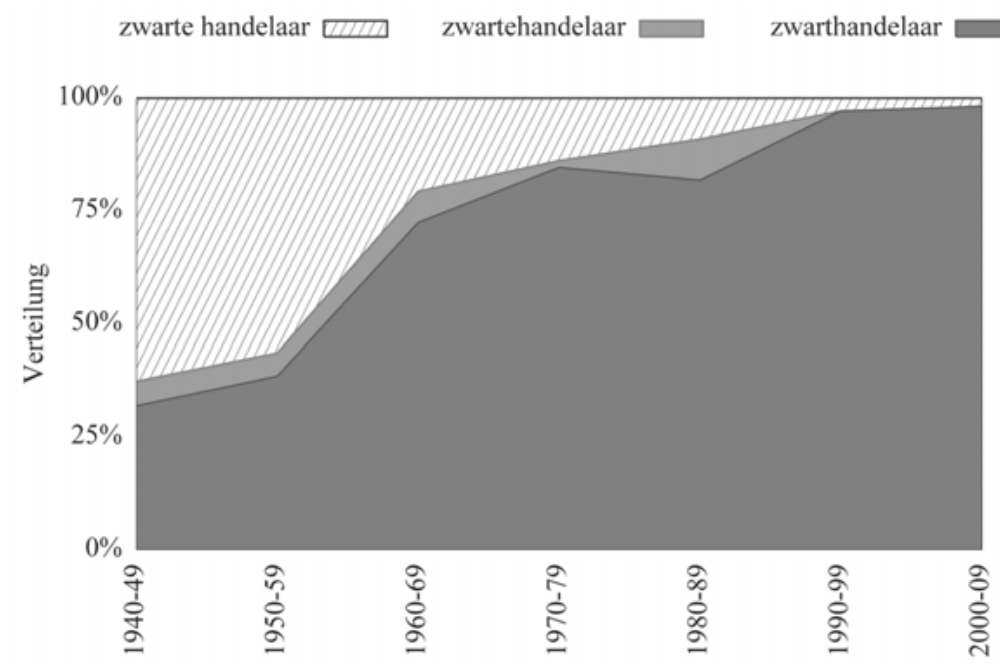

Abb. 5.6: zwarte()handelaar vs. zwarthandelaar (LCA, 1940-2009)

Bei schwarzer Markt - Schwarzmarkt dominiert bis Ende der 1970er Jahre die Phrase, auch wenn das Kompositum zunehmend an Terrain gewinnt und ab den 1980er Jahren die Phrase immer mehr verdrängt. Im Niederländischen zeigt sich bei zwarte handelaar - zwarthandelaar eine ähnliche Entwicklung, wobei das Kompositum jedoch schon in den 1960er Jahren dominiert, vgl. Tabelle 5.27.65 In beiden Sprachen laufen also Univerbierungsprozesse ab.

Allerdings gibt es auch zwischensprachliche Unterschiede. Erstens kann anhand verschiedener Verbindungen für das Deutsche gezeigt werden, dass die Univerbierung von der Phrase zum Kompositum umgreifender ist und sich nicht nur auf schwarzer Markt - Schwarzmarkt beschränkt, sondern z.B. auch auf schwarzes Geld - Schwarzgeld und die noch relativ neuen Verbindungen schwarzes Konto - Schwarzkonto zutrifft (vgl. Tab. 5.28).

65 Zur Erinnerung: zwarte handelaar wird bisweilen auch zusammen geschrieben, v.a. in Wörterbüchern, im LCA allerdings mehrheitlich getrennt. Bei der Korpusrecherche wurden alle drei Formen berücksichtigt. 
Tab. 5.28: Tokenfrequenzen verschiedener Verbindungen mit schwarz (ZEIT-Korpus, 1946-2009)

\begin{tabular}{lcccc}
\hline & schwarzes Geld & Schwarzgeld & schwarzes Konto & Schwarzkonto \\
\hline $1946-1949$ & 5 & 0 & 0 & 0 \\
$1950-1959$ & 2 & 0 & 0 & 0 \\
$1960-1969$ & 0 & 1 & 0 & 0 \\
$1970-1979$ & 13 & 11 & 0 & 1 \\
$1980-1989$ & 11 & 14 & 2 & 0 \\
$1990-1999$ & 12 & 45 & 11 & 3 \\
$2000-2009$ & 15 & 144 & 35 & 18 \\
\hline
\end{tabular}

Im Vergleich hierzu haben sich im Niederländischen bisher kaum morphologische A+N-Benennungseinheiten mit zwart in der Bedeutung 'illegal' entwickelt. Eine Suche nach strukturell zulässigen Komposita als mögliche Alternativbildungen zu etablierten lexikalischen Phrasen im LCA zeigt, dass Wortbildungen die Ausnahme sind, vgl. Tabelle 5.29. ${ }^{66}$

Tab. 5.29: Tokenfrequenzen verschiedener Verbindungen mit zwart (LCA, 1940-2009)

\begin{tabular}{lrlr}
\hline zwarte markt* & 2558 & zwartmarkt & 0 \\
zwarte goederen & 10 & zwartgoederen & 0 \\
zwarte prijzen & 17 & zwartprijzen & 0 \\
zwart geld* & 1279 & zwartgeld & 11 \\
zwarte lonen & 454 & zwartlonen & 0 \\
\hline
\end{tabular}

Nur bei zwart geld - zwartgeld scheint das Kompositum eine kleine Rolle zu spielen. Allerdings handelt es sich auch hier um eine verschwindend geringe Treffermenge im Vergleich zur Frequenz der Phrase und die Kategorisierung als Kompositum basiert auf der Tatsache, dass die Verbindung in den Belegen zusammen geschrieben wird. Bei allen Treffern erlaubt der syntaktische Kontext aber auch die Interpretation von zwartgeld als zusammen geschriebene Phrase, da die Flexion in allen Beispielen sowieso ausfallen würde (die Verbindungen werden ohne Artikel gebraucht, bei het-Nomen wie geld bedeutet dies, dass das attributiv verwendete Adjektiv nicht flektiert wird).

66 Die mit einem Asterisk versehenen Trefferzahlen von zwarte markt, zwart geld und zwarte lonen sind noch nicht manuell bereinigt, d.h. hierunter fallen auch Treffer, die nicht die gesuchte Phrase darstellen. Suchanfragen im LCA liefern nicht immer exakte Ergebnisse. Da es sich aber jeweils um große Trefferzahlen handelt, ist die Tendenz deutlich. 
Der Prozess, der sich bei zwarte handelaar vollzogen hat, ist also im Niederländischen eher ungewöhnlich. Die einzige weitere Ausnahme findet sich bei einer verwandten Verbindung, der Phrase zwarte handel 'Schwarzhandel'. Diese erhält seit etwa zwei Jahrzehnten zunehmende Konkurrenz durch die Wortbildung zwarthandel (vgl. Tab. 5.30). Zwarthandel ist noch in keinem der untersuchten Wörterbücher des Primärmaterials verzeichnet; lediglich das WNT (zWART, 1997) verweist auf die Bildung und nennt sie ungebräuchlich.

Tab. 5.30: Tokenfrequenzen zwarte handel - zwarthandel (LCA, 1940-2009)

\begin{tabular}{lclc}
\hline & zwarte handel & zwartehandel & zwarthandel \\
\hline $1940-1949$ & 553 & 0 & 4 \\
$1950-1959$ & 94 & 1 & 1 \\
$1960-1969$ & 66 & 0 & 1 \\
$1970-1979$ & 111 & 2 & 1 \\
$1980-1989$ & 81 & 1 & 3 \\
$1990-1999$ & 103 & 0 & 37 \\
$2000-2009$ & 67 & 0 & 49 \\
\hline
\end{tabular}

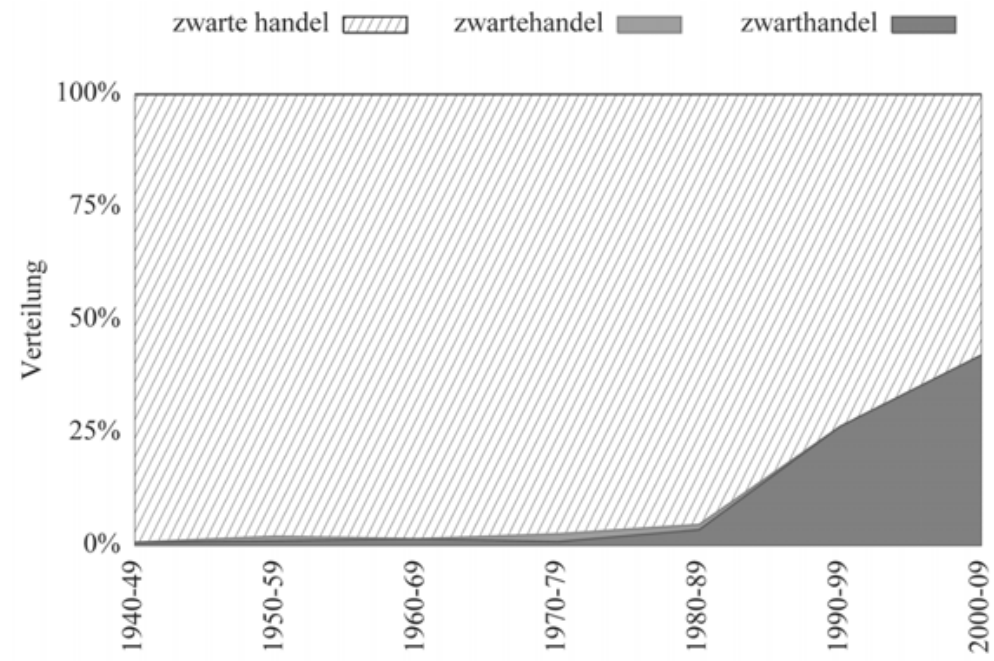

Abb. 5.7: zwarte handel vs. zwarthandel (LCA, 1940-2009) 
Der zunehmende Gebrauch eines Kompositums zeigt sich also ausschließlich bei den verwandten Formen zwarthandelaar und zwarthandel, betrifft aber keine der anderen Verbindungen mit zwart. Dies legt eine zweite mögliche Interpretation des Entwicklungsprozesses von zwarte handelaar zu zwarthandelaar (wie auch von zwarte handel zu zwarthandel) nahe. Es handelt sich hier zwar prinzipiell um die Verdrängung einer Phrase durch eine Wortbildung, aber zwarthandelaar lässt sich strukturell ebenso gut als deverbales Derivat $\mathrm{zu}$ zwart handelen 'schwarz handeln' analysieren. Dafür spricht nicht nur die beschränkt auftretende A+NKomposition bei Verbindungen mit zwart mit Nomen, die keinen verbalen Charakter haben (wie geld, markt etc.), sondern auch, dass gerade deverbale Ableitungen mit zwart im Niederländischen sehr frequent sind und produktiv gebildet werden. Vgl. zur Illustration hier einige etablierte Bildungen aus Van Dale Online (2012) in (176) sowie weitere Gelegenheitsbildungen im LEXNEX-Korpus (1997-2011) in (177):

zwartrijder 'Schwarzfahrer', zwartvisser 'Schwarzangler', zwartwerker 'Schwarzarbeiter', zwartblaffer 'Hund, für den keine Hundesteuer gezahlt wird' (von blaffen 'bellen')

zwartknipper (von knippen 'schneiden'), zwartlapper (von lappen 'Fenster putzen'), zwartreiziger (reiziger 'Reisende/r'), zwartslaper (slaper = 'Schläfer'), zwartvaarder (von varen 'mit dem Schiff fahren'), zwartverdiender (von verdienen 'verdienen'), zwartzoeker (von zoeken 'suchen'; hier: 'Person, die etwas ohne Erlaubnis sucht')

Einige dieser Bildungen können als reguläre $\mathrm{A}+\mathrm{N}$-Komposita interpretiert werden, wenn das Nomen selbst ebenfalls üblich ist, u.a. zwartslaper, zwartreiziger. Dies schließt aber nicht aus, dass ihre Verwendung durch frequente Bildungen wie zwartrijder und zwartwerker und die entsprechenden Verbalphrasen zwartrijden 'schwarzfahren' und zwartwerken 'schwarzarbeiten' gefördert wurde. Das Verb zwart handelen 'schwarzhandeln' kommt zwar nicht sehr häufig vor (nur 15 Treffer im LEXNEX-Korpus gegenüber ca. 270 Treffern für zwarthandelaar), dennoch könnte die Nutzungsfrequenz von zwarthandelaar durch strukturelle Parallelen zu Bildungen wie zwartrijder etc. erhöht worden sein. Der zunehmende Gebrauch von zwarthandel (anstelle von zwarte handel) könnte wiederum durch den verstärkten Gebrauch des synthetischen zwarthandelaar beeinflusst sein. Mit der Reinterpretation als Derivate wandelt sich die interne Struktur der Verbindungen. Im Falle von zwarthandelaar und zwarthandel kann das Adjektiv nun auch als Adverb reanalysiert werden. Ein solcher Prozess ist nicht ungewöhnlich, vgl. das deutsche Beispiel grüner Markt > Grünmarkt '’([...] veralt.) Markt, auf dem Gemüse u. Kräuter verkauft werden' (Brockhaus Wahrig: GRÜNMARKT), wobei das grün in grüner Markt aber ursprünglich als Verkürzung für grüne Ware stand. 
Als Fazit bleibt, dass sich der Verdrängungsprozess bei zwarte handelaar zwarthandelaar (und möglicherweise auch der Wandel von zwarte handel zu zwarthandel) sowohl als Entwicklung hin zum Kompositum als auch hin zur Ableitung analysieren lässt. Diese prinzipielle Unentscheidbarkeit zwischen beiden Analysen macht deutlich, dass Wortbildungen durch systematische FormBedeutungsrelationen in einem vielfältigen paradigmatischen Geflecht zueinander stehen können. Beide Interpretationen - als A+N-Kompositum und als Derivat - sind möglich und stehen nebeneinander.

Die Fallstudie zu schwarz - zwart zeigt zweierlei: Erstens sind Verdrängungsprozesse im Deutschen häufiger als im Niederländischen. Zweitens muss die Entwicklung scheinbar deutlicher Fälle im Niederländischen nicht immer zwangsläufig als Stärkung des A+N-Kompositums gewertet werden. Dieser zweite Punkt wurde mit Hilfe des Einzelfalls zwarte handelaar - zwarthandelaar illustriert. Detaillierte Fallstudien zu anderen Adjektiven und ihren Bindungspräferenzen sind wünschenswert, momentan jedoch schwer $\mathrm{zu}$ verwirklichen, da viele historische Korpora und Textsammlungen für umfangreiche lexikalische Studien deutlich zu klein sind und aus den oben genannten Gründen nur bei den Bildungen mit schwarz - zwart 'illegal' der Rückgriff auf umfangreiche moderne Text- und Korpusmaterialien möglich war.

\subsection{Zusammenfassung}

In diesem Kapitel wurde die Entwicklung benennender Adjektiv-Nomen-Verbindungen anhand von Fallstudien im Deutschen und Niederländischen nachgezeichnet. Es ergab sich ein differenziertes Bild: Man kann weder im Deutschen noch im Niederländischen von einer allgemeinen deutlichen Entwicklungsrichtung zugunsten der A+N-Komposition oder der A+N-Phrasenbildung sprechen. Die einzelnen Adjektive haben zum Teil sehr unterschiedliche Realisierungspräferenzen. Bei einigen sind die Präferenzen für ein Verfahren über den gesamten Zeitraum relativ stabil (z.B. still/stil, NL sociaal, civiel), andere entwickeln eine im Vergleich zu Beginn des Untersuchungszeitraums abweichende Präferenz (was wohl für DE geheim und kalt gilt). Eine weitere Gruppe von Adjektiven bleibt von Beginn an unbestimmt und ist prinzipiell für beide Verfahren offen (v.a. die Farbadjektive). Andere wiederum werden überhaupt erst im Verlaufe des Untersuchungszeitraums produktiv in der Benennungsbildung eingesetzt (vgl. z.B. DE fremd, das erst ab Mitte des 19. Jahrhunderts gehäuft in Benennungen auftritt). In jedem Fall lässt sich für die untersuchten Daten weder im Deutschen noch im Niederländischen ein eindeutiger Trend ausmachen, der $\mathrm{zu}$ einem systematischen Anstieg der Produktivität der A+N-Komposition oder der A+N-Phrasenbil- 
dung für Benennungseinheiten führen würde. In theoretischer Hinsicht lassen sich die eindeutigen Präferenzen einiger Adjektive in der A+N-Benennungsbildung als Schematisierungsprozesse im Sinne von Noël (2006) beschreiben, die zur Bildung von lexikalisch teilspezifizierten Subschemata führen, die zwischen die allgemeinen Schemata zur Bildung klassifikatorischer A+N-Einheiten und die individuellen Mikro-Konstruktionen treten. Die Ergebnisse der historischen Untersuchung erlauben eine differenziertere Sicht auf die Konkurrenz von Phrasenbildung und Komposition, die nicht für jedes Adjektiv im gleichen Maße zu gelten scheint.

Es wurde zugleich deutlich, dass die Entwicklung von Dubletten ein wichtiger Divergenzfaktor in beiden Sprachen ist. So konkurrieren gleichbedeutende Phrasen und Komposita im Deutschen viel häufiger als im Niederländischen miteinander und es kommt deutlich häufiger zur Verdrängung der ursprünglichen, phrasalen Benennungseinheiten durch Komposita (vgl. gelbes Fieber > Gelbfieber, kalte Schale > Kaltschale etc.). Diese Entwicklung beschränkt sich nicht nur auf die in dieser Arbeit untersuchten Adjektive. In der Fachliteratur lassen sich auch Beispiele mit anderen Adjektiven finden (vgl. Bach 1965: 232 bzw. 303):
a. hohe Schule > Hochschule
b. festes Land > Festland
c. neue Zeit > Neuzeit

Die entsprechenden niederländischen Verbindungen sind noch immer phrasal: hogeschool, vasteland (werden laut niederländischer Rechtschreibung zusammen geschrieben), nieuwe tijd. Die gegenwärtig als divergierend wahrgenommene Distribution benennender $\mathrm{A}+\mathrm{N}-$ Verbindungen beruht also zumindest teilweise auf Veränderungen im Deutschen, nicht etwa im Niederländischen. Phrasen mit Schwa-Apokope, die u.a. von Booij (2002a) als weitere Möglichkeit zur A+NBenennungsbildung gedeutet wurden, spielen in den vorliegenden Daten zumindest bei genuin qualitativen Adjektiven nur eine marginale Rolle.

Unter dem Eindruck dieser nur teilweise systematischen Entwicklung der $\mathrm{A}+\mathrm{N}-$ Verbindungen stellt sich demnach die Frage, weshalb für einen Teil der Verbindungen im Sprachvergleich zunehmende Konvergenzen, für andere wiederum zunehmende Divergenzen und schließlich auch parallele Entwicklungsprozesse anzunehmen sind. Im nächsten Kapitel werden einige mögliche inner- und außersprachliche Faktoren besprochen, die diese Prozesse beeinflussen und möglicherweise auch Unterschiede zwischen dem Deutschen und dem Niederländischen schlüssig erklären können. 
